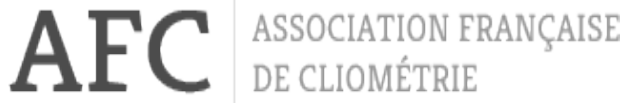

WORKING PAPERS

\section{Nr. 7, 2012}

Understanding Aging during the

Epidemiologic Transition

Suchit ARORA 


\title{
Understanding Aging during the Epidemiologic Transition
}

\author{
Suchit Arora ${ }^{1}$
}

September, 2011.

\begin{abstract}
The Epidemiologic Transition can help us understand population aging. Noninfectious degenerative diseases, the ones associated with aging, were prominent in the Malthusian epidemiologic regime through the 1860 s. They used to be fatal at much younger ages than they are today. Shortly after infectious maladies began receding in the last three decades of the nineteenth century, noninfectious diseases began trending downward, ushering in more aging and longer lives than before. Hidden in the descent of noninfectious diseases were age-profiles of cohorts raised in the different regimes. As the regimes transitioned from the Malthusian to the modern one, the age-profiles had shifted downward: noninfectious diseases had shrunk at each age, increasing the aging potentials of the cohorts. The shifts associated closely with the epidemiologic conditions in childhood, whose influence surfaced at early adult ages and extended to the advanced ages. The changing childhood conditions also appear to be one circumstance under which the aging potentials of the newer cohorts were misgauged, including in one troubling episode in the first half of the nineteenth century when, contrary to expectation, the potentials were thrown into reverse.
\end{abstract}

JEL classification: E24, I15, I18, J11, N33, O10

Keywords: Aging; epidemiologic transition; health human capital

${ }^{1}$ The State Teachers Retirement System of Ohio (STRS), 275 East Broad Street, Columbus, OH 43215 (aroras@strsoh.org). The views expressed are not of the STRS. I am grateful to the seminar participants of the Department of Economics at the University of Oregon for helpful comments. 
Macroeconomists have recently begun exploring the role of longevity in economic progress. ${ }^{2}$ To grasp the foundations of growing longevity, they have been drawing ever more from biodemography, epidemiology, anthropometric history and public health history, disciplines that have long inquired into the longevity potentials of populations.

At the center of that vast domain is the Epidemiologic Transition. The tenets of its received view outline how various types of diseases have evolved since the Malthusian times. 3 Nearly four decades of research on the Transition has fortified the consensus that studying the changing mix of diseases clarifies how longevity and aging advance. By exploring the disease mix since the nineteenth century the paper reaffirms the consensus. However, in the mix of diseases it also finds facets that only partially agree with the received view. Some of the facets recommend reframing the received view so that it can be reconciled with the historical experience and can be used to shed light on issues vital to macroeconomics.

The historical experience shows seems to show that the Transition has distinct regimes. They are, however, fully visible only if the data can span more than a hundred years. Besides helping explore longevity, they shed light on how one views human capital models because the main feature of the models - demographic change coinciding with new human abilities - is clearer in the trans-regime perspective than in as many as 50 years of recent history. One can see in the trans-regime view, for instance, how the social choices to restrain disease had caused demographic change. 4 Whether any new human abilities arose from the change, however, remains an open issue, one that researchers have been trying to explore. 5

For the explorations to make headway, it is vital to outline the main features of the Transition. There are two ways how that can be done. The traditional way outlines the time trends in the fatalities from broad disease categories such as infectious diseases and various noninfectious, degenerative ones. It also tracks the periodlife expectancies that condense each period's fatalities into probabilistic expressions. The traditional way of studying the Transition is essential, a step the paper will take.

However, there is reason to go a bit further. More suitable to human capital models would be the way that studies the Transition from the vantage point of birth-cohorts, of generations. The models envision a particular type of human development, one whose foundation is set up in childhood. From the foundation develop long-reaching capabilities that confer benefits in adulthood. To fit with the vision, an inquiry should study the life cycles of cohorts, observe the epidemiologic experience in the formative years, and then assess its influence in the advanced years. Such an inquiry into the Transition is the additional step the paper takes.

Inquiring at the cohort level helps find out what may have shaped the traditional aggregate-level trends themselves. For instance, one of the Transition's main features is that most noninfectious degenerative diseases - the ones associated with aging - have been falling for nearly a century. Their century-long descent does not seem to have a cogent explanation within the framework of the received view. The hidden cohort-level changes uncovered in the paper provide a clearer account of the descent. Cohorts raised in different regimes had different age-profiles of noninfectious maladies. The paper illustrates how the contributions by the profiles may have shaped the downward path of aggregate noninfectious maladies.

Besides suitability to human capital models, what is the reason for studying how cohort-level changes relate to aggregate-level trends? Why not just study the aggregate trends themselves? The reason first surfaced about three decades ago when the research on the Transition and on population Aging began overlapping. Before then, time trends alone had proven to be an effective tool as infectious diseases with largely

2 Zon and Muysken (2001, 2005), Arora (2001, 2003, 2005), Chakraborty (2004), Howitt (2005), Cervellati and Sunde (2005, 2011), De la Croix and Licandro (2010).

3 Omran (1971).

4 Mercer (1985, 1990), Szreter (1988, 1997).

5 Morand (2005), Arora (2005), Birchnell (2007), Strulnik (2008), Aksan and Chakraborty (2011). 
concurrent causes used to be the focus. Scholars used time trends to shed light on the timing and the effectiveness of various containment strategies since the nineteenth century. ${ }^{6}$

After infectious diseases were contained by mid-twentieth century, the focus had gradually shifted to noninfectious, degenerative ones as the fatalities they caused to middle-to-older-age people had remained elevated. Scholars believed that longer lives had naturally made people more prone to such diseases. Since lifespans in the Malthusian era were much shorter, it was only inevitable that degenerative diseases would grow in the modern era of growing lifespans.7 The inevitability was expressed in the received view's modern "age of degenerative and man-made disease," the last stage in its original 3-stage set up. Reinforcing the sense of inevitability, period-life expectancy by 1950 had inched up only two years for 65 -year olds. ${ }^{8}$ It seemed as if there was an intransigent limit to life expectancy and that would check aging. 9

However, the status quo was shaken in the 1970 and the 1980 s when the fatalities from many noninfectious degenerative maladies in the middle-to-older-aged people began receding. What had seemed like an unsurpassable limit to life expectancy was being surpassed. Scholars reconciled the new development with the received view by appending a new stage, the "age of delayed deaths from degenerative diseases": the rates of noninfectious maladies would eventually rise; their inevitable increase is merely being delayed.

Meanwhile, the new longevity trends also prompted new questions. The research on Aging and on the Transition converged on the childhood origins of the new trends. They found that many noninfectious maladies were traceable to deficiencies of childhood development, including infectious maladies experienced in the childhood years, and the in-utero stresses before birth. ${ }^{10}$ The new anthropometric history shed more light on the matter. It uncovered the physiological statuses children had attained in the past and assessed the risks of noninfectious disease incurred decades later when the children had aged. ${ }^{11}$

The research arrived at somewhat of a consensus: the middle-to-older-aged in the 1970s and 1980s were a newer set of cohorts whose childhood epidemiologic regimes were likely different from the ones that the preceding cohorts had faced as children. Three implications follow from it. First, unlike infectious diseases, studying time trends alone would not suffice because the causes were not necessarily concurrent. Second, if childhood regimes in the past had changed, their influence could be revealed in the cohort-level changes until decades later. Third, since many coexisting birth-cohorts constitute the aggregate, cohort-level changes, originating from their childhoods, could shape the aggregate-level trends - the reason for relating the cohorts to the aggregate. Since noninfectious maladies signal senescence and aging, the childhood regime could have been critical to the trends in aging as well.

How does the paper build on the implications? To find support at the aggregate level the linkages between childhood deficiencies and adulthood degenerative diseases must encompass a broader spectrum of agegroups (including the middle-to-older-aged), cover the larger universe of noninfectious maladies, and function in several generations since the Malthusian times. That can be found out only by studying the different regimes of the Transition, by observing what cohorts of children raised in them had faced, and by assessing the change in noninfectious maladies as the cohorts had aged.

${ }^{6}$ Logan (1950), Cockburn (1967), Beveridge (1977), Mckeown and Brown (1955), Mckeown and Record (1962), Mckeown, Record and Turner (1975), Mckeown (1976), Razell (1977), Mercer (1985, 1990), Szreter (1988).

7 Gruenberg (1977).

${ }^{8}$ Human Mortality Database.

9 Fries $(1980,1989)$.

1o Barker and Osmond (1986a, 1986b), Barker (1992, 1994), Ben-Shlomo and Davey-Smith (1991), Kuh and Davey-Smith (1993), Leon et al. (1998), Elo and Preston (1992), Fogel and Costa (1997), Costa (2002), Barker and Lackland (2003, 2006), Bentsson and Lundstrom (2003), Finch and Crimmins (2004), Crimmins and Finch (2006), Doblhammer and Vaupel (2001), Doblhammer (2003), among others, cited later.

${ }^{11}$ Waaler (1984), Steckel and Costa (1997), Fogel and Costa (1997). 
Which tools can help study the aging of cohorts? To see the noninfectious diseases in a cohort, a significant segment of its life cycle has to be isolated. One tool that performs such a function is the age-profile. It tracks the fatality rates in the cohort as it ages. Tagged for their childhood regimes - Malthusian or modern - the profiles allow clear cross-cohort or cross-generation comparisons.

What types of things can age-profiles reveal? They show measurable changes between cohorts whose childhoods were in distinct epidemiologic regimes. Say, you want to compare a 30-year old to a 50-year old. Usually, 30-year olds are less prone to degenerative maladies than 50-year olds. However, comparisons of cohorts raised in distinct regimes show the opposite. When people raised in the Malthusian regime were 30 years old, their fatalities, in a range of degenerative maladies, were more than what the 50-year olds born in the modern regime had faced. The Malthusian profile was located well above the modern one, signifying generational change.

Which ideas can help grasp the generational change? Evolutionary biologists see aging differently from what is called senescence. Aging is chronological time, for each cohort. Senescence, on the other hand, is the underlying intrinsic physiological deterioration that occurs with time. Everyone experiences senescence because it is not inheritable. ${ }^{12}$ With time or with age, senescence expresses itself in impaired function of one type or another. The impairments can differ in intensity across cohorts, but they ultimately ensure death, or the finiteness of life, or an age limit - for all. Within the limit lies the vast potential for longevity and aging. The force of senescence and the resulting limit to lifespan help interpret the aging potentials of generations.

How are aging potentials measured? One global measure is called the mortality-rate-doubling-time. The doubling time is number the years in which the death rate in a cohort doubles. It is widely known that degenerative diseases are the signatures of senescence, of the intrinsic physiological deterioration that limits lifespans. Measured from the age-profiles of degenerative conditions, the doubling time expresses how fast the cohorts had deteriorated. The doubling times show that the aging potential had changed since the Malthusian era cohorts, but not always for the better.

What issues can the measures of aging illuminate? Along with the shifts in the levels of the profiles, they shed light on several matters central to population Aging. Which cohort's age-profile deteriorated faster, the Malthusian cohort or the modern one? The somewhat surprising answer to that question indicates which one had more aging potential and why. How does the projected aging potential based on current period's data differ from actual aging that occurs decades later? In the brief modern history of aging, under what conditions could the projected potential have differed from actuality?

Was there a historical pattern to aging? The data reveal that noninfectious degenerative maladies used to curtail life at relatively early ages in the nineteenth century. The cohort-level change since then has also surfaced at the early stages of the life cycles before it was visible at the advanced stages. The descent of many noninfectious maladies sped up in the still-young cohorts born in the last 3-4 decades of the nineteenth century. It coincided with a marked change in their average adult statures; with the plunge in infectious maladies during their childhoods; and with falling pregnancy complications in the cohorts' years of birth.

What is the historical significance of the findings? While the causes of epidemiologic change are an open issue, the cohort-level features are clear about the consequence: what occurred in the Transition is population aging. What we do not know is when it began, how it progressed and how its progression may be measured. The paper finds that it was developments since the late nineteenth century that ushered-in - for the masses - the new aging capability, the way Sen (1999a, b) has explained. The seemingly new trends in aging seen since the 1970s were likely a ripple of what had begun decades earlier.

12 Medwar (1946, 1952), Williams (1957), Hamilton (1966), Kirkwood (1977, 1981, 1985), Kirkwood and Holliday (1979). 
The epidemiologic framework of the received view is outlined in the next section. The one after that outlines the time trends of disease categories, examines the extent to which they agree with the received view, and revises its tenets where the agreement is partial. It is essential to see that segment for it opens up the very questions that direct the inquiry to the cohort-level data. After outlining key cohort-level features, section four illustrates how they may account for the aggregate trends and how some issues about aging have fared historically. Like the traditional set up of the received view, each section frames "propositions" for the main features of the Transition. They could be seen as what macroeconomists call "stylized facts" for modeling. Section five offers some evidence on the association between the childhood epidemiologic regime and various facets of the age-profiles, including their aging potentials. Section six gathers some of the findings that inform human capital models. The data pertain to England and Wales only. Therefore, the findings should be seen as a benchmark and may not be generalizable.

\section{What is the received view?}

The Transition is traditionally outlined in terms of deaths, not illnesses. The paper follows the tradition. In the best of worlds, annual data on illnesses over 150 years would also have been available, but that is not so. Their unavailability is confining, and an appeal to tradition is dissatisfying. Nonetheless, as Sen (1998) has cogently explained, deaths underscore the gravity of illnesses. The information they provide should be taken seriously. Reported illness in surveys can be noisy, even misleading, especially when it is found that fatalities had outnumbered the illnesses that were reported. Self-reported illnesses can be driven by self-awareness or by cultural forces and can often depart from the underlying trends in fatalities. ${ }^{13}$

Studying the data on disease-caused deaths, Omran (1971) outlined the original structure of the received view in three sequential stages or epidemiologic regimes: (1) The Malthusian "age of pestilence and famine;" (2) The transitional "age of receding pandemics;" (3) The post-transition "age of degenerative and man-made diseases." A fourth stage called the "age of delayed deaths from degenerative disease" was appended after degenerative fatalities in middle-to-older age people began falling since the $1970{ }^{14}$

In the Malthusian "age of pestilence and famine," infectious diseases are the main cause of fatalities. They result in relatively shorter lifespans (and low life expectancies). For various reasons the "age of receding pandemics" begins when infectious maladies start falling. As a result, life expectancies start rising. More people begin reaching the age when degenerative maladies afflict them. Elevated rates of such diseases forms the modern "age of degenerative and man-made diseases." The central tenet, stated as proposition 2 in Omran (1971), says:

"During the transition, a long-term shift occurs in mortality and disease patterns whereby pandemics of infection are gradually displaced by degenerative and man-made diseases as the chief form of morbidity and primary cause of death."

However, the tenet seems only partially true. The true segment, as we will see shortly, is that the pandemics and infectious diseases were indeed prominent in the Malthusian times. The ambiguity is in the part about noninfectious degenerative diseases. The tenet suggests that such maladies may have been relatively less prominent than the infectious ones in the Malthusian regime. It is also unclear if "the primary" cause of death refers to levels or to proportions. Knowing that is crucial because it identifies the path of degenerative maladies between the regimes. For instance, when degenerative diseases "displaced" the infectious ones, did they become as severe as the infectious disease rates were in the past? If so, then degenerative disease rates

${ }_{13}$ Johansson (1991, 1992). Manton (1982), Murray and Chen (1992), Riley (1989), Riley and Alter (1989), Riley (1991).

14 Omran (1982), Olshansky and Ault (1986). 
must have risen over time, as they were relatively less significant in the past, and displaced what used to be relatively more significant then.

Meanwhile, over the years, a consensus has developed about the Transition: once infectious diseases began retreating, lifespans began growing. Inevitably, degenerative maladies began increasing because longer lives increase people's susceptibility to them. ${ }^{15}$ The next section evaluates the consensus. It uses data on broad disease-categories: infectious diseases, noninfectious diseases. The aggregate noninfectious diseases are calculated as all causes less all external causes (e.g. accidents, homicides etc.) and all infectious causes (including respiratory maladies, which are mostly infectious or contagious). It includes many degenerative sub-categories such as maladies of the circulatory, the nervous, the digestive, the musculoskeletal, and the genitourinary systems. Each sub-category is examined separately to check for exceptions. All categories were aligned across time to the ninth revision of the International Classification of Diseases (WHO 1978).16

\section{Assessing the received view}

Figure 1a shows that period-life expectancy at birth in England and Wales fluctuated between 25 and 40 years for at least three centuries. Only toward the end of the nineteenth century, about hundred years after the onset of industrialization and income growth, did it breach the Malthusian range permanently, a change also visible in life expectancy after birth in Figure $1 \mathrm{~b}$. They indicate that stimuli unique to the last few decades ushered in a transitional period. About $80-85 \%$ of the total change since 1870 was achieved in that period, indicating that the data after World War II will be unable to shed light on why that progress occurred.

Reductions in infectious diseases were one main reason for the progress. Marked by several outbreaks, the contour of infectious diseases in Figure 2 depicts the change since the 1870s, and roughly, the three epidemiologic regimes. The rest of the paper is set up according to the regimes indicated in Figures 1 and 2: the decades before the 1870 os labeled the Malthusian regime; the period from 1870 through roughly the 1930 s labeled the transitional regime; and the period that followed, labeled as the post-transition regime.

Figure 2 indicates that severe rates of infectious diseases had coincided with the shorter lifespans and low life expectancies in the Malthusian regime. It agrees with the received view's portrayal of the "age of pestilence and famine." While, the data on all infectious diseases for the first half of the nineteenth century are unavailable, the rising frequency of epidemic outbreaks in Figure 3 a indicates that epidemiologic conditions may have been worsening then. A similar pattern is visible for France in Figure 3b, suggesting conditions may have been deteriorating in the early industrialization of other places as well. Inter-regional migration was increasing the urban population densities and people likely did not know what caused infectious diseases and how they spread.

The miasma theory appears to have been the reigning paradigm of causation then. In the Registrar General's Statistical Reviews of England and Wales, through at least the 186os, influenza, for example, was a miasmatic disease; so were dysentery, typhoid, malaria (ague), cholera, diphtheria, diarrhea, typhus, scarlet fever. Tuberculosis was a "constitutional" malady, not necessarily a contagious one; jaundice and hepatitis were "local maladies" not infectious. They were classified differently from their modern classifications. ${ }^{17}$ People had long known the vivid symptoms, but they likely believed that the causes were invisible miasmas. With no pragmatic way to rein-in something invisible, the diseases likely went unchecked. On top of the normally-

15 Olshansky and Ault (1982), Carnes and Olshansky (1993).

${ }^{16}$ Charlton and Murphy (1997), Arora (1999, 2003, 2005).

${ }_{17}$ Farr (1885). 
elevated rates, outbreaks of cholera, dysentery, diarrhea, influenza, typhoid fever, typhus, among others, erupted frequently.

During the transitional stage infectious diseases began shrinking even as urban crowding continued. A new epidemiologic regime had begun. Multiple factors likely contributed to it, prominent among them being the ascendancy of the germ theory of diseases. By renewing people's understanding of disease causation, it may have bolstered public sanitation and stimulated advances in bacteriology, a quest that eventually led to the antibiotics decades later. Increasingly, people were able to curb various diseases through arterial systems of water supply and sewage disposal; through pasteurization, sterilization and antiseptic procedures; through dissemination of preventive information. While all of them did not occur at once, each one likely reinforced the rapid change in the transitional stage. Influential among the social choices were a series of Public Health Acts $(1866,1872,1875)$ that laid the administrative foundation critical to the change. ${ }^{18}$ Delivering a major blow to the Malthusian positive checks, the transitional period lasted 7-8 decades. By 1950 about $95 \%$ of the total reduction over 1870-2000 was achieved.

That achievement illustrates one significant issue mentioned in the introduction: data spanning even five decades of recent history will altogether miss this key development of the Transition. Post-World War II data alone would be unable to shed light on the influence of infectious maladies on, say, period-life expectancies. The major change in such maladies had already ended before the period had begun.

Figure 4 shows the changing disease mix: infectious diseases and noninfectious diseases as percentages of all disease-caused deaths. As infectious diseases fell, the share of noninfectious ones began rising. However, the share of noninfectious diseases was large even in the Malthusian regime and that differs from the received view's portrayal of the relative shares. ${ }^{19}$ Moreover, the "age of pestilence and famine" and the "age of degenerative and man-made diseases" had overlapped throughout. Until about 1870, the regime had low life expectancies (Figure 1), severe rates of infectious disease (Figure 2), and frequent outbreaks (Figure 3) all Malthusian regime features; but noninfectious diseases were prominent as well. Therefore, a restatement:

Proposition 1: In the Malthusian regime, both infectious diseases and noninfectious diseases coexisted as significant proportions of all disease-caused deaths.

Figure 5 shows the path of noninfectious maladies along with that of infectious diseases (reproduced from Figure 2 as the broken line). Since at least the mid-nineteenth century, rates of noninfectious maladies in the Malthusian regime may have been substantial.

Proposition 2: In the Malthusian regime, rates of noninfectious degenerative diseases may have been at least as large as the rates of infectious diseases.

Since average lifespans were relatively short in the Malthusian regime, one may conjecture:

Proposition 3: In the Malthusian regime, noninfectious maladies were fatal at relatively younger chronological ages than during the post-transitional regime.

In Figure 5 as infectious diseases began shrinking rapidly, noninfectious diseases started diminishing about four decades later. Period-life expectancies were increasing. However, the received view holds that rates of noninfectious diseases increase as lifespans lengthen and life expectancies grow. A revision follows:

Proposition 4: In the Transition, while the descent of noninfectious diseases lagged that of infectious ones, the overall rates of both categories diminish.

${ }^{18}$ Flinn (1965), Frazer (1950), Woods (1985, 2009), Szreter (1988, 1997), Easterlin (1999), Mokyr (2000).

19 This includes "Ill-defined causes," that accounted for about $23 \%$ of all disease-caused deaths through the early 1870 , the bulk of which were "old age and senility," a degenerative condition in people 65 years of age and older. 
Although infectious diseases fell more rapidly, the fall of both categories suggests there was a synergy between them. What was behind the synergy? Why had noninfectious maladies lagged? Why had they not shrunk before the infectious ones? The cohort-level inquiry will explore the likely sources of the synergy and the reason for the lag.

Moreover, as noninfectious maladies were falling, lifespans and life expectancies were increasing. The reverse of proposition 3 was likely occurring: lesser fatality rates from degenerative maladies coincided with more aging. In the received view, however, such maladies increase as people age. The cohort-level inquiry will try to resolve the puzzle.

Furthermore, rising life expectancies along with falling noninfectious diseases suggest that the received view's "age of delayed deaths from degenerative maladies" may have been the norm rather than something new to the 1970 s and 1980 s. The cohort data will uncover when and among whom the delays truly began.

Meanwhile, some accounting solidifies the key measures of progress. Table 1 shows the contribution of each category to the reduction in all disease-caused fatalities. The column labeled (1) shows the results for the aggregate population over 1870/74-1950/54: about $77 \%$ of the reduction was attributable to infectious diseases; a measureable $23 \%$ to the noninfectious ones. Infectious diseases made hefty contributions in all age groups. In the $65^{+}$group, their contribution is slightly more than $100 \%$ because noninfectious maladies had increased marginally through the early 1950s. The positive contribution of infectious maladies was being nearly offset by the negative contribution from the noninfectious ones. That may have been the reason for the stagnant life expectancy scholars had observed for the 65-year olds until then. ${ }^{20}$

Proposition 5: In the transitional stage, the reduction of infectious diseases accounted for the bulk of decrease in all disease-caused death rates for the aggregate population and for the broader age-groups.

Since period-life expectancy calculations use data on current deaths (largely from disease), one can say:

Proposition 6: In the transitional stage, the reduction in infectious diseases likely accounted for much of the increase in the period-life expectancies at various ages.

Table 1 also indicates the manner in which life expectancies advanced. Infectious maladies improved life expectancies at all ages before the 1950s. Over the entire period 1870-2000, however, their contribution diminished and that of noninfectious maladies nearly doubled. After infectious maladies were subdued, most of the progress came from the noninfectious ones, especially in age-groups 15-64 and 65+.

Proposition 7: In the Transition, both infectious and noninfectious maladies contributed to the improvement in period-life expectancies, but the noninfectious ones continued, on the margin, to improve life expectancies after the transitional period as well.

The relative contribution of noninfectious maladies, before and after the 1950s, roughly illustrates that before the 1950s, the "delays" likely occurred in (or within) 15-64-year olds; whereas after the 1950s, they appeared in ages $65^{+}$. The cohort-level data looks into the reason for that pattern of the "delays."

Before ending this section, some points are worth restating. First, both infectious and most noninfectious maladies fell; without either, one sees at best a partial picture. Second, the widely-used post-World War II datasets will be unable to see the Transition in advanced countries. They cannot shed light on how epidemiologic change influenced life expectancies or economic progress within countries, especially if the new steady-state growth paths (coming out of the Malthusian regime) had set before then. Consequently,

${ }^{20}$ In ages 0-14, most of the improvement in noninfectious disease is in prenatal/neonatal causes, ill-defined causes and congenital anomalies, which are not the types of aging-related degenerative conditions that afflict adults. 
studies of post-World War II cross-country growth may have to include initial levels to compensate for what was already achieved, especially for countries whose epidemiologic regimes had advanced by then.

\section{What do the cohort-level data show?}

\subsection{Noninfectious maladies}

The aggregate-level period-rates do not reveal generational change, even as the rates are based on fatalities in different age-groups, each one belonging to a different birth-cohort. The shifting regimes meant that successive cohorts were being raised under newer conditions. It should be asked, among whom were noninfectious maladies rising or falling? Did cohorts with childhoods in the Malthusian regime fare better or worse than the ones brought up in the regimes that followed? What was each cohort's contribution to the period-rates of aggregate noninfectious diseases? Why did the descent of aggregate noninfectious diseases lag that of the infectious ones? Why have aggregate rates of noninfectious maladies not risen over the century as the received view said they inevitably would?

To observe the cohort-level changes, we need to isolate the age-profiles of birth-cohorts. The profiles show the cohort life cycles from ages 25 through 74, the fifty years critical to noninfectious maladies. For comparisons of cohorts across the regimes, it is mandatory to define age-groups consistently; and only the age-groups from 25 through 74 can be defined consistently because the reporting format has changed thrice over the decades. The adult age-groups were originally reported as 10-year age intervals; the last three were 65-74, 75-84 and 85+. After a minor change in the 1901s, the format changed again in the 1920s to 5-year intervals; the last four were $65-69,70-74,75^{-79}$ and $80+$. It then became even more granular to include $80-$ 84 and $85^{+}$. From the different formats a consistent series across regimes can be made only for 10-year ageintervals, where the oldest ones are 65-74 and 75+. The last one cannot be assigned a birth-cohort; hence each profile runs fifty years, from ages 25-34 through 65-74.

Furthermore, the years of birth for cohorts are decades such as 1840-49, 1850-59, through the 1940s and 1950s. Each cohort is labeled by the regime in which it was born. Continuing the labeling from the last section, cohorts born in each decade before the 1870 s are labeled as the Malthusian cohorts; in each decade from the 1870 s through the 1920 are the transition cohorts; the rest are the post-transition cohorts.

The cross-regime differences are illustrated in Figure 6a that plots the age-profiles for all noninfectious maladies in four representative cohorts: (1) the Malthusian cohort, which is the average of the 1840 ond 1850 s cohorts' age-profiles; (2) the early-transition cohort, which is the average of the 1870 s and $1880 \mathrm{~s}$ cohorts' profiles; (3) the late-transition cohort, the average of the 1910 s and 1920s cohorts' profiles; (4) the post-transition cohort, the age-profile of the 1940 os birth-cohort. The substance of the discussion below is unchanged if one cohort per regime were selected instead of averaging two per regime.

Figure 6a has several notable features. First, each cohort's profile slopes upward exponentially. Increasing age coincided with higher death rates; age, per se, is not the affliction. Moreover, the profiles are not senescence itself, a non-inheritable trait that ensures finite lives. Senescence is unassociated directly with the codes in the International Classification of Diseases. The upward slope only shows that the potency of senescence strengthens with age.

Second, the levels of the profiles had shifted from one regime to the next. At each age, the Malthusian profile had higher rates than others, suggesting that senescence was expressed more intensely in the Malthusian cohort. Further, each cohort has a distinct intercept. The Malthusian cohort's intercept is the highest and 
the post-transition cohort's is the lowest. They indicate that generational change in degenerative conditions can appear early in the adult life cycle, perhaps shortly after the onset of adulthood.

Third, their curvatures or slopes had changed. Traditionally, a measure called the mortality-rate-doubling time is used to interpret the slope. ${ }^{21}$ To calculate it, biodemographers and evolutionary biologists first fit to the age-profile an exponential curve

$$
M t=A \cdot e^{\beta t}
$$

where $M(t)$ is the death rate in the profile at age $t$. The value of the parameter $A$ is the estimated initial level for the profile; parameter $\beta$ expresses the slope. Preferred over the slope parameter is the doubling time: the natural logarithm of 2 (i.e. 0.693 ) divided by the $\beta$. It is the number of years in which the death rate doubles in each cohort, a measure of its pace of deterioration with age. Shorter the doubling time, faster the deterioration. Figure $6 \mathrm{~b}$ shows that the exponential curves fit well to the profiles.

What can be inferred from the differences in slopes? If - and only if - the initial level is the same for two cohorts, shorter the doubling time, faster the increase in degenerative fatalities with age. The cohort with shorter doubling time perishes faster and therefore must have poorer aging potential. But what is the inference when initial levels differ? When initial levels differ, something else must also enter the picture: the natural limit to the human lifespan, some maximal age that must apply to all cohorts. Facing some terminal age the deterioration must speed up if greater fractions of a cohort enter advanced ages unscathed. The faster speed means a steeper slope and a shorter doubling time. Therefore, when levels differ, cohorts with steeper slopes (shorter doubling times) are the ones that had more aging potential.

What do the slopes of the profiles reveal? Figure $6 \mathrm{c}$ shows the natural logarithms of the profiles. Cohorts that began at lower levels experienced faster deterioration. Further, the profiles tend to be converging, though over the ages considered here they had not intersected. Their tendency to converge is a sign of a limiting age-interval or a limiting age to the human lifespan.

For assessments of aging, which one is the more crucial variable, the slope or the levels? For aging, the achievement resides in the attainment of lower rates (level) at each age. It tells us that more people from a cohort were able to attain advanced ages. But the slope is relevant too. While it is a result of the levels and some finite terminal age for human lifespans, it encompasses all ages and is a succinct measure of the speed of deterioration or of the aging potential.

How do the levels and the slopes measure up? The values of parameter $A$ in Table 2 indicate that the initial levels had shifted substantially. The Malthusian cohort's estimated initial level is 1.8 times that of the earlytransition cohort; about 4 times that of the late-transition cohort; and about 10.4 times that of the posttransition cohort. The slope parameters imply that the doubling time for the Malthusian cohort was about 10.6 years; for the early-transition cohort was 9.8 years; for the late-transition cohort was 8.6 years; and for the post-transition cohort was 7.7 years. The measures runs counter to the casual thinking about aging. It is casually thought that the modern cohorts are sturdier and deteriorate slower than the Malthusian cohorts. However, that thinking does not consider the inevitable finiteness of the human lifespan that must apply to all cohorts. Hence, the first two propositions of the cohort-level view:

Proposition 8: Though age-profiles of noninfectious diseases slope upward exponentially, the long-term change in the Transition involved downward shifts in the age-profiles of cohorts raised in its different epidemiologic regimes since the Malthusian one.

${ }^{21}$ Kirkwood (1985), Finch (1990). 
The Malthusian cohort had more incapability from degenerative disease. It disallowed a larger percentage of its members from reaching older ages. On average its members likely aged less than the members of other cohorts. The shifted levels crystallize the generational change in aging.

Meanwhile, the doubling time shrank as the regimes transitioned. The longer doubling time for the Malthusian cohort may seem puzzling. However, as mentioned earlier - and worth reemphasizing - the slope should not be interpreted alone without the levels. The levels and some terminal age determine the slope and not the other way around.

Proposition 9: In the Transition, the downward shifts in the age-profiles coincided with faster deterioration as death from degenerative maladies was pushed to more advanced ages than before.

The two propositions, especially proposition 8 , are the cohort-level parallel to the "age-of delayed deaths from degenerative diseases" in the received view. In the received view the period-rates of degenerative maladies were being delayed in the 1970s. In the cohort-level view entire profiles are shifting downward. How do they differ? Figures $6 \mathrm{a}, 6 \mathrm{~b}$ and $6 \mathrm{c}$ clarify the timing of the "delays." They have been occurring since the beginning of the transition in the nineteenth century. They showed up first in the early years of the ageprofiles, and then sequentially at later ages. The delays scholars had observed among the 50- to 60-year olds in 1970 s and 1980 s may have been a ripple of what had begun decades earlier. The shifts may explain why, in Table 1, the "delays" were first visible within the age-group 15-64 before they surfaced at ages 65+.

Moreover, it is evident, or even self-evident, that degenerative maladies increase as people age. Senescence is said to become more potent with age, and the age-profile of such maladies slopes upward. From that premise the received view generalizes that longer lifespans (or more age) would increase the aggregate rates of degenerative maladies. However, the evidence in the previous section was the reverse: longer lives and greater life expectancies had coincided with the century-long downward trend.

It is possible now to reconcile the evidence with the received view. Hidden in the descent were newlyemerging cohort profiles. Even as people were living longer, and even as each profile sloped upward, the aggregate trended downward because each cohort had charted its own profile below the profile of the preceding cohorts. The received view assumes that there is only one stable profile. It envisions that all life cycles adhere to it and all of them age along its upward slope to generate growing rates of degenerative fatalities in aggregate. The downward shifts in the profiles, however, led to the reverse, creating the centurylong descent. The shifts represented the new capabilities to age.

Though the exponential curve parameters clarify the broader differences, the raw data on the levels give a better sense of the overall change. Reading from Figure 6a, noninfectious maladies in the Malthusian 35-44year olds were 4 times bigger than what the post-transition cohort's 35-44-year olds had faced. By the time the Malthusian cohort was 45-54 years old, its noninfectious maladies were 3 times bigger than that of the 45-54-year olds from the post-transition cohort. By age 65-74, the Malthusian cohort's rate was 1.5 times the late-transition cohort's rate. The gaps between the cohorts diminished with age.

The shifts also led to cross-age differences that speak of substantial generational change. The fatalities in the 25-34-year olds from the Malthusian cohort were almost as high as those of 45-54-year olds from the posttransition regime. The fatality rate among the Malthusian 35-44-year olds was 1.8 times the rate in the posttransition 45-54-year olds. They recommend:

Proposition 10: The age-profiles in the Transition shift in a non-parallel manner, reflecting substantial cross-age improvements as well as the likely limiting age or limiting age-interval to lifespans. 
The cross-age comparisons may suggest the common refrain that " 50 is the new 30 or the new 40 ". However, the refrain may not extend in that way to the advanced ages as the shifts were non-parallel (Figure 6c). For aging to be possible - that is, for greater fractions of cohorts to reach advanced ages - the profiles must become non-parallel because some natural terminal age applies to all. Consequently, difference between $70-$ year olds across cohorts would be less than the differences between 50-year olds.

The shifted profiles, and their tendency to converge, inform one central issue in population Aging. Some scholars have argued that there is no a priori limit to life expectancies, especially at very advanced ages. ${ }^{22}$ The argument gained strength when period-life expectancies in the 1970s and 1980s began surpassing what was seen as their limit in the 1950 s and 1960s. Figure 6a, 6b and 6c indicate that the shifts in the cohort profiles may have been behind that change. A series of downward shifts mean that more people survived into advanced ages and that could generate the new upward trend in period-life expectancies. On the other side of the debate, some scholars posit finite lifespans. Even if one cannot set an a priori limit for period-life expectancies, they should nonetheless be finite, and may not increase indefinitely. ${ }^{23}$ The converging profiles in Figure 6c suggest that there is merit in that argument as well.

However, the age intervals in Figure $6 \mathrm{c}$ are unable to distinguish between the potential outcomes at very advanced ages. The first one is if the profiles do not converge to a unique limiting age or age-interval. Then recent cohorts may attain a new limit that the Malthusian cohort could not and a greater percentage of the recent cohorts reach all ages (including the limit). The second one is if all profiles end at roughly the same limit, but only a larger proportion of the newer cohorts survive until then (because their profiles converge from below). It is possible that even if more age-groups were included in Figure $6 c$, the modern history of aging may still be too brief to know the alternative outcomes for the limiting age.

Nonetheless, they reveal something more important than the limiting age: the large improvements at ages before it. They indicate at least two sources of heterogeneity in aging. The first one is the within-cohort differences in people's capability to age. It occurs along a given profile as some members of a cohort were longer-lived than others. The second source of heterogeneity is in the shifts, the cross-cohort differences in the capability to age. The shifts are pivotal to the emergence of aging in the modern era. Without them all profiles would have looked roughly like the profile of the Malthusian cohort. A likely third source of heterogeneity will be discussed in the last section of the paper.

Meanwhile, Table 3 extends the cross-cohort comparisons to the main sub-categories of noninfectious maladies. Between the Malthusian and the post-transition cohort, the level parameter $A$ reduced measurably. Like the aggregate, nearly all slope parameters had changed as the downward shifts coincided with faster deterioration. The exceptions are neoplasms between the Malthusian and the early-transition cohorts, where the levels increased slightly and the doubling time grew; and the genitourinary system maladies between the early-transition and the late-transition cohort, where the poorer fit makes inference unsafe. Most of the level parameters, nonetheless, suggest that cohorts raised in the newer regimes had more potential to outlast than cohorts from the preceding regimes.

What do the sub-categories reveal that the aggregate does not already show? First, they help spot exceptions (e.g. neoplasms). Second, the aggregate term "noninfectious degenerative disease" is generic and does not convey a sense of what is degenerating. The sub-categories provide that sense: organs of the circulatory system, musculoskeletal system etc. Senescence can express itself in non-specific internal impairments of several types, affecting different organs of the body. The sub-categories highlight its many likely manifestations. They each need to be checked for the essential pattern (upward slopes), especially in cross-

${ }^{22}$ Vaupel and Lundstrom (1994), Thatcher (1992, 1999), Oeppen and Vaupel (2002), Rau et al (2008).

${ }_{23}$ The "entropy" in period-life tables; see Horiouchi (1989), Keyfitz (1985), Lee and Carter (1992), Olshansky, Carnes and Cassel (1990). 
cohort comparisons (shifted levels and steeper slopes). Third, no person from a cohort is reported dead twice, decades apart. Each sub-category pertains to different people from each cohort. The sub-category profiles confirm that even if the set of people differs, as long as the malady is degenerative, the pattern within the cohort and the progress across them holds. Fourth, the recorded data reveal just one malady per person. No doubt, in an untold number of cases there were secondary dysfunctions. Without that information across time it is prudent to check all types of degenerative categories. The secondary impairment that went unrecorded for some may have been the primary one recorded for others.

They also allow richer interpretation of the aging capability. Sen (1999a, b) explained that capability is more encompassing than human capital. Its breadth should prompt us to ask: capability of what kind? The categories highlight the different types in terms of organs and organ systems. Malfunction of any one can make people incapable or less capable. The data pertain to deaths, which is absolute incapability. Nonetheless, we can still say, for instance, arthritis, which is the loss in the capability of joints, was unable to curtail life as much as it used to in cohorts past. As a result people became more capable of living more years than before. Further, since the causes of arthritis differ from heart disease, the categories draw attention to different reasons for the improvement.

Moving away from the exponential curve parameters the panels of Figure 7 try to shows the changes in the raw data themselves. To cut through the tedium in the data, a benchmark value of 100 is assigned to the fatalities in the Malthusian cohort (not shown in Figure 7). The bars represent the other cohorts' levels relative to the Malthusian cohort's 100. Values below 100 indicate improvement, and above it indicate deterioration. This format makes it is easier to read the improvement in each disease category and for each age. The disease categories (LABEL) are all noninfectious diseases (ALL NID), and some of its main components: the circulatory system (CS), the nervous system (NS), the digestive system (DS), the genitourinary system (GUS), the musculoskeletal system (MS) and neoplasms (NEO).

Nearly all age-groups show improvement in most categories. In Figure 7a, for example, noninfectious diseases among the late-transition 25-34-year olds had shrunk to about $41 \%$ of what the Malthusian 25-34year olds had experienced. The post-transition 25-34-year olds experienced less than a quarter of what the Malthusian 25-34-year olds had faced. In all categories, the post-transition 25-34-year olds had a better start. The main exception is neoplasms.

Moving to Figure $7 \mathrm{~d}$ for age 55-64 the data for the post-transition cohort are from the 1930 s cohort instead of the 1940s. That is unsymmetrical to the other panels (and is not the actuality for the 55-64-year olds from the 1940 s cohort). However, they give some indication of the likely improvement compared to the Malthusian cohort, even if it is assumed that the 1940s cohort will do no better than the 1930s cohort. All noninfectious disease may have shrunk to $45 \%$ of what the Malthusian cohort had at age 55-64.

For a cross-age comparison consider the Malthusian 25-34-year olds versus the post-transition 45-54-year olds. In Figure 8, the fatalities in the post-transition 45-54-year olds are benchmarked as unity to show how much more the Malthusian cohort faced by age 25-34. The circulatory maladies in the Malthusians 25-34year olds were nearly as high. Their fatalities from nervous system maladies were 3 times higher; from digestive maladies were 1.9 times greater; from genitourinary maladies 16 times larger; and musculoskeletal maladies 6 times more than the 45-54-year olds from the post-transition regime.

How may the findings shed light on the aggregate-level trends? How may they inform the debate on population Aging over the past four decades? Until the 1950s and the 1960s period-life expectancies at middle-to-old ages had nearly stagnated. At ages 60-64, for instance, they had risen only 2-3 years through the first half of the twentieth century. Observing the elevated period-rates of degenerative maladies, scholars were pessimistic about the prospects of life expectancies and of aging. The grim outlook matched with the 
received view's "age of degenerative and man-made disease" in which such maladies were inevitable for modern populations.

Who had experienced the elevated rates through the 1950s? In the 1950s, the 60-64-year olds were from the 1890 s cohort; the 65-74-year olds were from the 188 os cohort; people 75 years of age or older were from even earlier birth-cohorts. They were raised in the Malthusian and the early-transition periods, when the childhood epidemiologic regime was severe. They ended up with elevated death rates from degenerative maladies at each age of their profiles. In the last section, Figure 2 revealed that the underlying regime had begun changing. When the cohorts from the newer regimes became middle-to-old aged, they experienced much lower death rates than the preceding cohorts. That showed up in the period-rates of 1970 and the 1980s; period-life expectancy at middle-to-older ages began surpassing what was until then seen as the limit.

Observing that change, scholars appended the new "age of delayed deaths from degenerative diseases" to the Transition's original 3-stage structure. Various "cause-delay" models for projecting future rates were proposed. Such maladies could be wholly or partially eliminated in theory. Many infectious diseases had been nearly "eliminated," so why not the degenerative ones? ${ }^{24}$ However, the theoretical scenarios ran into what is called the Taeuber's paradox: other maladies would eventually replace the theoretically-eliminated ones. Why? Older age makes people only more prone to degenerative conditions. There was no way of knowing what those maladies would be and the extent to which they could appear. ${ }^{25}$

Instead of framing future scenarios, some scholars looked into the past, at the childhood development of the middle-aged people. In the 1970s and 1980s, the 55-to-64-year olds were from the cohorts born and raised in the late-transition period (1910s, 1920s). The epidemiologic regime had improved measurably by then. Following them, the post-transition cohorts (1930s and 1940s) have fared even better; their childhoods coincided with antibiotics that had suppressed infectious maladies more than all preceding cohorts. At each step of the way, the childhood regime seems to be a broadly accurate guide to the direction of cohort-level trends for the middle-aged, decades later. Hence, a conjecture:

Proposition 11: In the Transition, the childhood epidemiologic regime could influence the noninfectious maladies in the adult stages of cohorts' life cycles.

The new consensus about childhood development reconnected to an older tradition that used to look at matters in terms of generations. ${ }^{26}$ However, unlike the older tradition, the new findings pointed to specific elements in childhood development as a likely reason for degenerative conditions in adults. ${ }^{27}$ New microlevel databases were set up to examine such issues in the studies of retirement for middle-to-older age men. ${ }^{28}$

How does the aggregate-level data inform that body of knowledge? The global view reveals the shifts in the initial levels as well as the shifts in the entire age-profiles, from early in adulthood. Neither the initial levels nor the curvatures can be uncovered from one or two segments of middle-aged people in the micro-level studies. The tendency of the profiles to converge also cannot be known from them. Second, it exposes multiple intermediate cohorts that micro-level studies of very distant ones may be unable to interpolate accurately. Third, it is able to indicate at least two sources of heterogeneity in aging, within-cohorts and across cohorts. For clear inferences about aging it may be insufficient to only know that early-age deficiencies tell on adult-age degenerative conditions because that does not clarify whether it is a within-

24 Manton, Parrick and Stallard (1980), Bourgeois-Pichat (1978), Tsai, Lee and Hardy (1978), Keyfitz (1977), Preston, Keyfitz and Schoen (1972).

25 Taeuber (1976).

${ }^{26}$ Ben-Shlomo and Davey Smith (1991), Kuh and Davey Smith (1993), Ben-Shlomo and Kuh (2004), Harris (1997), Kermack et al (1934),

Derrick (1927), Spicer (1954).

${ }_{27}$ Barker (1992, 1994, 1998).

${ }^{28}$ See Steckel and Costa (1997), Fogel (2003), Helmchen (2003), Lee (1997, 2003), Costa (2003). 
cohort or a cross-cohort influence. Fourth, the aggregate-level data show the trans-regime change more clearly. Only after seeing the Malthusian, the transitional and the post-transition cohorts is it possible to know that the "age of delayed deaths from degenerative diseases" has been going on for long.

It is then possible that a changing cohort mix may have been shaping the aggregate time trends throughout. For instance, the older segments of the Malthusian cohorts may coexist with the younger age-groups of the transition cohorts, each one with its own burden of degenerative conditions. The aggregate trends may have been shaped by the relative shares in the population of various cohorts and by the different rates of degenerative maladies in each cohort. Examining the changing mix may clarify two issues left unaddressed in the previous section. Why had the descent of noninfectious maladies lagged that of infectious ones? (Figure 5, proposition 4). Why had the descent solidified even when longer lives should have made people more prone to degenerative conditions?

Figure 9 shows the mix of cohorts behind the path of aggregate noninfectious maladies. In each year on the horizontal axis, fatalities in ages 25 through 74 are segmented by cohort. For example, in 1900, fatalities in the 40- the 50- and the 60-year olds are the contributions of the $1860 \mathrm{os}$, the $1850 \mathrm{os}$ and the 1840 Malthusian cohorts; fatalities in 30-year olds were the contribution of the 1870 os early-transition cohort; and so on.

Through the 1890s, all noninfectious fatalities in ages 25 through 74 were in the Malthusian cohorts. Figures $6 \mathrm{a}, 6 \mathrm{~b}$ and $6 \mathrm{c}$ revealed that their rates were the heaviest. The contribution of the early-transition cohorts (18\%) is evident only in the first decade of the twentieth century. If the childhood regime had been influential, the Malthusian cohorts' heavier burden may have kept the aggregate elevated. Even as infectious diseases had been falling since almost four decades earlier, the burgeoning improvement in the still-young transitional cohorts may not have been hefty enough to change the aggregate's path. That may explain why the descent of aggregate noninfectious maladies lagged.

Beyond that point, however, the contributions of the early transition (1870s, 1880s) and the mid-transition (1890s, 1901s) cohorts increased, while the Malthusian cohorts' weights fell. This newer mix may have solidified the descent of noninfectious maladies. By the 1950s the cohort mix was predominantly earlytransition and mid-transition (74\%) and the late-transition (23\%). Since then the mix has tilted toward the late-transition and the post-transition cohorts who had even lower death rates since early in their adult lifecycles. Consequently, aggregate noninfectious maladies have trended downward. Hence, the conjecture:

Proposition 12: If the childhood epidemiologic regime influences the subsequent age-profiles of noninfectious maladies, then the mix of birth-cohorts raised in different epidemiologic regimes can shape the trends or the period-rates of aggregate noninfectious maladies.

As mentioned in the introduction, proposition 12 links the cohort-level developments to the aggregate-level trends. It may look like obvious accounting. However, the reason for even looking into it comes up after it is recognized that the influences originating in childhood may have been relevant: the childhood regime of the past matters to current noninfectious maladies; and the current childhood regime matters to future noninfectious maladies. It is the cohort-level developments that connect the past to the current trends. Without that knowledge it might be difficult to explain why noninfectious maladies had remained elevated even as the infectious ones were falling.

Further, without knowing the potential role of the childhood regime, it is also unclear why shrinking fatalities from noninfectious maladies would coincide with longer lives. Growing lifespans should have made people more prone to deaths from such maladies, but what happened was just the reverse. As infectious diseases shrank, the new childhood epidemiologic regimes improved. When the newer children became adults, they 
experienced lesser fatalities than the Malthusian cohorts. As successive new cohorts contributed to the descent of noninfectious maladies in aggregate, the observed average lifespans grew.

What does it all mean for observed aging, longevity and period-life expectancies? Degenerative fatalities (among others) determine the age at death. The age at death defines the length of an observed lifespan. Therefore, the lifespans observed during the Transition could depend upon (not causally) the relative weights of coexisting cohorts in the population. Progressively longer average lifespans would be observed when people from newer cohorts gradually dominate the population. Since the calculation of period-life expectancies is based, at least partially, on the current period fatalities from noninfectious degenerative maladies in various age groups, it is reasonable to conjecture:

Proposition 13: In the Transition, all else held constant, projections of period-life expectancies, especially at adult ages, may remain off the mark if the cohort-mix of the population changes rapidly.

Depending on the direction in which the mix evolves, the period-life expectancies may under-project or overproject potential future outcomes. If the mix in the future is one in which the more salutary cohorts carry greater weight in the population, then the current period-rates - in which the salutary cohorts are still a minor segment - would over-predict the future rates of degenerative fatalities. Consequently, future periodlife expectancies, especially at various adult ages, would be under-predicted.29 Over-projection would occur if the reverse happens. The perceived "limit" to period-life expectancies may therefore remain a moving target as long as the future cohort mix differs from the current one. 30

The issue of whether current period-rates are accurate guides to the future came up during the 1980 os and 1990s. Surprised by the advances in the period-life expectancies, scholars came up with future scenarios for degenerative maladies. However, some scholars remained cautious about extrapolating from the current rates. Their caution rested on two matters. First, extrapolations make unrealistic assumptions about future risks people may face, even aside from Taeuber's paradox. Second, the upward-sloping age-profiles indicate that aging prospects only diminish with age, so the prospects can only be grimmer than what the current period rates indicate. $3^{1}$

The evidence in the paper clarifies the second issue. We have seen that the age-profile slopes upward; potential progress must diminish with age as lifespans for all cohorts must be finite. However, we also saw that the profiles can shift. The shifted profile, too, is subject to the finiteness of life and to diminishing potential with age. Yet, greater fractions of the newer cohorts can end up being longer-lived.

There is actually another twist to the matter. The profiles like the ones in Figures $6 \mathrm{a}, 6 \mathrm{~b}$ and $6 \mathrm{c}$ pertain to birth-cohorts and can be seen only after decades. Meanwhile, the profiles usually cited to highlight the diminishing potentiality for aging pertain to the current period-rates, the age-specific rates from within a given year or within a given decade. The period-profiles slope upward with age as well. To gauge aging prospects, then, what difference does it make if a period-profile were used instead of a cohort-profile? How have the two differed in the Transition? This exercise, for obvious reasons, can be done only in retrospect.

Figure 10 sheds some light on the differences. In Figure 10b the age-profile shown as the solid line (P) represents the average of the current period-rates of noninfectious maladies in the entire decade of 1901s. It shows the actuality in the decade. By the end of the decade experts would have known this information. Its upward slope emphasizes the diminishing prospects as age increases. The broken line (C) is the age-profile for the 1901s birth-cohort, information experts could not have known by the end of the 1901s. It also slopes

${ }^{29}$ All else held constant applies. I am assuming that degenerative maladies will remain the dominant cause at adult ages.

${ }^{30}$ Crimmins (1984), Vaupel and Lundstrom (1994), Oeppen and Vaupel (2002), Thatcher (1992, 1999), Olshansky et al (2005).

${ }^{31}$ The "entropy"in period-life tables; see Horiouchi (1989), Keyfitz (1985), Lee and Carter (1992), Olshansky, Carnes and Cassel (1990). 
upward. Nonetheless, in retrospect, it is clear that the levels differed. The difference is visible in Figures 10c and $10 \mathrm{~d}$ for the 1890 s and the $1870 \mathrm{os}$. However, the reverse occurred for the $1850 \mathrm{O}$ and $1840 \mathrm{~s}$ : the cohortprofiles had shifted upward, faring worse than the period-profiles.

In Table 4, the parameters express the differences in the outlook. Since at least the 1870s, parameter $A$ is distinctly smaller for the cohort-profiles than for the period-profiles. The $\beta s$ indicate that the slopes differed as well. For example, the 1920 s period-profile was less optimistic about aging than the actuality of the $1920 \mathrm{~s}$ cohort; the doubling time for the cohort-profile was shorter. Since the 1870 s the period-profiles had indicated less aging potential than what actually occurred. The comparisons clarify that the diminishing prospect with age, the upward slope, is true for both the period-based and the cohort-based profiles. Senescence does become more potent with age and that is not contentious. The shift in the levels and the change in the steepness of slopes are what make the difference for aging potentials and its outlook.

Why would the period-profiles differ from the cohort-profiles? The period-fatality rates - say, in the 1870 , 1890 s - pertained to people who were brought up under a worse childhood regime from decades earlier. The cohort-rates for the 1870 s or 1890 s cohorts pertained to people who were still children in the newlyemerging regime of the late nineteenth century. The period-profile could not have taken into account the inter-temporal influence of the new regime as the children raised in it had aged. Projections of aging based on the period-profile assume that the profile will be stable, but end up being off the mark as the assumption likely did not hold during the transition.

The likely role of the childhood regime - in the opposite direction - shows up for the 1840 and 1850 s cohorts in Table 4. The 1840 os and 185 os cohorts ended up with poorer age-profiles (C) than what the period rates in both decades had indicated because the period rates pertained to people who had grown up earlier in the nineteenth century and in the late eighteenth century. The regime may have been better then, but had likely worsened through the 1840 s and 1850 os. Therefore, contrary to the outlook based on the period-rates, the two cohorts likely aged less than the preceding ones.

\subsection{The Reversal in the Malthusian cycle}

The 1840 ond 1850 s cohorts were in the middle of a longer cycle well-known to anthropometric historians. There was a troubling reversal in the average adult stature of successive cohorts. It lasted at least five decades through the mid-nineteenth century. From about 5.6 feet for the 1801s cohort, adult stature shrank to roughly 5.3 feet for the mid-nineteenth century cohorts. ${ }^{32}$ Subsequently, an upward trend started. It improved to about 5.4 feet for those born during the 1870 s, followed by a sharp increase to about 5.7 feet for the $1901 \mathrm{~s}$ cohort, and finally to about 5.9 feet for the 1940 s and 1950 s cohorts.

Adult stature reflects cumulative cellular growth through adolescence.33 It has shed light on matters such as living standards, inequality, slavery, and the risks of degenerative disease. 34 The long-reaching influence of cellular development has been studied in many countries and across time and is called "the biological standard of living." 35 It is also a cornerstone of the trans-generational "Technophysio Evolution" in which poorer physiological status attained by the onset of adulthood raises the subsequent risks of noninfectious degenerative disease. $3^{6}$ Among the explanations researchers have offered for shrinking stature are child

${ }_{32}$ Floud, Wachter and Gregory (1990), Nicholas and Steckel (1991), Komlos (1993a, 1993b, 1993c), Steckel and Floud (1997), Johnson and Nicholas (1997).

33 Tanner (1990), Steckel (1995).

34 For an in-depth discussion, see Steckel and Floud (1997).

35 Komlos (1993c, 1995, 2004), Komlos and Baten (1998).

${ }^{36}$ Fogel and Costa (1997). 
labor, increasing inequality, propinquity to food, and more exposure to infectious disease.37 All of them are likely related to the severity of the epidemiologic regime of the time. The Transition's conventional outline indicated that the regime may have been worsening in the first half of the nineteenth century when migration to urban areas coincided with more frequent outbreaks of infectious maladies. 38

Figures 11a through 11e show the upward movement in noninfectious diseases since the 1880 os cohort. Some of Figures are truncated because the annual period-data start in the mid-1850s. Consequently, the earliest observation for 65-74-year olds is for the 1880 cohort; for 25-34-year olds, the earliest observation is for the 1820 s cohort. The entire profile from age 25 through 74 is visible only since the 1820 s cohort. The first bar in each panel, the first available observation, is indexed to 100. To assess the cumulative deterioration, the remaining bars represent the fatality rates relative to the first one.

Three main features stand out. Figure 11d and Figure 11e suggest that the upswing may have begun at least since the late eighteenth century cohorts; it peaked roughly around the mid-nineteenth century cohorts. Second, the damage was worse at younger ages than at older ones. Third, the cycle likely lasted about seven decades. By and large, the pre-cycle levels were not re-attained until the 1870 s and 1880 os cohorts.

Moreover, the age-specific rates shown here were not coincident. Depending on the age, they were recorded in official documents from one to five decades after each cohort had begun adulthood. For example, the fatalities in 70-year olds from the 1850 s cohort occurred in the 1920s; for 30-year olds from the same cohort, the fatalities had occurred in the 1880s, roughly four decades earlier. Common between them are only their first three decades of life, especially the first two decades of their childhood regime.

Consider the 25-34-year olds and the 35-44-year olds from successive cohorts. At the peak of the cycle, death rates in them were about 1.4 times their benchmarks. The deterioration was similar at ages 45-54 and 55-64 (about 1.3-1.4 times) and slightly less for 65-74-year olds (1.1 times). However, the benchmark cohort for each age is different. It is difficult to say when the cycle in each age-group may have truly begun; Figure 11e suggests that it may have begun as early as the late eighteenth century.

Meanwhile, Table 5 shows the parameters for the age-profiles. The initial levels $(A)$ shifted upward through the 1840 os/1850s cohorts. The pre-cycle levels were not regained until the early-transition cohorts (1870s and 1880s). The doubling time rose from 9.2 years for the 1810s cohort, peaked at 10.6-10.8 years for the 1840 s and 1850 s cohorts, and then shrank subsequently. Cohorts born in the upswing perished faster and likely aged less than the preceding ones.

Figure 12 is the long-term picture of the differences between the period-profiles and the cohort-profiles in the Transition. On the horizontal axis, the decade of birth for cohorts coincides with the decade of the periodrates. The Figure plots aging potentials indicated by the doubling times, calculated from the cohort-profiles versus the period-profiles in each decade. 39 It helps to remember that shorter doubling times coincided with more aging potentials.

Two features stand out in Figure 12. First, since the 1870s, the cohort-based doubling time has been shorter than period-based one: the cohorts aged more than what the period-profiles had indicated. Second, the doubling times for both profiles have trended downward at least since the 1870s: successive period-profiles were indicating more aging potential, too, but they were underestimating it throughout the transitional stage.

37 Komlos (2004), Voth and Leunig (1996), Horrell et al (1998), Humphreys (2010), Harris (1994), Whitehead (1977); for background studies on the mechanisms, see Martorell (1975), Martorell (1980), Martorell and Habicht (1986), Preston and Haines (1991), Higgs (1979), Mata (1978), Tanner (1990).

$3^{8}$ Woods $(1985,2000)$, Mercer (1985), Szreter (1988, 1997), Szreter and Mooney (1998).

39 The period rates for the 1940 sertain only to 1946-49 because of World War II. 
The rapid change in the childhood regime over 7-8 decades may have been one reason for the gap. The period rates would continue to project based on people who had been raised under worse regimes from decades past. Before the 1870 , the reverse might have occurred. Since at least the 1801 s through the 1850 , the aging capability of successive cohorts was likely diminishing. If it is true that the childhood regime influences the adulthood age-profiles of noninfectious diseases, then:

Proposition 14: In the Transition, the potential for aging of cohorts may be misgauged if the underlying childhood epidemiologic regime changes rapidly.

The direction of error may depend on whether the current regime is worsening or improving compared to the past. The mix of risks may also change over time. For the cohorts born after World War II, infections were likely less than the past, but newer risks such as obesity may have entered the picture.40

Before going further, it helps to briefly recap the main cohort-level features. Expressing senescence, the ageprofiles of noninfectious degenerative diseases sloped upward exponentially. As the regimes changed, the profiles mostly shifted downward, leading to measurable differences in the aging potentials of cohorts. The shifts appeared as early as age 25-34 and extended into relatively advanced ages. The gaps between cohorts were wider at early ages than at older ones. As the profiles were shifting, the cohort mix of the population was evolving. The Malthusian cohorts carried more weight in the late nineteenth century and the early twentieth century; the late-transition and the post-transition cohorts dominated the more recent mix. The changing mix may have shaped the path of aggregate noninfectious maladies. In the early transitional period, the heavier weight of the Malthusian cohorts may have delayed the descent of aggregate noninfectious diseases, but the downward trend eventually solidified as cohorts with more salutary profiles carried more weight. The improving childhood epidemiologic regime may have been a reason why the cohort mix evolved in the more salutary direction and why the period-rates under-predicted the aging potentials of successive cohorts. Most of these changes are hidden in the traditional view of the Transition.

\subsection{Infectious maladies}

A diverse set of maladies constitute the infectious group. As early as the mid-nineteenth century, experts who were formulating the blue prints for the International Classification of Diseases (ICD) had attempted to classify such maladies in a unique group. The ICD-lists classify most noninfectious maladies by anatomical sites (circulatory system, digestive system etc.). Infectious diseases were (and are) grouped irrespective of the anatomical site. ${ }^{41}$ The main reason was epidemiologic surveillance, a priority maintained through all revisions of the ICD to date. While all of them are contagious or parasitic, tuberculosis is also seen as degenerative and chronic. Some respiratory infections are like tuberculosis, whereas others like influenza are highly contagious. The constituents of this broad category are diverse and need be seen separately.

Three main regularities appeared in the age-profiles of noninfectious diseases. First, they sloped upward with age. Second, they were mostly distinct. Third, they had shifted. The shifts were apparent as early as age 25-34 and extended to older ages. The profiles did not show a strong, common, time-specific event that may have merged or collapsed them irrespective of age or cohort. Figure 13a, 13b and 13c show profiles for: (1) all infectious diseases excluding tuberculosis; (2) respiratory maladies; (3) tuberculosis. There is an extra age group, 15-24, because infectious diseases were significant at that age. Two questions can be asked: (1) Do the profiles show rising age-coincidence? (2) Do the profiles mix (intersect), and why?

The first panel reveals the widely-known fact that infectious diseases can strike people of all ages, irrespective of the birth-cohort. The profiles do not indicate rising age-coincidence. Instead, the downward slope

40 Olshansky et al. (2005).

${ }_{41}^{1}$ Neoplasms are another exception. 
indicates that the lesser fatalities at older ages coincided with the progressively improving concurrent regime as the cohorts had aged. Moreover, the age-profiles have large shifts. They too coincide with the change in the concurrent regime seen in the time trends. For example, the substantial drop in the Malthusian profile came at age 25-34; the cohort was 25-34-years old in the 1870 os and 1880 os when infectious maladies were plummeting. The early-transition profile is inexplicably flat, but dipped at age 65-74 (in the 1930s and 1940s), which coincided with the introduction of antibiotics - another calendar-year development. Meanwhile, the downward shift for the late-transition cohort is substantial, each age of its profile benefiting from the rapidly-falling rates in the concurrent regime. Finally, the post-transition profile is nearly indistinguishable from zero, although it marginally crossed the late-transition profile at age 45-54. Infectious maladies had been restrained to a low level by the time the post-transition cohort began.

The profiles for respiratory maladies are akin to the ones for noninfectious maladies. They indicate an agecoincidence, though the levels for recent cohorts are much subdued. There is a big shift between the Malthusian and the early-transition cohort when each was 65-74 years old. At that age the early- and latetransition cohorts had benefited from the antimicrobial therapies that were unavailable to the Malthusian cohort's 65-74-year olds. Nonetheless, the distinct shift at each age indicates that the childhood epidemiologic regime may have been influential. ${ }^{42}$ On the other hand, antimicrobial chemotherapy may also have affected all age-groups for some respiratory maladies. The following section will include respiratory maladies with the sub-categories of the previous section.

The panel for tuberculosis is unique for a degenerative malady. Unlike other degenerative conditions, the age-profiles of the Malthusian and the early-transition cohorts slope downward, similar to all other infectious maladies. It has long been known that tuberculosis, especially respiratory tuberculosis, later in life was usually caused by an infection acquired well in the past, and the incidence at older ages was much less than at younger ones (hence, the downward slope).43 The downward slope also coincided with the concurrent regime in which rates of all other maladies were falling. The concurrent regime's influence is visible, for example, in the late-transition cohort's plunge at age 35-44. The age-profile had flattened as antibiotics began. Specific chemotherapy and BCG vaccine had become widely available for the post-transition cohort and its entire ageprofile is nearly indistinguishable from the horizontal axis.

All told, except for some respiratory maladies, the age-profiles of most maladies in the infectious group display, to a great extent, the concurrent regime, in which multiple age-groups were affected simultaneously, irrespective of their birth-cohort. Nonetheless, in terms of aging, all infectious maladies had an immediate consequence: they allowed people to reach older ages. Moreover, their time trends defined the Transition's underlying epidemiologic regimes. Children's development in the regimes could have influenced the ageprofiles of noninfectious maladies, an issue investigated in the following section.

\section{How long-reaching could be the influence of the childhood regime?}

Much of the micro-level evidence linking degenerative conditions to childhood development pertains to the relatively recent years, to middle-to-older age people from one or two cohorts. In the trans-regime context, however, we have entire age-profiles, a larger universe of maladies, and several cohorts since nineteenth century. Therefore, the questions have to be reframed: is there any linkage between the cohorts' childhood epidemiologic regimes and their age-profiles of degenerative maladies? Stated in terms of aging: is there any linkage between the cohorts' childhood epidemiologic regimes and their aging potentials?

${ }^{2}$ Wesley (1991), Markowitz and Neiberg (1991), Barker et al (1988, 1989, 1991), Shaheen et al (1994), Shaheen (1997), Barker and Osmond (1986), Cameron (1979).

43 Brownlee (1916), Frost (1939), Springett (1951, 1952), Lowe (1954), Spicer (1954). 
The two age-profile parameters - the fitted initial levels $(A)$, and the pace of deterioration expressed by the curvature parameter $(\beta)$ - are a useful starting point. Including respiratory maladies and the aggregate noninfectious maladies, there are now eight categories, each with two profiles (male, female), observed for fourteen cohorts. An exponential curve was fit to each one to obtain the parameters $(A, \beta)$. Table 6 summarizes their goodness of fit. About $84 \%$ of the curves yield an R-squared of 0.9 or above (for about $91 \%$ of them, it is more than 0.95); another $12 \%$ of all cases yield between 0.7 and 0.89 (majority of them 0.80 or above). Only for about $2.2 \%$ of the cases were the R-squared they less than 0.5 . By disease category, most of the poorer fits were in the genitourinary and the musculoskeletal maladies; and a much smaller fraction in nervous system maladies. The reasonably good fits for the majority makes the parameters valuable to the matter at hand: does the childhood regime associate with initial levels of degenerative maladies and with the pace of deterioration in the cohorts' degenerative maladies?

Taking the cues from the literature, four indicators of the childhood epidemiologic regime are relevant. The first two measure the extent of fatalities from infectious maladies during childhood. From infancy through adolescence, cellular development of children occurs at different rates. The very early stage of life is when critical organs develop. Their subsequent development is reinforced or weakened through adolescence. The stages recommend two indicators: infectious maladies in 0-4-year olds in each cohort's birth decade, and the extent of infectious maladies in 5-14-year olds in the years when each cohort was 5-14 years of age.44

The third indicator measures the complications of pregnancy, childbirth and puerperium in each cohort's birth decade. It is the average of the annual rates from pregnancy complications in each birth decade. It includes complications such as pregnancy with hemorrhage, hypertension complicating pregnancy, fetal and placental problems affecting management of mother, abnormality of organs, malposition and malpresentation of fetus and complications of puerperium, among others. It may reflect two closely-related things: the level of regime-specific in-utero stresses; and the pregnant women's net nutritional status, revealed in the inability to give birth without major complications. In either sense, it may encompass the very early-life stresses that after-birth indicators may be unable to capture.45 Some scholars have interpreted inutero stresses in terms of gender inequality and its long-term implications for degenerative maladies. 46

The fourth indicator is the physiological status achieved through adolescence: average adult stature of each cohort. It is a widely-used indicator of cellular development. Studies of retirement and aging have used it extensively to gauge the risks of degenerative conditions in middle-to-older age men. 47 It will be used here to study the linkage with entire age-profiles instead.

Each indicator was examined for its association with the parameters of the exponential curves for each disease category. The fatalities that yielded the parameters and the data that indicate the childhood regime occurred far apart in time. The relation being examined is not contemporaneous. The disease categories (LABEL) are: aggregate noninfectious maladies (ALL NID), circulatory system (CS), nervous system (NS), digestive system (DS), genitourinary system (GUS), musculoskeletal system (MS), respiratory system (RS), neoplasms (NEO), and an average (AVG.).

Eight categories, four regime indicators and two global parameters make 64 individual correlations, shown in Figure 14. Plotted in Figure 14a are the correlations between the four indicators and the cohorts' estimated initial levels $(A)$ in each disease category. For example, the triangles represent the correlations of cohorts' $A$

44 Buck and Simpson (1982), Barker and Osmond (1986a, 1986b, 1986c), Wesley (1991), Johnson (1994), Markowitz and Neiberg (1991), Paneth and Susser (1995), Forsen et al (1997), Wong and Gallaghar (1999), Epstein and Zhu (1999), Lindholt et al (1999), Grayston et al (2000), O' Connor et al (2001), Harris (2001), Kuh et al (2002), Lee (2003), Barker and Lackland (2003), Doblehammer (2003), Mazumdar et al (2010).

45 Most notably, Barker (1992, 1994); also see, Paneth and Susser (1995), Forsen et al (1997), Leon et al (1998), Kajante et al (2005).

${ }^{4}$ Osmani and Sen (2003), Forsen et al (1997), Kajante et al (2005), Leon et al (1998).

47 Leon et al (1995), Fogel (1997), Costa and Steckel (1997), Jousilahti (2000), Costa (2002), Fogel (2003), Crimmins and Finch (2006). 
with infectious maladies when each cohort was 0-4 years old; the squares are correlations of $A$ with infections when the cohorts were 5-14 years old. The correlations for the noninfectious disease category are plotted vertically above its label on the horizontal axis (below the label, for stature).

All regime indicators correlate well with the $A$ for aggregate noninfectious maladies, circulatory, nervous, digestive, and respiratory system maladies. The relation is weaker for genitourinary and musculoskeletal maladies; and weak-to-trivial for neoplasms. The correlations with neoplasms are not statistically significant; neither is the one for genitourinary system and stature. The one with musculoskeletal maladies and infections at age 0-4 is statistically significant at the $5.0 \%$ level; the rest are statistically significant at the 1.0\% level.

On average across the categories, the correlation with infectious maladies at ages 0-4 is 0.62; with infections at age 5-14 is 0.72; with pregnancy complications is 0.7 and with stature is -0.6. Excluding neoplasms, aligned vertically with AVG., the average correlation with infections at age $0-4$ is 0.7 and at age 5-14 is 0.8 ; with pregnancy complications is 0.77 ; with stature is -0.66. The results indicate, for example, poorer physiological development in childhood associated with greater initial levels of degenerative disease; or, cohorts raised in regimes with greater burden of infections tended to have more elevated initial levels of degenerative maladies later.

Plotted in Figure 14b are the correlations with the curvature parameter for each disease category. Here, the correlations flip signs. Recall that larger the $\beta$, greater the aging potential. All else held constant, cohorts whose childhood regimes had lesser infections than others would have age-profiles with larger $\beta$ s (and steeper slopes) than others. Childhood infections would correlate negatively with $\beta \mathrm{s}$. For stature, the expected association is positive: better the physiological development, larger the $\beta$.

For aggregate noninfectious diseases in Figure 14b, the correlations with the infections indicators are -0.69 and -0.78 , with the pregnancy indicator is -0.84 , and with stature 0.81 . Excepting the weak result with neoplasms and genitourinary maladies, all correlations are positive for stature. Between the indicators, infections 0-4 and pregnancy complications relate more strongly than others in most disease categories, likely because critical organs develop at early stages. Moreover, the results for the genitourinary system are poor, possibly because some of the parameters came from poorly-fit curves. Moreover, and unsurprisingly, musculoskeletal maladies relate more with stature than with other indicators. Like Figure 13a, the correlations with neoplasms and genitourinary maladies are not statistically significant. The correlations of infection indicators with musculoskeletal maladies are statistically significant at the $5.0 \%$ level; the rest are statistically significant at the $1.0 \%$ level.48 All told, the size of the correlations indicate that aging potentials were closely associated with the past childhood regime, suggesting that changes in the regime may have been behind the shifts in the age-profiles.

The preliminary results prompt a deeper look because the curvature parameters have a limitation: individual age-groups are suppressed and only the global property matters. While all indicators seem to tell on the global curvature of the age-profiles, it is unclear whether they associate as strongly with each age. For example, even if stature associated with the initial levels or with the curvatures, it is worth finding out if the association had extended equally to age 25-34 and age 65-74.

Examining the relation of each indicator to each age-group can uncover more nuances. At least three main question strings are pertinent and they can be best outlined by example - say, circulatory maladies. First, does the regime indicator associate with circulatory maladies at age 65-74 as much as with circulatory maladies at age 25-34? If not, there must be other risks that build up between ages 25-34 and 65-74. Or, the

$4^{8}$ Number of observations is 14 for stature and 22 for the other indicators. 
types of circulatory maladies at age $25-34$ are different from the types at age $65-74$, and the indicator associates with them asymmetrically.

Second, does an indicator associate uniformly with all disease categories? That is, do pregnancy complications, on average, correlate with circulatory maladies as much as with respiratory maladies? If not, there must be factors peculiar to the disease category that the indicator does not influence.

The third pertains to comparisons of the indicators within one disease category: is the average correlation of infections at age 0-4 with circulatory maladies stronger than the average correlation of infections at age 5-14 with circulatory maladies? If so, then infections at ages 0-4 may be more of a risk to circulatory maladies than infections at age $5-14$.

Each panel of Figure 15 displays the correlations between one childhood regime indicator and various noninfectious maladies in each age. For the disease category mentioned on the horizontal axis, each set of vertical plots has 6 correlations: one for each of the five age-groups and one for an average across those age groups. For example, the solid squares represent the correlations with the 25-34-year olds; the stars represent the correlations with 65-74-year olds; the dash represents the average correlation across the age groups. 49 The time when the indicator is observed and the time when the fatalities occurred are decades apart. For example, the degenerative fatalities when each cohort was 55-64 years old were aligned with infectious diseases when they were 0-4-years of age, 5-6 decades earlier.

Excepting neoplasms, all correlations are positive and statistically significant at the $1.0 \%$ level, even with such limited amount of data. The sizes of the correlations are strong and they are unsupportive of the notion that there were no linkages between the childhood regime and noninfectious diseases at various adult ages. Like the prior results, neoplasms appear to have little or no relation with the regime indicators. It appears that the risks of neoplasms in aggregate may reside outside childhood development. Here on, the averages, plotted vertically above or below AVG, exclude neoplasms.

Figures 15a, 15b, 15c and 15d have several features unavailable from Figures 14a and 14b. Start with Figure 15 a that depicts the positive association with infectious diseases at age $0-4$. Within each disease category, the relation is stronger at younger ages than at older ones. The solid squares (for 25-34) largely appear near the top for each category, the stars (for 65-74) largely toward the bottom: the correlations diminish with age. Averaging across all categories (shown above AVG), the correlation is 0.83 for 25 -34-year olds, 0.77 for $35^{-}$ $44,0.70$ for $45-54,0.67$ for $55-64$ and 0.63 for $65-74-$ year olds. The influence of early-life infections may have been felt less strongly at 65-74 than at 25-34, likely because additional risks may have built up with age (e.g. obesity, smoking, sedentariness, among others). ${ }^{50}$ It is also likely that within each disease category individual maladies that afflict at age 25-34 may be more sensitive to childhood development than the ones that strike at age 65-74 when the underlying force of senescence is more potent.

Further, the infections 0-4 indicator does not associate uniformly across all categories. Its correlation with musculoskeletal maladies is weaker than with other maladies, a result similar to the one obtained before. For the aggregate noninfectious diseases, the average correlation across the age-groups (the dash) is about o.8. For musculoskeletal, the average is 0.46 ; for circulatory and nervous system maladies, it is 0.69 ; for digestive, genitourinary and respiratory maladies it ranges from 0.8 to 0.83 . Furthermore, the results for genitourinary maladies are different from Figures 14a and 14b; parameters from poorly fitted curves may have fogged the association with the individual age-groups. In contrast to the new results for genitourinary maladies, the weak relation with neoplasms persists, the same as Figures 14a and 14b.

49 The number of observations is 26 for 25-34-year olds, 24 for 35-44-year olds, 22 for 45-54-year olds, 20 for 55 -64-year olds and 18 for 65-74-year olds.

50 Ben-Shlomo and Davey Smith (1991), Ben-Shlomo and Kuh (2004), Kuh and Davey Smith (2004). 
Figure 15b has the results for infectious maladies when each cohort was 5-14 years old. The correlations are stronger for younger ages than older ones. On average across all disease categories (AVG), it is 0.91 for $25^{-}$ 34-year olds, 0.9 for $35-44,0.84$ for 45-54, 0.83 for 55-64 and 0.70 for $65-74$-year olds. Compared to infections at ages $0-4$, the correlations of infections 5-14 are more dispersed for circulatory maladies than for other categories. For circulatory maladies, infections at ages 0-4 may have been riskier more consistently than infections at age 5-14. For other disease categories, however, the correlations are marginally stronger compared to the infections $0-4$ indicator. The stronger correlation with musculoskeletal maladies, for example, suggests that infections that hinder the adolescent growth spurt, relevant to muscle and bone development, may tell on musculoskeletal maladies until decades later. On average across the age-groups (dashes), this indicator's correlation is about 0.9 with the maladies of the nervous, the digestive and the genitourinary maladies; about 0.76 with musculoskeletal and 0.83 with the respiratory system maladies.

Plotted in Figure 15c are the correlations for pregnancy complications. The results are nearly as strong as the first two indicators. For circulatory maladies, the correlations are closer to those of the first regime indicator (age 0-4) than to the ones for the second indicator (age 5-14), likely because of the proximity of early age (o4) to pregnancy. However, the association with the nervous system maladies is slightly stronger than that of the age 0-4 indicator. The central nervous system forms mostly before birth and the in-utero stresses are likely critical to its development. Meanwhile, like both prior indicators, the correlations diminish with age. On average (AVG) they are 0.85 for age 25-34, 0.83 for 35-44, 0.74 for 45-54, 0.7 for 55-64 and 0.6 for 65-74.

The correlations for adult stature in Figure 15d are negative: poorer the average physiological development of a cohort by adulthood, greater the noninfectious maladies at various advanced ages of its profile. Like other indicators, the correlations weaken with age. On average across disease categories, they diminish from -0.76 for age $25-34,-0.68$ for $35-44,-0.58$ for $45-54,-0.50$ for $55-64$ and -0.40 for age $65-74$. Stature's average correlation (dash) with circulatory maladies is weaker than that of other regime indicators because of its weaker association with the advanced ages (55-64 and 65-74) of the profiles.

While correlations are not causation, the long lags between the variables indicate that the linkages microlevel studies have uncovered may extend to the aggregate level and across generations. Thus,

Proposition 15: In the Transition, childhood physiological development can be an inter-temporal source for the synergy between infectious and noninfectious maladies and for the consequent population aging.

Scholars have long known some of the mechanisms behind the linkages. ${ }^{51}$ The pathways between deficient organ development and adult-age degenerative conditions are an open area of inquiry, but it is generally accepted that early-age permanent damage to organs makes them likelier to malfunction in the adult years. Figures 14 and 15 suggest that the causes of infectious and noninfectious maladies may have overlapped, but their influences on noninfectious maladies are not revealed until decades later.

\section{Conclusions: aging capability and human capital in the Transition}

The non-inheritable trait of senescence expresses itself in the upward slopes of the age-profiles of degenerative maladies. As evolutionary biologists have outlined, if selection had been intense on the fundamentals of such maladies, they may have gradually faded from human experience, leading to indefinitely extending lifespans. The evidence agrees with the basic tenets of the theories of senescence: the profiles remained upward sloping and the shifted profiles tended to converge at older ages. Moreover, the change since the nineteenth century was rapid on the evolutionary time scale. The 7-8 decades of the

${ }^{51}$ Tanner (1990), Martorell et al (1975, 1986), Cole and Parkin (1977), Chen and Scrimshaw (1983), Finch and Crimmins (2004), Crimmins and Finch (2006). 
transitional stage is a rough guide to how rapid it was and the first 5-6 decades of the nineteenth century show how quickly things can reverse. The faster speed of change distinguishes the Transition from the very gradual change that may have occurred in the evolutionary history of humans on earth. $5^{2}$

In the received view, severe rates of infectious maladies should have led to few survivors to older ages, and that should have subdued the expressions of senescence. However, it was puzzling that the disease mix indicated the opposite: noninfectious, degenerative disease rates were more severe in the Malthusian regime. Cohort-level age-profiles were then able to shed some light on the puzzle. While the age-profiles sloped upward with age, the level of the Malthusian age-profile was more elevated than that of the modern one. Instead of being subdued, senescence was expressed more intensely in the Malthusian cohorts. There remained a missing piece to the puzzle: why had the profiles shifted since then? Following the cues from the literature, the paper tried to look into inter-temporal linkages. Severe infections and physiological damage in children implied heavier rates of degenerative maladies in the Malthusian cohorts' adult years. As the childhood epidemiologic regime began shifting, the linkages suggest that the age-profiles could shift too.

More immediately, however, as infectious maladies were suppressed, more aging was possible for all age groups to whom such maladies had been fatal (Table 1). This occurred over 7-8 decades. While that was occurring, aging likely received one more internal boost, from the inter-temporal influence: as the newer cohorts of children aged, their age-profiles, while upward sloping, had shifted downward. The new aging potentials, hidden in the shifting cohort-level profiles, likely shaped the century-long downward trend of aggregate noninfectious maladies (Figure 5).

The shifts emerge as the central element for modeling at the aggregate level. One likely shift factor, the intertemporal influence of childhood development, is something macroeconomists model as the "quantityquality" tradeoff, the backbone of human capital models.53 For example, the social choices that subdued infectious diseases may have raised the "quality" of the childhood regime and of the children raised in it. However, such models explore capital formation, which, in economic theory, has a specific meaning. "Capital" benefits the owner or the owner's immediate family (excludable or alienable), as the owner sacrifices time (the investment) to acquire skills that confer benefits over an extended period (durability). Alienability, current sacrifice for future benefit, and durability are necessary properties of capital. Moreover, skills and knowledge, at the social level, can potentially improve indefinitely, and credit markets play a central function in capital formation and its accumulation.

The aging capabilities, however, do not fit neatly in the "capital" framework. Excepting infectious maladies, it is self-evident that physiological statuses are largely alienable. The cross-cohort change in aging potentials also indicates growing durability. However, unlike skills and knowledge, the basic tenets of evolutionary biology (the upward slopes, the finite lifespans) tell us that the durability may not improve indefinitely, even if it may be reproducible. Moreover, the "sacrifice" over the lifetime is unclear. Mokyr (2000) has pointed out that when the new knowledge of disease prevention arrived, women's labor force participation may have reduced as they reallocated time to the new chores that may have benefited children. However, children's physiological growth and its maintenance also require eating food, which is consumption, not sacrifice for investment. Consequently, aging capabilities may not be modeled cogently as "capital" formation or its "accumulation." At the social level, however, Easterlin (1999) has emphasized that the sacrifice of consumption for the new infrastructure in the nineteenth century may have been influential. However, that is more a public goods issue than a private goods one that human capital models illuminate. Furthermore, insurance markets instead of credit markets are more relevant for aging.

$5^{2}$ Fogel and Costa (1997).

53 Lucas (2002), Galor and Weil (1999). 
Relevant to modeling is also the issue of finite horizons. Models of finite horizons often use exogenous probabilities of death to illustrate optimal choices when lifespan is uncertain. However, that framework may not be replicable for models of aging because it amounts to assuming what needs to be explained. The theory needs to generate the hazard rates or the probabilities rather than take them as givens. Even in models where exogenous probabilities illustrate another core issue, it is unclear which probabilities are appropriate, the ones from the cohort-profiles or the ones from the period-profiles? The period-rates inaccurately reflect the cohort-rates. Both were actualities, but each pertained to different people and were revealed decades apart. Their differences present a paradox for modeling: when regimes are changing, the period probabilities may be irrelevant, even misleading, for forward-looking choices, while the cohort probabilities are unavailable because the events that generate them have not yet occurred. Modeling of - say, savings behavior - based on period rates may generate sub-optimal solutions. Modeling based on cohort rates presupposes a high degree of prescience about the entire cohort, decades ahead.

Furthermore, Johansson (1999) has expressed dismay about the "therapeutic nihilism" in the literature. The findings of this paper may be seen as correcting for that tendency. If knowledge - of antiseptic procedures, sterilization, among others - is non-excludable, then the transitional regime might be seen as a drawn-out episode of knowledge being imbibed socially and in medical practice. If so, the paper could be seen as a "before-after" type study of age-profiles as the regime changed from one in which the miasma theory prevails to the one in which the germ theory, or antibiotics, dominate children's development. Beyond that, however, scholars have been uncertain about therapeutic technology because the data required for an assessment are immense. The unavailability of data at the aggregate level is also reason for at least one more caveat, best explained by asking another question: how would the age-profiles of, say, circulatory maladies, change if new therapies for, say, heart disease, were available in 1970 ?

Assuming perfect access, if the therapy were 100\% effective, after 1970, the profiles may drop to near-zero at all ages (like the last two tuberculosis profiles in Figure 13c). A less dramatic shift would appear if the therapy were partially effective. In either case the childhood regime would be overemphasized if the effectiveness of the new therapy were overlooked. In the adult life cycles, therefore, the time when a new technology is available would be another source of heterogeneity. In the evidence presented in the last section, one clue surfaced in the form of correlations diminishing with age. New therapies could have reduced the influence of childhood development at advanced ages. While the tenets of evolutionary biology, as well as Taeuber's paradox, caution about expecting collapses in the age-profiles of degenerative maladies, therapeutic advances may make the profiles steeper than a counterfactual. This third source of heterogeneity in the profiles may need more careful consideration in the modeling.

In cross-country settings the "classical" transitions like that of England and Wales are viewed differently from the ones ongoing in Asia, Latin America and Africa. The classical transitions began at lower levels of per capita income than others and have preceded the others by decades. They each have features (e.g. HIV/AIDS) likely different from the ones this paper illustrated. One crucial difference may be in the current mix of cohorts and the resulting mixes of infectious and noninfectious diseases in their populations because each transition had begun at different times. The disease mix, however, can be seen only by going beyond period-life expectancies. In cross-country comparisons, one often comes across the notion that heftier rates of noninfectious maladies surface as countries advance economically. The within-country benchmark, however, shows the reverse: most noninfectious maladies were worse at the economically less-advanced stage of the past. That could be another way the classical cases differ from the others.

Furthermore, to obtain a consistent trans-regime view, the paper had to truncate the adult life cycle at age 74, sacrificing the information at older ages. To make use of that information, future work may have to focus on within regimes to refine the estimates of aging potentials at various stages of the Transition. 
In conclusion, for much of human history, it is said, few survived into the older ages seen today. That likely began changing in the late nineteenth century when the capability to age became more commonplace. The paper presented some features of an epidemiologic transition to find out why it began and how it progressed. Changes in children's development since the Malthusian times appear to be behind several facets of aging. They include, why period-profiles differ from cohort-profiles of degenerative diseases; why cohort-profiles differ from each other since early in adulthood; why the descent of aggregate noninfectious diseases lagged that of infectious ones; why the cohort mixes have advanced in the salutary direction; why aggregate noninfectious maladies trended downward; why the measures of aging potential based on current period rates tend to misgauge actual aging potentials; and why the reversal in the Malthusian cycle occurred. None of them are readily visible in the conventional view of the Transition. 


\section{References}

Arora, Suchit, (1999), "Health and Long-Term Economic Growth: A Multi-country Study, Ph.D dissertation, The Ohio State University.

(2001), "Health, Human Productivity, and Long-term Economic Growth," Journal of Economic History 61(3):699-749.

(2003), "Disease, Human Disability and Long-term Economic Growth," CESifo Institute Conference paper on Health and Economic Policy, June 2003.

(2005), "On Epidemiologic and Economic Transitions: an Historical View," in Health and Economic Growth: Findings and Policy Implications ed. Lopez-Casasnovas, G., B. Rivera, L. Currias, pp. 197-238, Cambridge: MIT press.

Aksan, Anna-Maria and S. Chakraborty, (2011), “Twin Transitions,” Working Paper, Economics Department, University of Oregon.

Barker, D. J. P. and C. Osmond, (1986a), "Infant Mortality, Childhood Nutrition and Ischemic Heart Disease in England and Wales," Lancet May 10(1)(8489): 1077-1081.

and C. Osmond (1986b), "Childhood Respiratory Infections and Adult Chronic Bronchitis in England and Wales," British Medical Journal 293(6557): 1271-1275.

K. M. Godfrey, C. Fall, C. Osmond, P. D. Winter and S. O. Shaheen (1991), "Relation of Birth weight and Childhood Respiratory Infection to Adult Lung Function and Death from Chronic Obstructive Airways Disease,” British Medical Journal 303(6804):671-675.

1992 Fetal and Infant Origins of Adult Disease, London: British Medical Journal.

1994 Mothers, Babies and Disease in Later Life, London: British Medical Journal. 1998 Mothers, Babies and Health in Later Life, Edinburgh: Churchill Livingstone.

and D.T. Lackland, (2003), "Prenatal Influences on Stroke Mortality in England and Wales," Stroke 34(7): 15981602.

Ben-Shlomo, Y. and G. Davey-Smith, (1991), "Deprivation in Infancy or in Adult Life: Which is More Important for Mortality Risk?” Lancet, 337(8740): 530-534.

and D. Kuh, (2002), "A Life Course Approach to Chronic Disease Epidemiology: Conceptual Models, Empirical Challenges and Disciplinary Perspectives," International Journal of Epidemiology 31(2): 285-93.

Bentsson, T. and Martin Lundstrom, (2003), "Airborne Infectious Diseases during Infancy and Mortality in Later Life in Southern Sweden, 1799-1894," International Journal of Epidemiology 32(2): 286-94.

Beveridge, W. J. B., (1977), Influenza: The Last Great Plague: An Unfinished Story of Discovery. New York.

Birchnell, J. (2007), "Escaping High Mortality,” Journal of Economic Growth, Vol. 12: 351-387.

Bourgeois-Pichat, J. (1978), "Future Outlook for Mortality Decline in the World," Population Bulletin of the United Nations 11:12-41.

Brownlee, J (1916), “Certain Conditions Regarding the Epidemiology of Phthisis Pulmonalis," Public Health 29: $130-45$.

Buck, C. and H. Simpson, "Infant Diarrhoea and Subsequent Mortality from Heart Disease and Cancer." Journal of Epidemiology and Community Health 36(1), (1982): 27-30.

Carnes, B. A. and J. Olshansky (1993), "Evolutionary Perspectives on Human Senescence," Population and Development Review 19(4): 793-806.

Cervellati, M. and U. Sunde (2005), "Human Capital Formation, Life Expectancy, and the Process of Economic Development," American Economic Review, 95(2), 1653-72.

(2011), "The Effect of Life Expectancy on Economic Growth Reconsidered," Journal of Economic Growth, 16(2): 99-133.

Chakraborty, S. (2004), "Endogenous Lifetime and Economic Growth,” Journal of Economic Theory, 116(1): 119-137.

Charlton, John and Mike Murphy, (1997), "The Health of Adult Britain 1841-1994, Decennial Supplement no. 13," Office for National Statistics: London.

Chen, L. C. and N. S. Scrimshaw (1983), Diarrhoea and Malnutrition: Interactions, Mechanisms and Intervention New York: Plenum.

Cockburn, A. (1967), Infectious Diseases, their Evolution and Eradication, Springfield, Illinoi: Thomas.

Cole, T. J. E and J. M. Parkin (1977), "Infection and its Effect on the Growth of Young Children: A Comparison of Gambia and Uganda," Transactions of the Royal Society of Tropical Medicine and Hygiene, 71(3): 196-98.

Costa, Dora L., (2002), "Changing Chronic Disease rates and the Long-term Declines in Functional Limitations among Older Men,” Demography, 39(1): 119-137.

"Understanding the Mid-Life and Older-age Mortality Declines: Evidence from the Union Army Veterans,” Journal of Econometrics, Vol. 112 (1): 175-192.

, L. Helmchen and S. Wilson, (2007), "Race, Infection and Arteriosclerosis in the Past," Proceedings of the National Academy of Sciences 104(33):13219-24

Crimmins, E. M. (1984), "Life Expectancy and the Older Population: Demographic Implications of Recent and Prospective Trends in Old-age Mortality," Research on Aging 64(4): 490-514. and C.E. Finch (2006), "Infection, Inflammation, Height and Longevity. Proceedings of the National Academy of Sciences 103(2):498-503; 
De la Croix, D. and O. Licandro (2010), "The Child is the Father of Man: Implications for Demographic Transition," mimeo CORE.

Doblhammer, G. and J. Vaupel, (2001), "Lifespan Depends on the Month of Birth," Proceedings of the National Academy of Sciences of the U.S.A., 98(5):2934-293

Doblhammer, G. (2003), “Commentary: Infectious Disea: 28 ing Infancy and Mortality in Later Life" International Journal of Epidemiology 32(2):294-95.

Easterlin, Richard A., (1999), "How Beneficent is the Market? A Look at the Modern History of Mortality," European Review of Economic History 3(3): 257-294.

Elo, I. T. and S. H. Preston, (1992) "Effects of Early Life Conditions on Adult Mortality: A Review," Population Index 58(2): 186-212.

Epstein, S. E., Y. F. Zhou and J. Zhu, (1999), "Infection and Artherosclerosis: Emerging Mechanistic Paradigms," Circulation, 100:E20-E28

Farr, W., (1885), in Vital Statistics: A Memorial Volume of Selections from the Reports and Writings of William Farr, Humphreys (1885), republished Metuchen, 1975, New Jersey: Scarecrow Press

Finch, C. E., (1990), Longevity, Senescence and the Genome, the University of Chicago Press: Chicago. and E. M. Crimmins (2004), "Inflammatory Exposure and the Historical Changes in Human Lifespans. Science 305:1736-39

Flinn, M. W., (1965), Report of the Sanitary Conditions of the Laboring Population of Great Britain by Edwin Chadwick, 1842, Edinburgh University Press.

Floud, Roderick, KennethWachter, and Annabel Gregory (1990), Height, Health, and History: Nutritional Status in the United Kingdom, 1750-1980. Cambridge: Cambridge University Press.

Fogel, Robert W. and Dora L. Costa, (1997), "The Theory of Technophysio Evolution with some Implications for Forecasting Population, Health Care Costs, and Pension Costs, Demography 34(1): 49-66.

Fogel, Robert W., (1994), "Economic Growth, Population Theory and Physiology: The Bearing of Long-Term Processes on the Making of Economic Policy." American Economic Review, 84(3): 369-395.

(2003), "Changes in the Process of Aging during the Twentieth Century: Findings and Procedures of the Early Indicators Project,” NBER Working Paper 9941.

Forsen T., J. G. Eriksson, J. Tuomilehto, K. Teramo, C. Osmond, D. J. P. Barker. (1997) "Mother's Weight in Pregnancy and Coronary Heart Disease in a Cohort of Finnish men: Follow-up study," British Medical Journal, 315(7112):837-840.

Franco, E. L., E. Duarte-Franco, A. Frenczy (2001), "Cervical Cancer: epidemiology, prevention, and the role of human papillomavirus infection," Canadian Medical Association Journal 164(7):1017-25.

Frazer, W. M. 1950. History of English Public Health 1834-1939. London: Bailliere, Tindalll and Cox.

Fries, J. F. (1980) “Aging, Natural Death and Compression of Morbidity," New England Journal of Medicine 303(3): 130-35

(1989) “The Compression of Morbidity: Near or Far?” Milbank Memorial Quarterly 67(2): 208-32.

Frost, W. H., (1939), "The Age Selection of Mortality from Tuberculosis in Successive Decades," American Journal of Epidemiology (section A), 30(3): 91-96.

Gale, C. R., C. N. Martyn, P. D. Winter, C. Cooper, (1995), "Vitamin C and Risk of Death from Stroke and Coronary Heart Disease in a Cohort of Elderly People, British Medical Journal, 310:1563-6.

Galor, Oded and David N. Weil (1999) "From Malthusian Stagnation to Modern Economic Growth," American Economic Review, 89(2): 150-54.

Grafmans, W. C. et al. (2002) "Birth Weight and Perinatal Mortality: A Comparison of 'Optimal' Birth Weight in seven Western European countries," Epidemiology 13(5): 569-574.

Grayston, J. T., (2000), "Background and Current Knowledge of Chlamydia Pneumoniae and Atherosclerosis," Journal of Infectious Diseases, 181: S402-410.

Gruenberg, E. (1977), “The Failures of Success,” Milbank Memorial Fund Quarterly/Health and Society, 55(1):3-24.

HMSO/ONS, Registrar General's Statistical Review of England and Wales, various years 1850-2000.

Harris, Bernard, (1994), "Height, Health and History: An Overview of Recent Developments in Anthropometric History," Social History of Medicine 7: 297-320.

(1997), "Growing Taller, Living Longer? Anthropometric History and Future of Old Age," Ageing and Society, 17(5): 491-512.

"Public Health, Nutrition and the Decline of Mortality: The Mckeown Thesis Revisited," Manuscript, Division of Sociology and Social Policy, University of Southhampton, Highfield, U. K.

(2001), "The Child is the Father to Man" The Relationship between Child Health and Adult Mortality in the $19^{\text {th }}$ and 20 ${ }^{\text {th }}$ Centuries," International Journal of Epidemiology 30: 688-696.

Hamilton, W. D. (1966), “The Moulding of Senescence by Natural Selection,” Journal of Theoretical Biology 12(1): 12-45.

Hayflick, L.(1985), "Theories of Aging," in R. Andres, E. L. Bierman, and W. R. Hazzard (eds.), Principles of Geriatric Medicine. New York: McGraw Hill, pp.9-21.

Higgs, Robert. (1979), "Cycles and Trends in Mortality in 18 Large American Cities, 1871-1900," Explorations in Economic History 16(4):381-408.

Heller R. F., D. Hayward and M. S. T. Hobbs, (1983), "Decline in rate of Death from Ischaemic Heart Disease in the United Kingdom, British Medical Journal, 286(Jan.):260-2. 
Helmchen, Lorens, (2003), "Changes in the Age of Onset of Chronic Diseases Among Elderly Americans, 1870-2000," Center for Population Economics, University of Chicago.

Horrell, S., J. Humphries and H.J. Voth, (1998), "Stature and Relative Deprivation: Fatherless Children in Early Industrial Britain," Continuity and Change, 13(1): 73-115.

Horiouchi, S. (1989), "Some Methodological Issues in the Assessment of the Deceleration of the Mortality Decline," in L. Ruzicka, G. Wunsch, and P. Kane (eds.), Differential Mortality: Methodological Issues and Biosocial Factors. Oxford: Clarendon Press, pp. 64-78.

Howitt, P (2005), "Health, Human Capital and Economic Growth: A Schumpeterian Perspective." in Health and Economic Growth: Findings and Policy Implications ed. Lopez-Casasnovas, G., B. Rivera, L. Currias, 17-40. Cambridge: MIT press.

Humphreys, J., (2010), Childhood and Child Labor in the British Industrial Revolution, Cambridge University Press.

Human Mortality Database, UC Berkeley, and Max Plank Institute for Demographic Research, www.mortality.org.

Janssen, F., Kunst, A. (2005), "Cohort Patterns in Mortality Trends Among the Elderly in Seven European Countries, 1950-1999," International Journal of Epidemiology 34:1149-1159.

Johansson, S. (1991), "The Health Transition: The Cultural Inflation of Morbidity during the Decline of Mortality," Health Transition Review 1:39-65.

(1992), "Measuring the Cultural Inflation of Morbidity during the Decline in Mortality," Health Transition Review 2(1): 77-87.

(1999), "Death and Doctors: Medicine and Elite Mortality in Britain from 1500-1800," Cambridge Group for the History of Population and Social Structure; Working Paper Series No. 7.

Johnson, R. T, (1994), “The Virology of Demyelinating Disease,” Annals of Neurology, 36 suppl: S54-S6o.

Johnson, P. and S. Nicholas, (1995), " Male and Female Living Standards in England and Wales, 1812-57: Evidence from Criminal Height Records," Economic History Review 48: 470-81.

Jousilahti, P., J. Tuomilehto, E. Vartiainen, J. Eriksson and P. Puska, (2000), "Relation of Adult Height to Cause-specific and Total Mortality: A Prospective Follow-up Study of 31,199 Middle-aged Men and Women in Finland," American Journal of Epidemiology, Vol. 151(11): 1112-1120.

Kajante, E., C. Osmond, D. J. P. Barker, T. Forsen, D. Phillips, J. Eriksson, (2005), "Size at Birth as a Predictor of Mortality at Adulthood: A Follow up of 350,000 person-years," International Journal of Epidemiology 34(3):655-663.

Kannisto, V., J. Lauristen, A. R. Thatcher and J. W. Vaupel, (1994), "Reductions in Mortality at Advanced Ages: Several decades of Evidence from 27 Developed Countries," Population and Development Review 20(4): 793-810.

Kermack, W. O., A. G. McKendrick, P. L. McKinlay, (1934), "Death Rates in Great Britain and Sweden; Some General Regularities and their Significance," The Lancet, March: 698-703

Keyfitz, N. (1977), "What Would it Make if Cancer were Eradicated. An Examination of the Taeuber paradox," Demography 14(4): 411-18.

Keyfitz, N. (1985), Applied Mathematical Demography, $2^{\text {nd }}$ edition. New York: Springer.

Khosla, S. N., (1981), “The Heart in Enteric (typhoid) Fever.” Journal of Tropical Medicine and Hygiene 84(3): $125-31$.

Kirkwood, T. B. L., (1977), "Evolution of Ageing," Nature 270: 301-304. and R. Holliday (1979), "The Evolution of Longevity," in Proceedings of Royal Society, B 205, pp. 532-546.

(1981), "Repair and its Evolution: Survival versus Reproduction," in C. R. Townsend and P. Calow (eds.), Physiological Ecology: An Evolutionary Approach to Resource Use. Oxford: Blackwell Scientific Publications, pp. 165-189.

(1985), "Comparative Evolutionary Aspects of Longevity," in Handbook of the Biology of Aging, $2^{\text {nd }}$ ed., C. E. Finch and E. L. Schneider (eds.), 27-45. New York: Van Nostrand.

(1999) Time of Our Lives: The Science of Human Aging. Oxford: Oxford University Press.

Kohn, G. C., Encyclopedia of Plague and Pestilence, Wordsworth Reference, Wordsworth Editions Ltd: Hertfordshire, U.K.: 1998.

Komlos, J. (1993a), "Further Thoughts on the Nutritional Status of the British population,” Economic History Review 46(3): 363-66.

(1993b) "A Malthusian Episode Revisited: the Height of British and Irish Servants in Colonial America," Economic History Review 46(2): 768-82.

(1993c), "The Secular Trend in the Biological Standard of Living in the United Kingdom: 1730-1860," Economic History Review 46(1): 115-44.

(1995) Biological Standard of Living on Three Continents. Boulder: Westview Press, 1995.

and G. Baten (1998a) eds., The Biological Standard of Living in Comparative Perspective. Stuttgard: Franz Steiner Verlag.

(1998b), "Shrinking in a Growing Economy: The Mystery of Physical Stature during the Industrial Revolution," Journal of Economic History 58(3), 779-802.

(2004), "On English Pygmies and Giants: the Physical Stature of English Youth in the Late $18^{\text {th }}$ Century and Early $19^{\text {th }}$ Centuries," Research in Economic History, 25(2):149-168.

Kuh, D., and G. Davey Smith (1993), "When is Mortality Risk Determined? Historical Insights into a Current Debate," Social History of Medicine, 6(1):101-123. 
, R. Hardy, C. Lagenberg, M. Richards, M. E. J. Wadsworth (2002), "Mortality in Adults Aged 26-54 years Related to Socioeconomic Conditions in Childhood: post-War Birth Cohort Study,” British Medical Journal 325 (Nov.): 1076-1080.

, and Y. Ben-Shlomo (2004), A Life Course Approach to Chronic Disease Epidemiology, 2 ${ }^{\text {nd }}$ edition, Oxford: Oxford University Press.

and G. Davey Smith, (2004), "A Life-Course and Adult Chronic Disease: an Historical Perspective with Particular Reference to Coronary Heart Disease," eds. Diana Kuh and Y. Ben Shlomo, A Life-Course Approach to Chronic Disease Epidemiology, Oxford: Oxford University Press

Kunitz, Stephen J., (2007), The Health of Populations: General Theories and Particular Realities, Oxford: Oxford University Press.

and Stanley L. Engerman (1992), “The Ranks of Death: Secular Trends in Income and Mortality," Health Transition Review, Vol 2, Supplementary Issue: 29-45.

Lee, Chulhee, (1997), "Socioeconomic Background, Disease, and Mortality among Union Army Recruits: Implications for Economic and Demographic History," Explorations in Economic History, 34(1): 27-55.

(2003), "Prior Exposure to Disease and Later Health and Mortality: Evidence from Union Army Medical Records," in Health and Labor Force Participation over the Life Cycle: Evidence from the Past, ed. Dora L. Costa. Chicago: University of Chicago Press.

Lee, R. D. and L, R. Carter, (1992), “Modeling and Forecasting United States Mortality,” Journal of American Statistical Association 87(419):659-671.

Leon D. A., G. Davey Smith, M. Shipley and D. Strachan (1995), "Adult Height and Mortality in London: Early Life, Socioeconomic Status, or Shrinkage," Journal of Epidemiology and Community Health 49(1):5-9.

, H. O. Lithell, D. Vagero, et al (1998), "Reduced Fetal Growth Rate and Increased Risk of Death from Ischaemic Heart Disease: Cohort Study of 15000 Swedish Men and Women born 1915-25," British Medical Journal 317(7153): 241-245.

, I. Koupilova, H. O. Lithell, L. Berguland et. al (1996), "Failure to Realize Growth Potential in Utero and Adult Obesity in Relation to Blood Pressure in 50-year old Swedish Men," British Medical Journal 312(7028):401-6.

Lindholt, J. S, H. Fasting, E. W. Hennenberg and L Ostergaard, (1999), "A Review of Chlamydia Pneumoniae and Atheroclerosis," European Journal of Vascular and Endovascular Surgery 17(4): 283-89

Logan, W. P. D. (1950), "Mortality in England and Wales from 1848 to 1957," Population Studies 4:132-78.

Logigian, E. L, et al (1990), "Chronic Neurologic Manifestation of Lyme Disease," New England Journal of Medicine, 323(21): 1483-44.

Lowe, C. R. (1954), "Recent Trends in Survival of Patients with Respiratory Tuberculosis," British Journal of Preventive and Social Medicine 8(3): 91-98.

Lucas, Robert E. Jr. (2002), Lectures on Economic Growth, Harvard University Press, Cambridge: MA.

Makela, P. H., (1999), "Is Cardiovascular Disease Preventable by Vaccination?” Annals of Medicine 31(1):61-65.

Manton, K. G., C. Parrick and E. Stallard, (1980), "Mortality Model Based on Delays in Progression of Chronic Diseases: Alternative to Cause Elimination Model," Public Health Reports, 95(6):580-88.

Manton, K. G. (1982), "Changing Concepts of Morbidity and Mortality in the Elderly Population," Milbank Memorial Fund Quarterly/Health and Society 60(2):183-244.

(1986), "Past and Future Life Expectancy Increases at Later Ages: Their Implications for the Linkage of Chronic Morbidity, Disability and Mortality," Journal of Gerontology 41(5):672-81.

Martorell R., J. P. Habicht, C. Yarborough, A. Lechtig, R. E. Klein and D. Western.,(1975), “Acute Morbidity and Physical Growth in Rural Guatemalan Children, "American Journal of Diseases of Children, 129(11): 1296-1301..

(1980) "Inter-relationships Between Diet, Infectious Disease and Nutritional Status,” in Greene, L. S., and Johnsston, F. E eds. Social and Biological Predictors of Nutritional Status, Physical Growth and Neurological Development, New York Academic Press: NY.

J. P. Habicht, (1986), "Growth in Early-Childhood in Developing Countries," in Human Growth: A Comprehensive Treatise, vol.(3), ed. F. Falkner and J. M. Tanner, New York: Plenum.

Markowitz, L. E. and P. Neiburg (1991), "The Burden of Acute Respiratory Infection Due to Measles in Developing Countries and the Potential Impact of Measles Vaccine." Review of Infectious Diseases, 13 (Supplement 6): S55561.

Mata, L. J. (1978), The Children of Santa Maria Cauque: A Prospective Field Study of Health and Growth. Cambridge: Mass.: MIT Press.

Mazumdar, B., D. Almond, K. Parka, E. M. Crimmins and C. E. Finch (2010), "Lingering Prenatal Effects of the 1918 Influenza pandemic on Cardiovascular Diseases," Journal of Developmental Origins of Health and Disease, Vol. 1(1), 26-34.

Medawar, P. B. (1952), An Unsolved Problem of Biology, London: Lewis.

Mercer, A. (1985), "Smallpox and Epidemiological-demographic Change in Europe: The Role of Vaccination," Population Studies 39(2): 287-307.

(1990), Disease, Mortality and Population in Transition: Epidemiological-demographic Change in England since the Eighteenth Century as Part of Global phenomenon, Leicester University Press, U.K.

Mckeown, T. and R. G. Brown (1955), "Medical Evidence Related to English Population Changes in the Eighteenth Century," Population Studies 9(2): 119-41. 
and R. G. Record (1962), "Reasons for the Decline of Mortality in England and Wales during the Nineteenth Century," Population Studies 16(2): 94-122.

R. G. Record and R. D. Turner (1975), "An Interpretation of the Decline of Mortality in England and Wales during the Twentieth Century, Population Studies 29(3): 391-422. (1976), The Modern Rise of Population, London: Edward Arnold.

Mokyr, Joel (2000), "Why "More Work for Mother?" Knowledge and Household Behavior, 1870-1945," The Journal of Economic History, Volume 60(1): 1-41

Morand, O. (2004), Economic Growth, Longevity and the Epidemiological Transition, European Journal of Health Economics 5 (2): 166-174.

(2005), "Economic Growth, Health and Longevity in the Very Long run: Facts and Mechanisms," in Health and Economic Growth: Findings and Policy Implications, ed. Lopez-Casasnovas, G., Rivera, B., Currias, L. Cambridge, Mass: MIT press.

Murray, C., L. Chen (1992), "Understanding Morbidity Change,” Population and Development Review 18(3):481-503.

Nicholas, S. and R. H. Steckel (1991), Heights and Living Standards of English Workers during the Early Years of Industrialization, The Journal of Economic History 51(4): 937-57.

Palloni, A. et al, (2005), "The Influence of Early Life Conditions on Health Status among Elderly Puerto Ricans," Social Biology, 52(3): 132-63.

O' Connor, S., Taylor C. Lee, A. C. Epstein and P. Libby (2001), "Potential Infectious Etiologies of Atherosclerosis: a Multifactorial Perspective," Emerging Infectious Diseases, 7(5): 780-88.

Omran, A. R. (1971), "The Epidemiologic Transition: A Theory of Epidemiology of Population Change," The Milbank Quarterly, 49(4): 509-38.

(1982), "Epidemiologic Transition,” In J. A. Ross Ed. International Encyclopedia of Population. London: The Free Press: $172-83$.

Oeppen, J. and J. Vaupel (2002), “Broken Limits to Life Expectancy,” Science, 296, pp. 1029-1031.

Olshansky, S. J. (1985), "Delay versus Elimination of Degenerative Diseases,” American Journal of Public Health 75(7): 754-57.

and A. B. Ault., (1986), The Fourth Stage of the Epidemiologic Transition: The Age of Delayed Degenerative Diseases, Milbank Memorial Fund Quarterly, 64(3): 355-91.

(1987), Simultaneous/Multiple cause delay (SIMCAD): An Epidemiological Approach to Projecting Mortality, Journal of Gerontology 42(4): 358-65.

B. A. Carnes, and C. Cassel. (1990), In Search of Methuselah: Estimating the Upper Limits to Human Longevity, Science, 250: 634-640.

et al (2005), A Potential Decline in Life Expectancy in the United States in the $21^{\text {st }}$ century, New England Journal of Medicine 352: 1138-1145.

Osmani, S. and A. K. Sen, (2003), “The Hidden Penalties of Gender Inequality: Fetal Origins of Ill-Health,” Economics and Human Biology 1(1): 105-121.

Paneth N. and M. Susser, (1995), "Early Origins of Coronary Heart Disease (the "Barker Hypothesis")" [Editorial], British Journal of Medicine, 310 (6977): 411-12.

Parsonet, J. "Bacterial Infection as a Cause of Cancer." Environmental Health Perspectives (1995), 103: suppl. 8: 263-68

Preston, S.H., N. Keyfitz and R. Schoen, (1972 ), Causes of Death: Life Tables for National Populations, New York: The Seminary Press. (1975), “The Changing Relation between Mortality and Economic Development," Population Studies 29 (1975): 213-48.

(1976), Mortality Patterns in National Populations, with Special Reference to the Recorded Causes of Death, New York.

Preston, S. H. and Michael R. Haines (1991), Fatal Years: child mortality in late-19 ${ }^{\text {th }}$ century America. Princeton, N.J.: Princeton University Press.

Razell, P., (1977), The Conquest of Small-pox: the Impact of Inoculation on Smallpox Mortality in Eighteenth century Britain, Sussex: Caliban.

Rau, R., Soroko, E. D. Jasilionis, J. Vaupel (2008), Continued Reductions in Mortality at Advanced Ages. Population and Development Review, 34(4): 747-768.

Riley, J. (1989) Sickness, Recovery and Death: A History of Forecast of Ill-health. Basingstoke: McMillan. , G. Alter (1989), "The Epidemiologic Transition and Morbidity, Annales de Demographie Historique, $199-213$.

The Sick and the Well: Adult Health in Britain during the Health Transition, Health Transition Review 6(suppl.):19-44.

Schofield, R. D. Reher, A. Bideau (1991), Decline of Mortality in Europe, Oxford: Clarendon Press.

Saikku, P., "Epidemiology of Chlamydia Pneumoniae in Atherosclerosis," American Heart Journal (1999) 138: S50o503 .

Sen, Amartya, K., (1998), "Mortality as an Indicator of Economic Success or Failure," The Economic Journal Vol. 108(446): 1-25. (1999a), Commodities and Capabilities, Oxford University Press: Oxford, U.K. (1999b), Development as Freedom, Oxford University Press: Oxford, U.K.. 
Shaheen, S. O., et al. (1994), The Relationship between Pneumonia in Early Childhood and Impaired Lung Function in Late Adult Life, American Journal of Respiratory Critical Care Medicine, 149(3):616-19.

Shaheen, S. O., (1997), "The Beginnings of Chronic Airflow Obstruction," British Medical Bulletin, 53(1):58-70.

Spicer, C. C., (1954), "The Generation Method of Analysis Applied to Mortality from Respiratory Tuberculosis," Journal of Hygiene 52(3):361-68.

Springett, V. H.,(1951), “Results of Reexamination of Mass Radiography,” British Medical Journal 2(4724):144-148.

"An Interpretation of the Statistical Trends in Tuberculosis", Lancet 259(6708):521-25.

Steckel, Richard H. (1979), Slave Height Profiles from Coastwise Manifests, Explorations in Economic History, 16(4): 363-380.

(1986) A Peculiar population: The Nutrition, Health and Mortality of American Slaves from Childhood to Maturity, Journal of Economic History, 46(3):721-41. (1995) Stature and the Standard of Living, Journal of Economic Literature 33(4): 1903-40. and Floud, Roderick., (1997) Health, Welfare and Industrialization. Chicago: University of Chicago Press. and Dora L. Costa, (1997), "Long-term Trends in Health, Welfare and Economic Growth in the United States." In Steckel, Richard H. and Roderick Floud, eds. Health, Welfare and Industrialization, Chicago: University of Chicago Press.

Strulik, H. (2008), "Geography, Health and the Pace of Demo-Economic Development," Journal of Development Economics, 86(1): 61-75.

Szreter, S. (1988), The Importance of Social Intervention in Britain's Mortality Decline Circa 1850-1914: A Reinterpretation of the Role of Public Health. Social History of Medicine 1(1): 1-37. (1997) "Economic Growth, Disruption, Deprivation, Disease, and Death: On the Importance of Politics of Public Health for Development," Population and Development Review, 23(4):693-728. and G. Mooney (1998), "Urbanization, Mortality, and the Standard of Living Debate: New Estimates of the Expectation of Life at Birth in the Nineteenth Century British Cities," Economic History Review, 51(1), 84-112.

Tanner, J. M., (1990), Fetus into Man: Physical Growth from Conception to Maturity, Harvard University Press: MA.

Taeuber, C., (1976), "If Nobody Dies of Cancer.....," Kennedy Institute Quarterly Report 2(2): 6-9.

Thatcher, A. R., (1992), "Trends in Numbers and Mortality at High Ages in England and Wales," Population Studies, 46(3): 411-26. (1999), "The Demography of Centenarians in England and Wales," Population, 13(1):139-56.

Tsai, S., E. Lee, and R. Hardy (1978) "The Effects of Reduction in Leading Causes of Death: Potential Gains in Life Expectancy," American Journal of Public Health 68(10): 966-71.

Vaupel, J. W. and H. Lundström, (1994), "Prospects for Longer Life Expectancy, ” in D. Wise (ed.), Studies in Economics of Aging, University of Chicago Press, Chicago.

Voth, H. and T. Leunig (1996), Did small-pox reduce adult height? Stature and the Standard of Living in London, 17701873, Economic History Review, Vol. XLIX (3): 541-60.

Waaler, H. T., (1984), "Height, Weight and Mortality: The Norwegian Experience," Acta Medica Scandinavia, Supplement 679: 1-51.

Wesley, A. G., "Prolonged After-Effects of Pneumonia in Children," South African Medical Journal, 79(2) (1991): 73-6.

Whitehead, R. G. (1977) Protein and Energy Requirements of Young Children Living in the Developing Countries to Allow for Catch-up Growth after Infections, American Journal of Clinical Nutrition 30(9): 1545-57.

Williams, G. C., (1957), "Pleiotropy, Natural Selection and the Evolution of Senescence," Evolution 11(4): 398-411.

Williamson, J. G. (1982), "Was the Industrial Revolution Worth it? Disamenities and Death in the Nineteenth Century British Towns", Explorations in Economic History, 19(July): 221-45.

Wilmoth, J. R. and H. Lundström, (1995), "Extreme longevity in Five Countries," European Journal of Population /Revue Européenne de Démographiee, 12(1): 63-93.

Wong, Y. K, Gallaghar, P. J, and Me. E. Ward, (1999), “Chlamydia Pneumoniae and Atherosclerosis," Heart, 81(3): 23238 .

Woods, R., (1985), "The Effects of Population Redistribution on the Level of Mortality in Nineteenth Century England and Wales," Journal of Economic History 45(3):645-51. (2000) The Demography of Victorian England and Wales, Cambridge University Press: U.K.

World Health Organization (1957), Manual of International Statistical Classification of Diseases, Injuries and Causes of Death: Seventh Revision. Geneva

Wrigley, E. A., and R. S. Schofield, the Population History of England, 1541-1871: A Reconstruction. Cambridge, MA: Harvard University Press, 1981.

Zon, A. H. van, and Joan Muysken (2001), "Health and Endogenous Growth," Journal of Health Economics 20(2): 169185 .

Zon, A. H. van, and Joan Muysken (2005), "Health as a Principal Determinant of Economic Growth," in Health and Economic Growth: Findings and Policy Implications ed. Lopez-Casasnovas, G., B. Rivera, L. Currias, 41-66. Cambridge: MIT press. 
Table1: Percentage contribution of principal disease categories to the decline in all disease-caused death rates

\begin{tabular}{|c|c|c|c|c|c|c|c|c|}
\hline \multirow{4}{*}{ Disease category } & \multicolumn{4}{|c|}{ 1870-74 through 1950-54 } & \multicolumn{4}{|c|}{ 1870-74 through 1996-2000 } \\
\hline & \multicolumn{4}{|l|}{ Age groups } & \multicolumn{4}{|l|}{ Age groups } \\
\hline & aggregate & $0-14$ & $15^{-64}$ & $65^{+}$ & aggregate & $0-14$ & $15-64$ & $65^{+}$ \\
\hline & (1) & $(2)$ & $(3)$ & $(4)$ & $(5)$ & (6) & (7) & $(8)$ \\
\hline Infectious diseases & 77.2 & 67.7 & 72.8 & 100.7 & 56 & 64.8 & $64 \cdot 3$ & 41.1 \\
\hline Noninfectious diseases & 22.8 & 32.3 & 27.2 & -0.7 & 44 & 35.2 & $35 \cdot 7$ & 58.9 \\
\hline
\end{tabular}

Table 2: Cross-regime differences in the age-profiles of noninfectious maladies

\begin{tabular}{llllc}
\hline cohort & $\mathrm{A}$ & $\beta$ & $R^{2}$ & $\begin{array}{c}\text { mortality-rate-doubling time } \\
\text { (years) }\end{array}$ \\
\cline { 2 - 5 } Malthusian & 43.3 & 0.0648 & 0.99 & 10.7 \\
Early-transition & 23.3 & 0.0706 & 0.99 & 9.8 \\
Late-Transition & 10.3 & 0.0801 & 0.99 & 8.6 \\
Post-transition & 4.2 & 0.0905 & 0.99 & 7.7 \\
\hline
\end{tabular}

Note: The exponential curve is $A e^{\beta t}$, where $t$ is age centered on each age-interval (i.e. 29.5, 39.5, 49.5, 59.5, 69.5). The implied fatality-rate-doubling time is calculated as $(\ln 2 \div \beta$ ), where $\ln$ is the natural log. The post-transition curve was based on the assumption of no change in the fatality rates at ages 55-64 and 65-74 since late-transition cohorts. 
Table 3: Cross-regime differences in the age-profile of principal noninfectious maladies

\begin{tabular}{|c|c|c|c|c|}
\hline cohort & A & $\beta$ & $R^{2}$ & $\begin{array}{c}\text { mortality-rate-doubling time } \\
\text { (years) }\end{array}$ \\
\hline & & \multicolumn{2}{|c|}{ Circulatory system } & \\
\hline Malthusian & 8.22 & 0.0782 & 0.99 & 8.8 \\
\hline Early-transition & 2.77 & 0.0933 & 0.98 & 7.4 \\
\hline Late-transition & 1.35 & 0.1081 & 0.99 & 6.8 \\
\hline \multirow[t]{2}{*}{ Post-transition } & 0.26 & 0.1257 & 0.99 & $5 \cdot 5$ \\
\hline & & \multicolumn{2}{|c|}{ Nervous system } & \\
\hline Malthusian & 9.77 & 0.0360 & 0.97 & 19.2 \\
\hline Early-transition & 6.27 & 0.0260 & 0.99 & 26.5 \\
\hline Late-transition & 1.37 & 0.0458 & 0.86 & 15.1 \\
\hline \multirow[t]{2}{*}{ Post-transition } & 0.38 & 0.0660 & 0.97 & 10.5 \\
\hline & & \multicolumn{2}{|c|}{ Digestive system } & \\
\hline Malthusian & 10.65 & 0.0438 & 0.98 & 15.8 \\
\hline Early-transition & 6.17 & 0.0453 & 0.99 & 15.2 \\
\hline Late-transition & 0.81 & 0.0649 & 0.96 & 10.6 \\
\hline \multirow[t]{2}{*}{ Post-transition } & 0.21 & 0.0874 & 0.99 & 7.9 \\
\hline & & \multicolumn{2}{|c|}{ Genitourinary system } & \\
\hline Malthusian & 4.75 & 0.0603 & 0.99 & 11.4 \\
\hline Early-transition & 4.04 & 0.0529 & 0.99 & 13.0 \\
\hline Late-transition & 3.12 & 0.0270 & 0.66 & 25.6 \\
\hline \multirow[t]{2}{*}{ Post-transition } & 0.06 & 0.0845 & 0.77 & 8.2 \\
\hline & & \multicolumn{2}{|c|}{ Musculoskeletal system } & \\
\hline Malthusian & 0.95 & 0.0550 & 0.89 & 12.5 \\
\hline Early-transition & 0.24 & 0.0650 & 0.98 & 10.6 \\
\hline Late-transition & 0.07 & 0.0735 & 0.72 & 9.4 \\
\hline \multirow[t]{2}{*}{ Post-transition } & 0.02 & 0.0933 & 0.91 & 7.4 \\
\hline & & \multicolumn{2}{|c|}{ Neoplasms (cancers) } & \\
\hline Malthusian & 1.12 & 0.0991 & 0.97 & 7.0 \\
\hline Early-transition & 1.51 & 0.0941 & 0.98 & $7 \cdot 3$ \\
\hline Late-transition & 1.38 & 0.0971 & 0.99 & 7.1 \\
\hline Post-transition & 0.82 & 0.1044 & 0.99 & 6.6 \\
\hline
\end{tabular}

Note: The exponential curve is $A e^{\beta t}$, where $t$ is centered on each age-interval (i.e. 29.5, 39.5, 49.5, 59.5, and 69.5). The implied fatality-rate-doubling time is calculated as $(\ln 2 \div \beta)$, where $\ln$ is the natural log. The posttransition curve was based on the assumption of no change in the fatality rates at ages 55-64 and 65-74 since the late-transition cohort. 
Table 4: The differences between the period-age-profile and the cohort age-profile of noninfectious maladies

\begin{tabular}{|c|c|c|c|c|c|c|c|c|}
\hline & \multicolumn{4}{|c|}{ Period age-profile } & \multicolumn{4}{|c|}{ Cohort age-profile } \\
\hline & $\mathrm{A}$ & $\beta$ & $R^{2}$ & $\begin{array}{c}\text { Mortality-rate- } \\
\text { doubling time (years) }\end{array}$ & $\mathrm{A}$ & $\beta$ & $R^{2}$ & $\begin{array}{c}\text { Mortality-rate- } \\
\text { doubling time (years) }\end{array}$ \\
\hline $1930 \mathrm{~s}$ & 11.9 & 0.0833 & 0.99 & 8.3 & $5 \cdot 9$ & 0.0919 & 0.99 & $7 \cdot 5$ \\
\hline $1920 \mathrm{~s}$ & 14.7 & 0.0796 & 0.99 & 8.7 & 7.9 & 0.0879 & 0.99 & 7.9 \\
\hline 1901s & $24 \cdot 7$ & 0.0741 & 0.99 & 9.4 & 14.9 & 0.0758 & 0.98 & 9.1 \\
\hline $1890 \mathrm{~s}$ & 33.9 & 0.0690 & 0.99 & 10.0 & $15 \cdot 5$ & 0.0760 & 0.99 & 9.1 \\
\hline $1870 \mathrm{~s}$ & 41.8 & 0.0644 & 0.99 & 10.7 & $25 \cdot 3$ & 0.0696 & 0.99 & 10.0 \\
\hline $1850 \mathrm{~s}$ & 29.3 & 0.0666 & 0.98 & 10.4 & 42.0 & 0.0642 & 0.99 & 10.8 \\
\hline $1840 \mathrm{~S}$ & 32.2 & 0.0645 & 0.97 & 10.7 & 41.8 & 0.0653 & 0.99 & 10.6 \\
\hline
\end{tabular}

Note: The exponential curve is $A e^{\beta t}$, where $t$ is age centered on each age interval (i.e. 29.5, 39.5, 49.5, 59.5, and 69.5). The implied fatality rate doubling time is calculated as $(\ln 2 \div \beta)$, where $\ln$ is the natural $\log$.

Table 5: Age-profiles of noninfectious maladies in cohorts during the Malthusian reversal

\begin{tabular}{llllc}
\hline cohort & $\mathrm{A}$ & $\beta$ & $R^{2}$ & $\begin{array}{c}\text { mortality-rate-doubling time } \\
\text { (years) }\end{array}$ \\
\cline { 2 - 5 } $1810-19$ & 21.93 & 0.0751 & 0.99 & 9.2 \\
$1820-29$ & 25.44 & 0.0736 & 0.99 & 9.4 \\
$1830-39$ & 33.58 & 0.0697 & 0.99 & 9.9 \\
$1840-49$ & 43.19 & 0.0653 & 0.99 & 10.6 \\
$1850-59$ & 43.32 & 0.0642 & 0.99 & 10.8 \\
$1860-69$ & 33.69 & 0.0675 & 0.99 & 10.3 \\
$1870-79$ & 26.15 & 0.0696 & 0.99 & 10.0 \\
$1880-89$ & 21.26 & 0.0717 & 0.98 & 9.7 \\
\hline
\end{tabular}

Note: The exponential curve is $A e^{\beta t}$, where $t$ is centered at each age interval (i.e. 29.5, 39.5, 49.5, 59.5, 69.5). The implied fatality-rate-doubling time is calculated as $(\ln 2 \div \beta)$, where $\ln$ is the natural log. The curve for 1810-19 cohort assumes that the fatality rate of 25-34-year olds from the1820s cohort. 
Table 6: The goodness-of-fit of the exponential curves of cohort age-profiles

\begin{tabular}{|c|c|c|c|c|c|c|c|}
\hline \multirow[b]{2}{*}{ Disease category } & \multicolumn{5}{|c|}{ R-squared } & \multirow[b]{2}{*}{$\leq 0.50$} & \multirow[b]{2}{*}{ Total } \\
\hline & $\geq 0.9$ & $0.80-0.89$ & $0.70-0.79$ & $0.60-0.69$ & $0.50-0.59$ & & \\
\hline All noninfectious diseases (ALL NID) & 28 & $\mathrm{O}$ & o & o & o & O & 28 \\
\hline Circulatory system (CS) & 28 & 0 & o & o & o & O & 28 \\
\hline Nervous system (NS) & 20 & 5 & 1 & o & 1 & 1 & 28 \\
\hline Digestive system (DS) & 26 & o & 2 & o & o & o & 28 \\
\hline Genitourinary system (GS) & 16 & 4 & 3 & 2 & 1 & 1 & 28 \\
\hline Musculoskeletal system (MS) & 17 & 6 & 1 & 2 & 1 & 1 & 28 \\
\hline Respiratory system (RS) & 24 & 3 & 1 & o & o & o & 28 \\
\hline Neoplasms (NEO) & 28 & O & o & o & o & o & 28 \\
\hline Total & 187 & 18 & 8 & 6 & 2 & 3 & 224 \\
\hline percentages & $83.5 \%$ & $8.0 \%$ & $3.6 \%$ & $2.7 \%$ & $0.9 \%$ & $1.3 \%$ & $100 \%$ \\
\hline
\end{tabular}




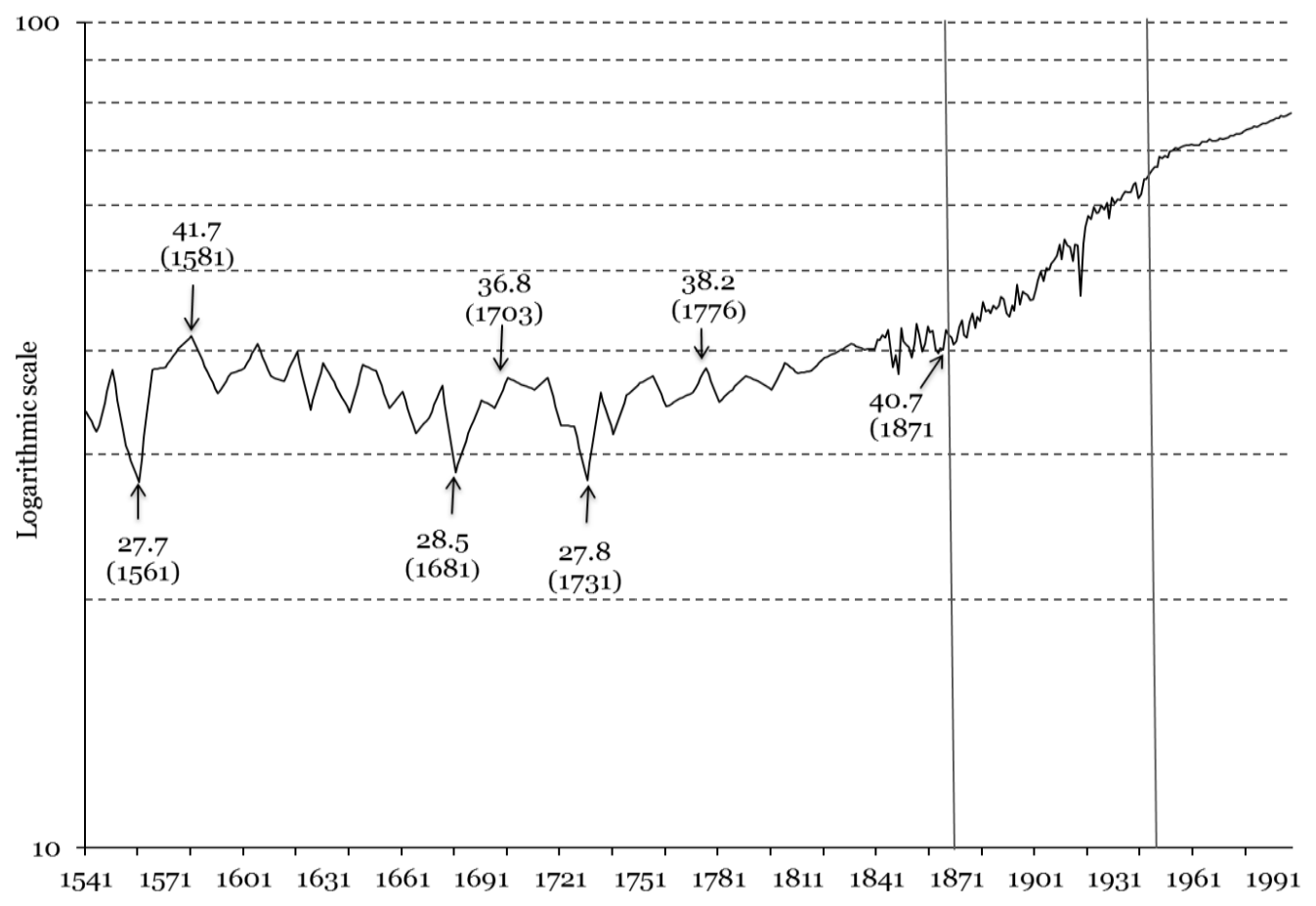

Figure 1a: Period-life expectancy at birth, 1541-2000

Source: Wrigley and Schofield (1981); Human Mortality Database.

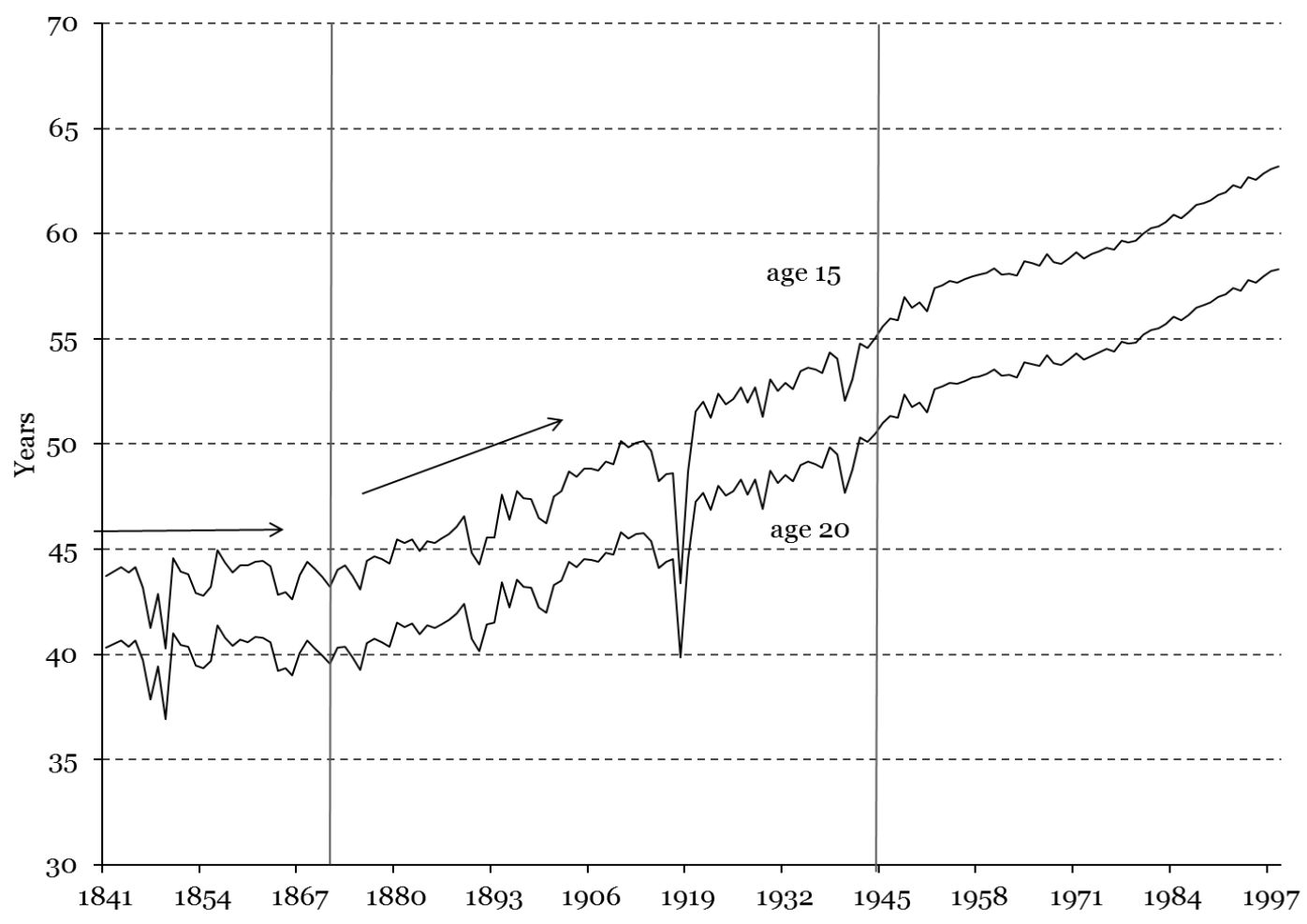

Figure 1b: Period-life expectancy at ages 15 and 20

Source: Human Mortality Database 


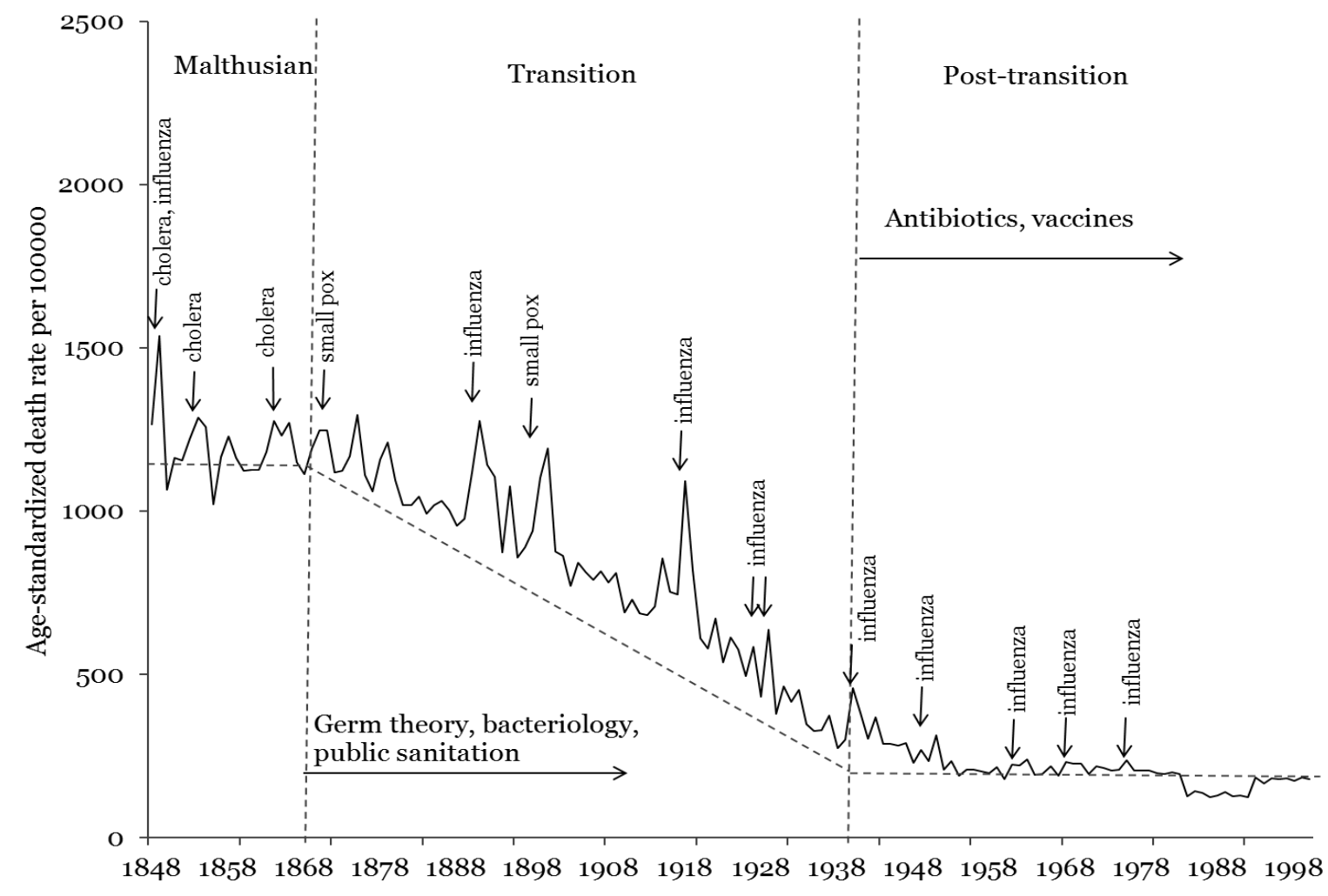

Figure 2: Infectious diseases, 1848-20oo

Source: HMSO; author's calculations. 


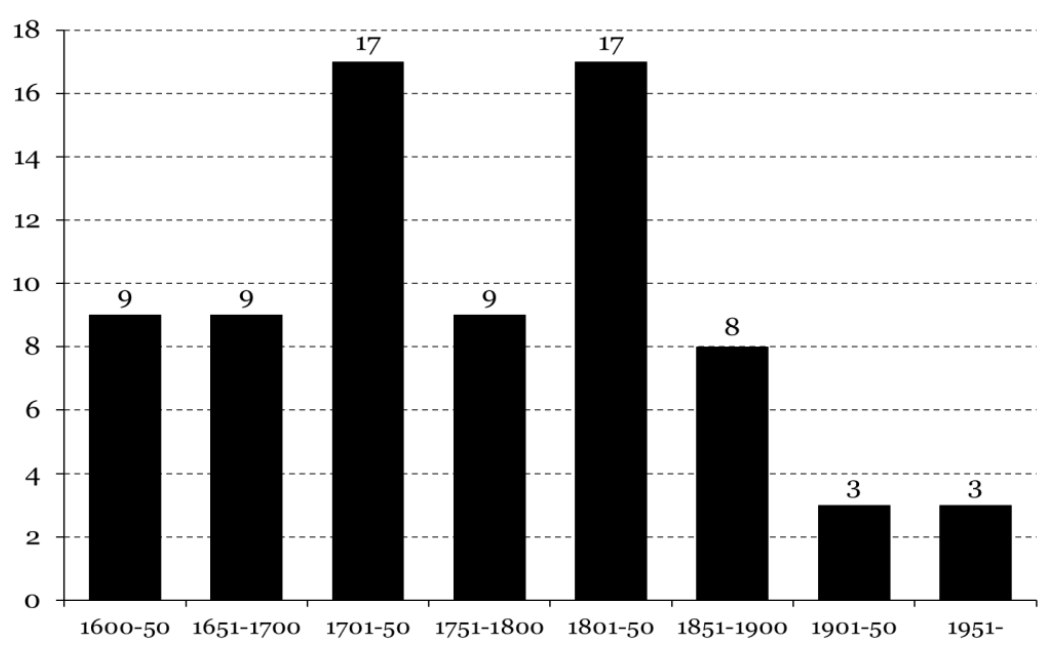

Figure 3a: Britain and Ireland

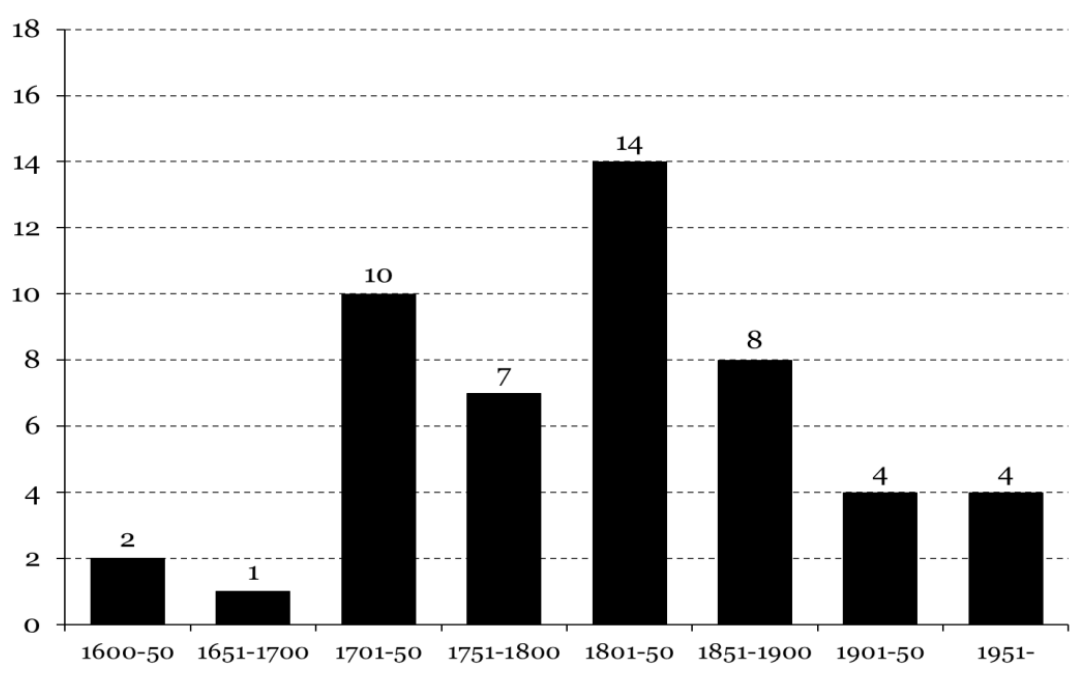

Figure 3b: France

Figure 3: The number of prominent infectious disease outbreaks, 1600 through circa 2000 Source: Kohn (1998) 


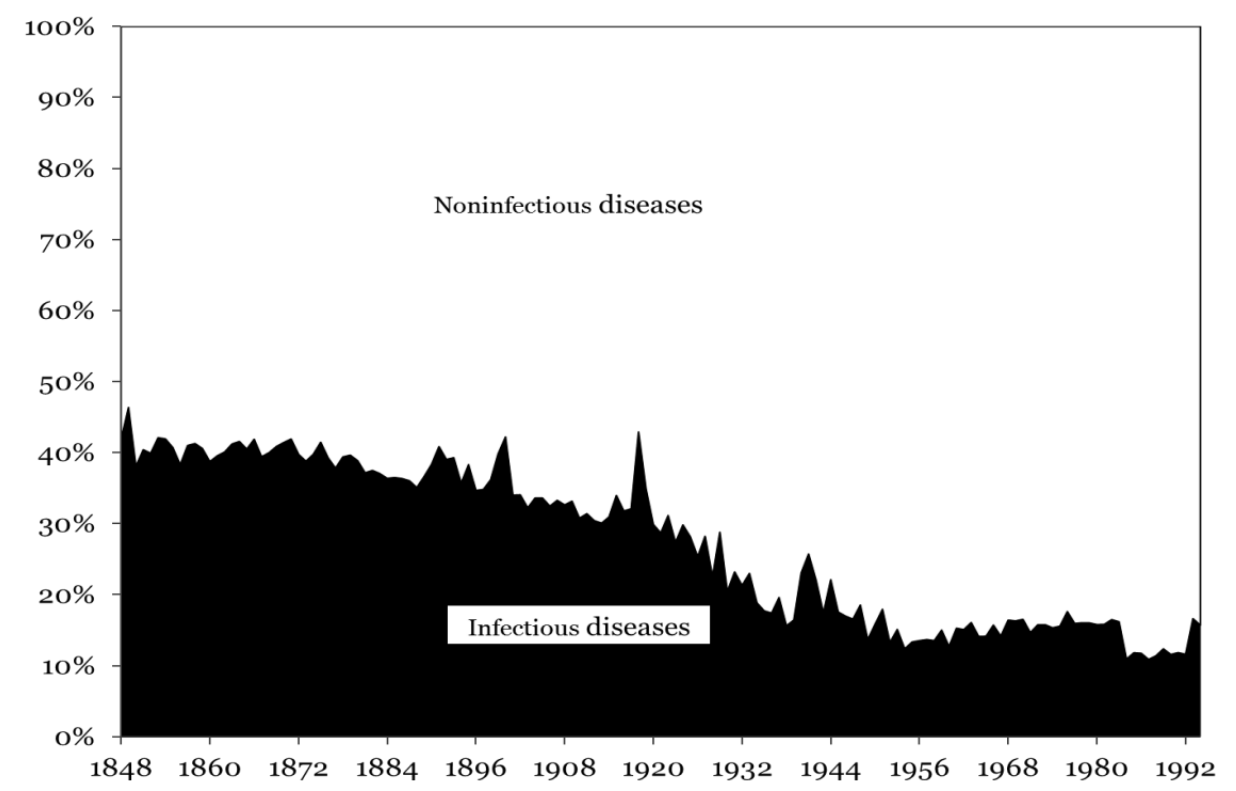

Figure 4: Infectious diseases and noninfectious diseases as a percentage of all disease-caused deaths Source: HMSO; author's calculations. 


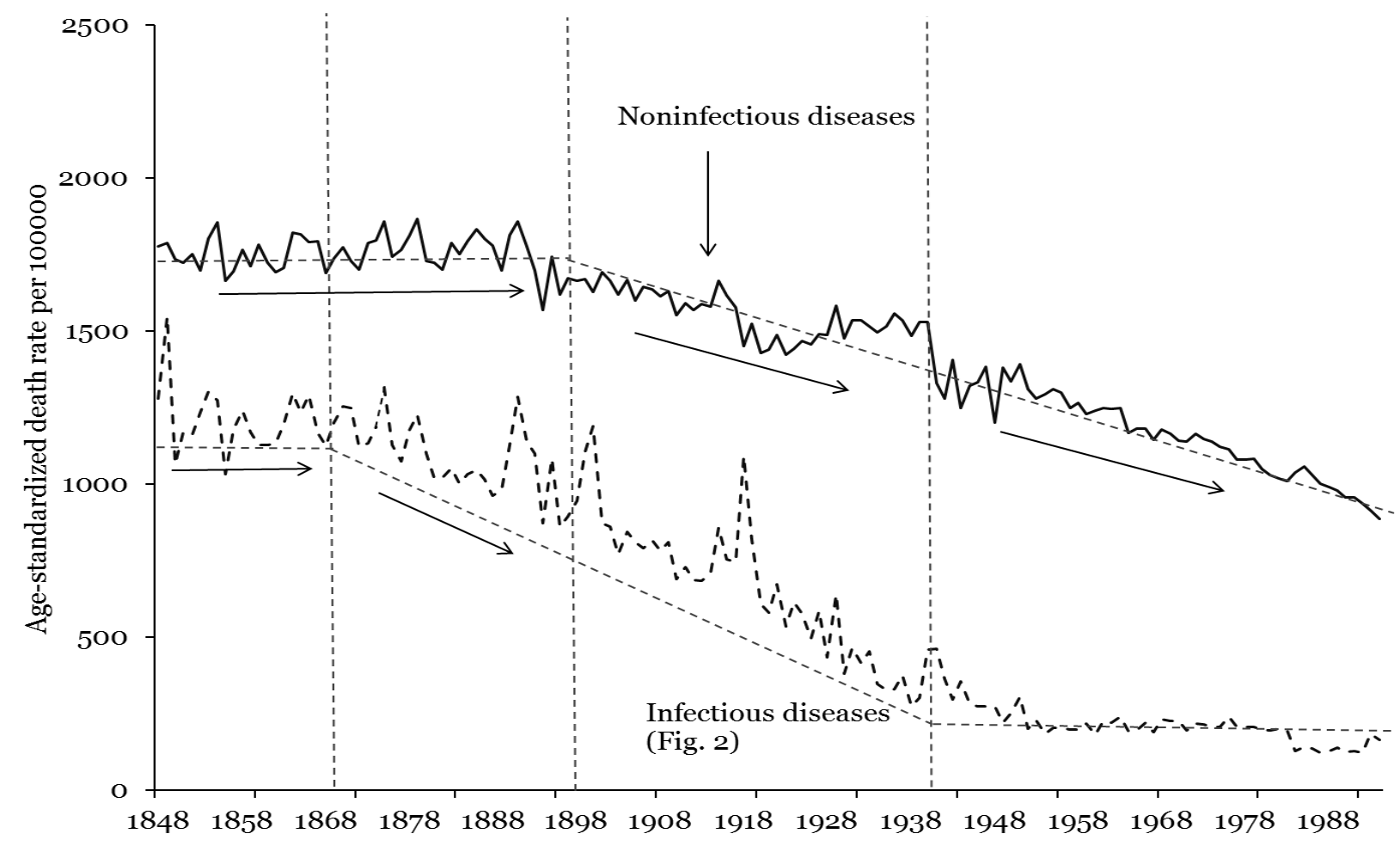

Figure 5: Infectious and noninfectious diseases, 1848-20oo

Source: HMSO; author's calculations. 


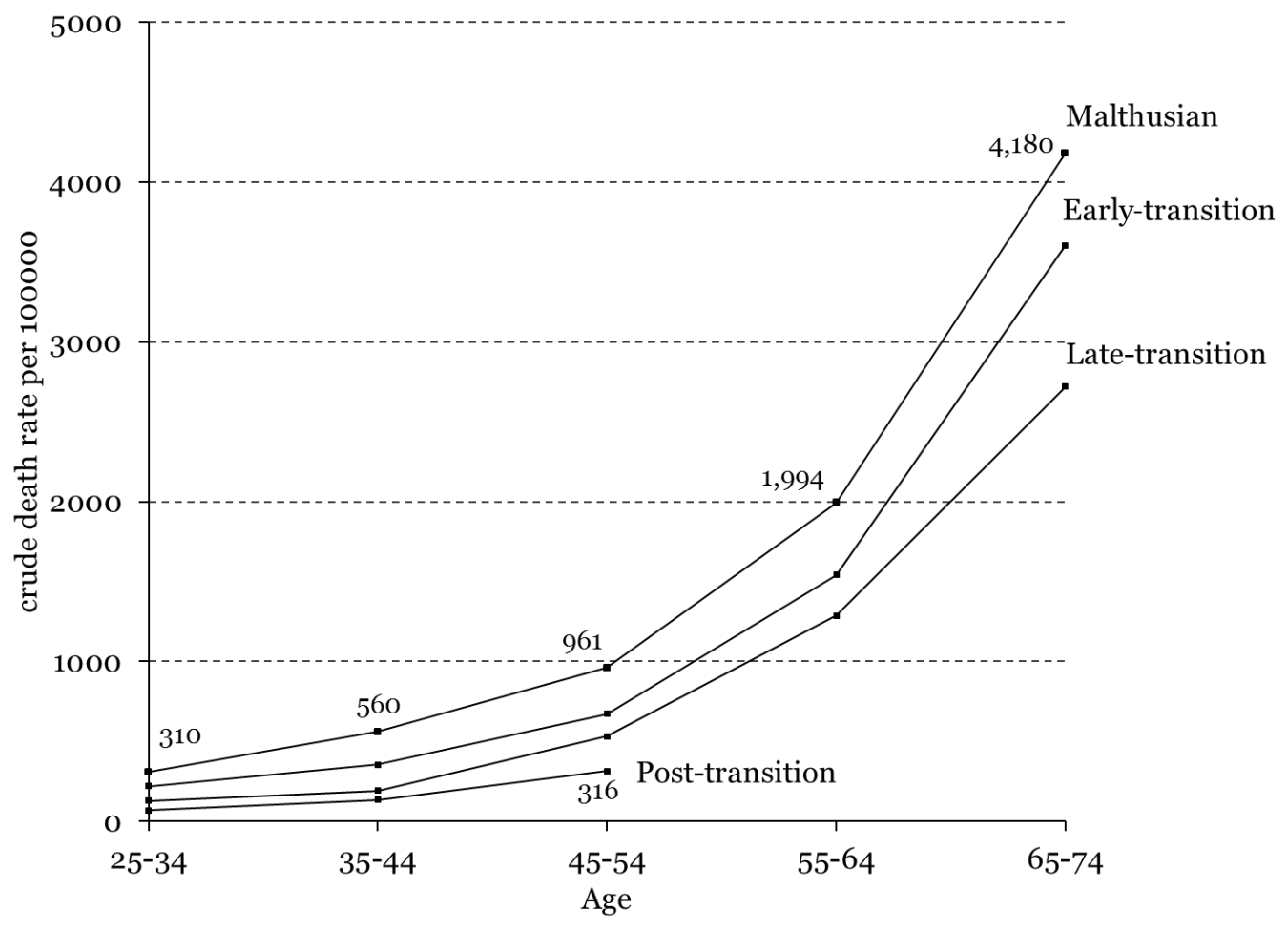

Figure 6a: All noninfectious diseases, age-profiles of representative cohorts from distinct epidemiologic regimes

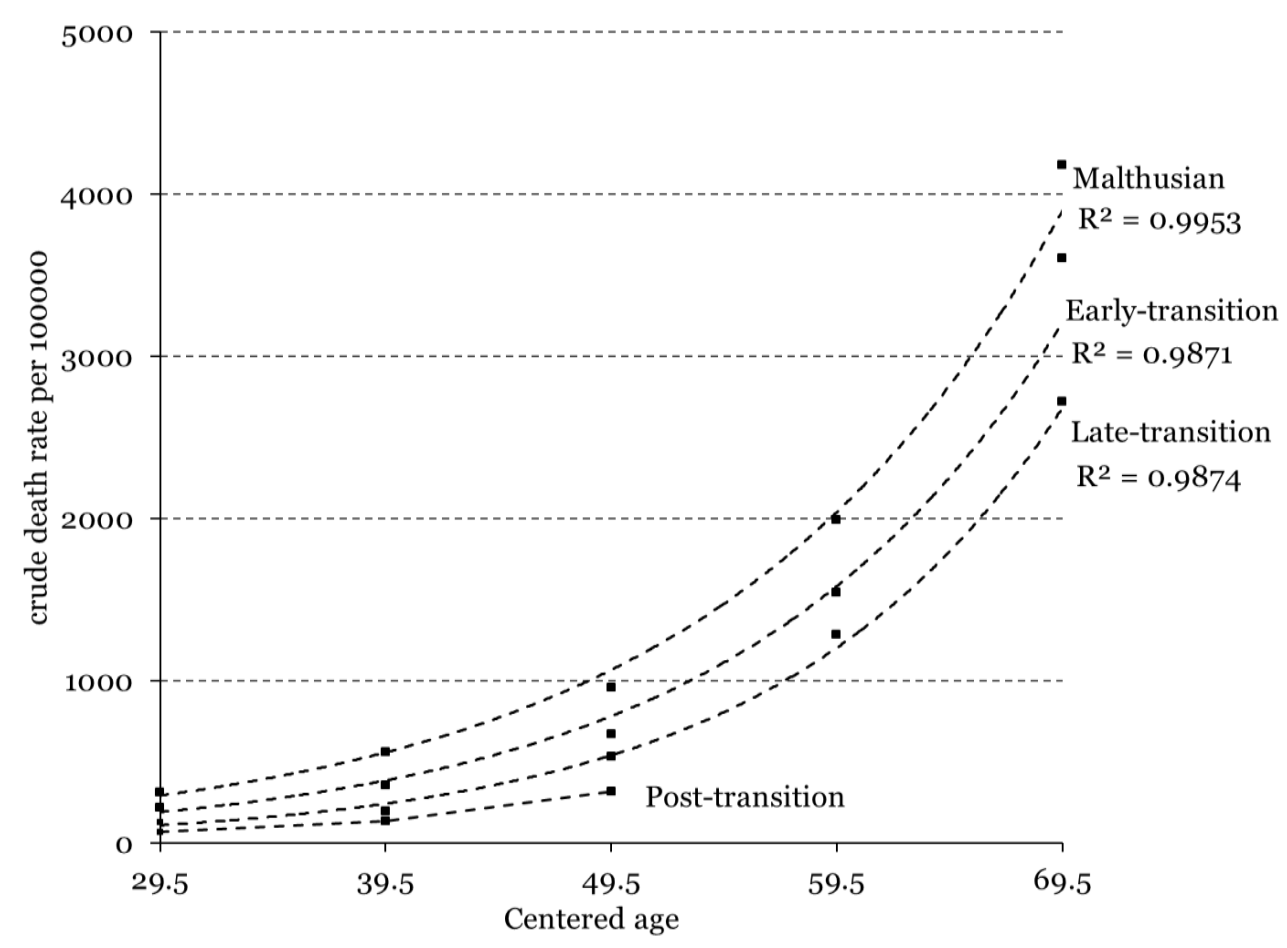

Figure 6b: Exponential curves fitted to the age-profiles in Figure $6 a$ 


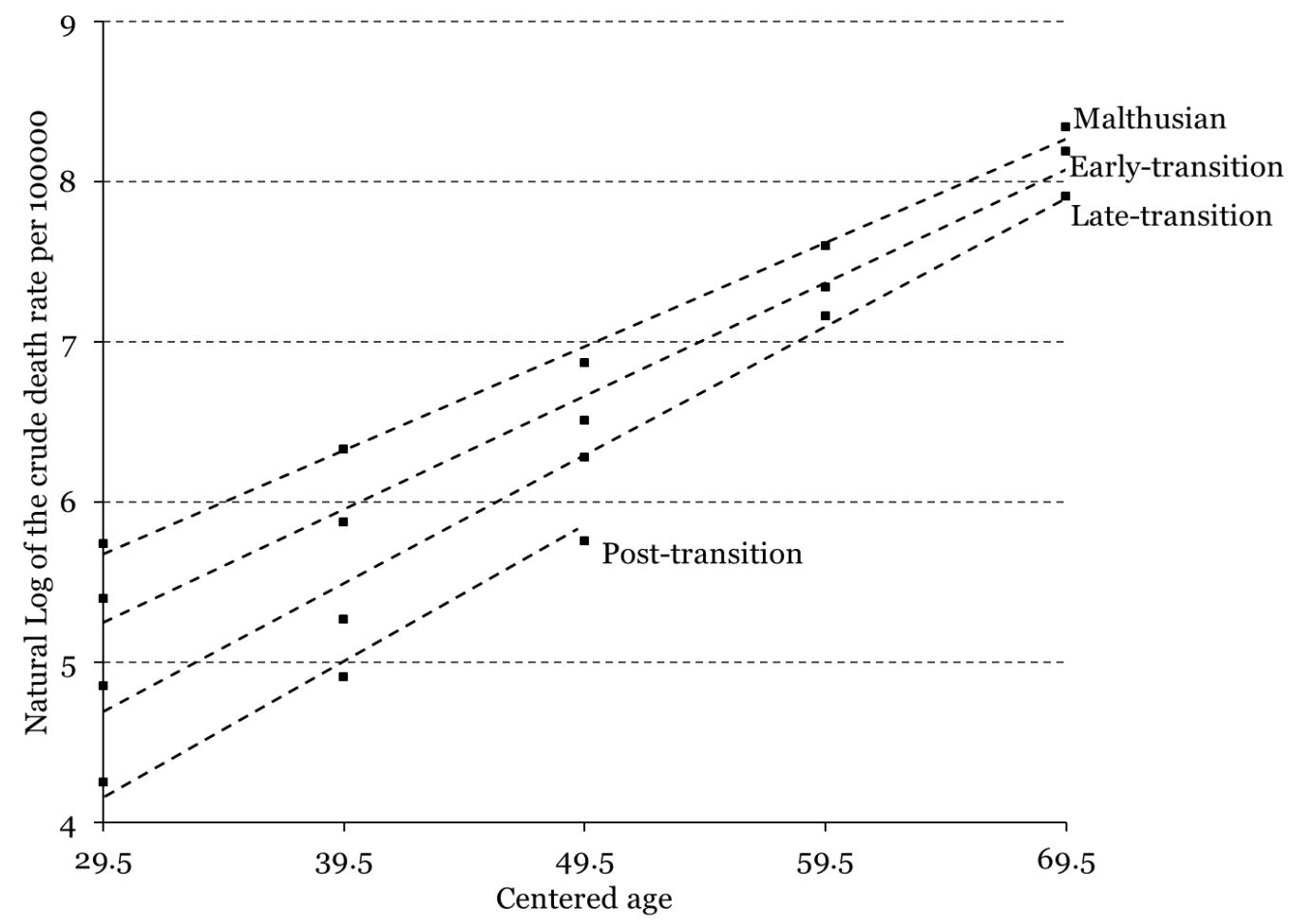

Figure 6c: Natural logarithms of the age-profiles in Figure $6 a$

Source: HMSO; author's calculations. 


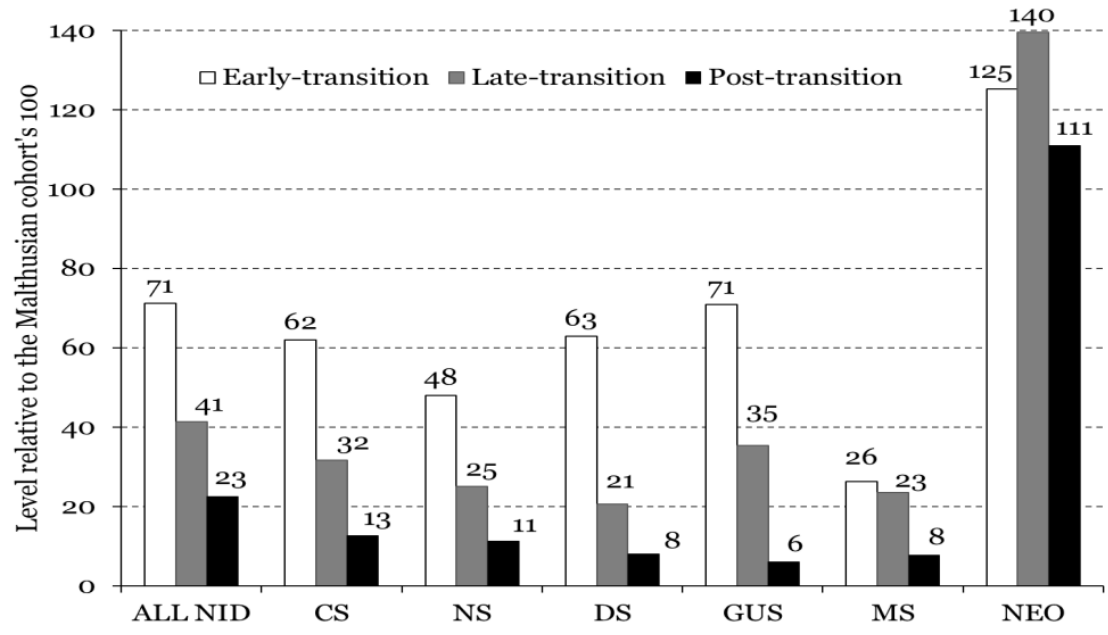

Figure 7a: Age 25-34

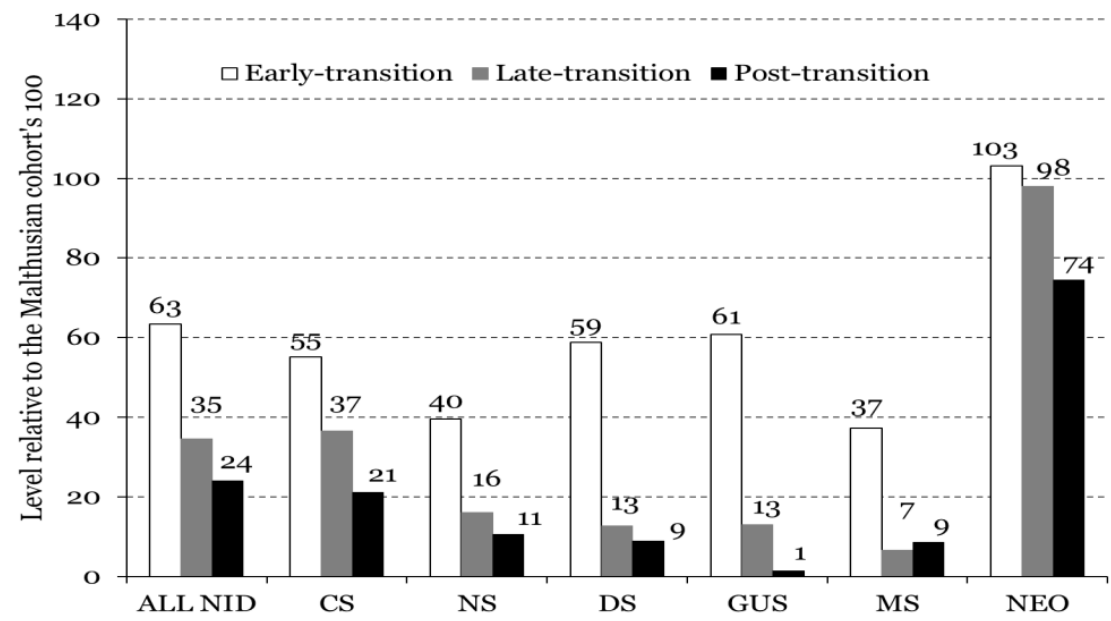

Figure 7b: Age 35-44

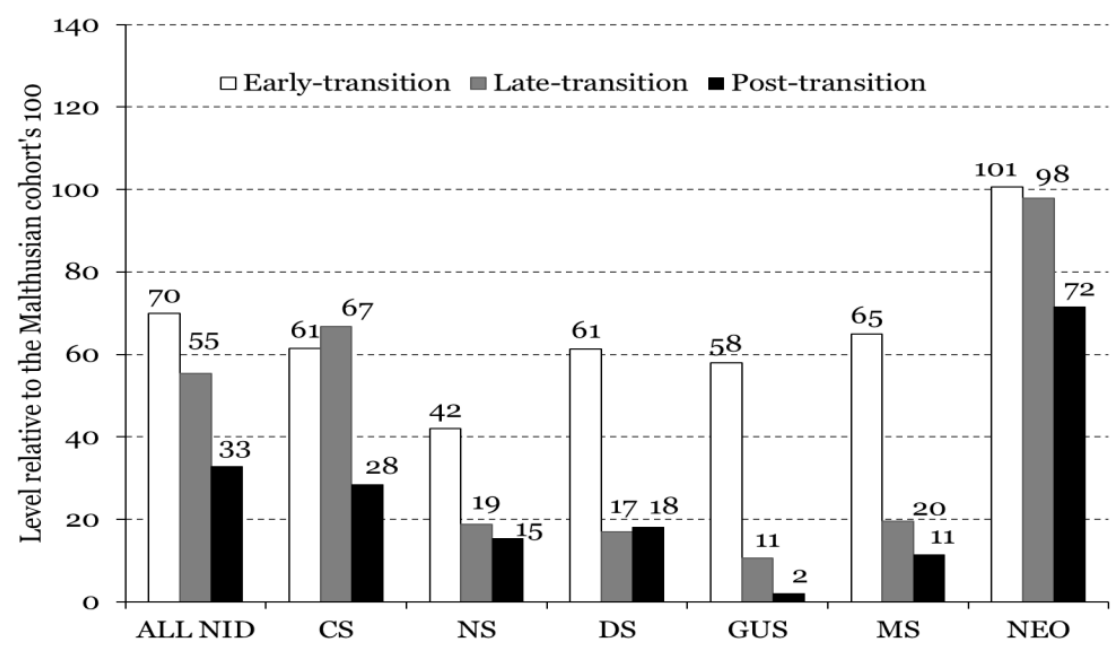

Figure 7c: Age 45-54 


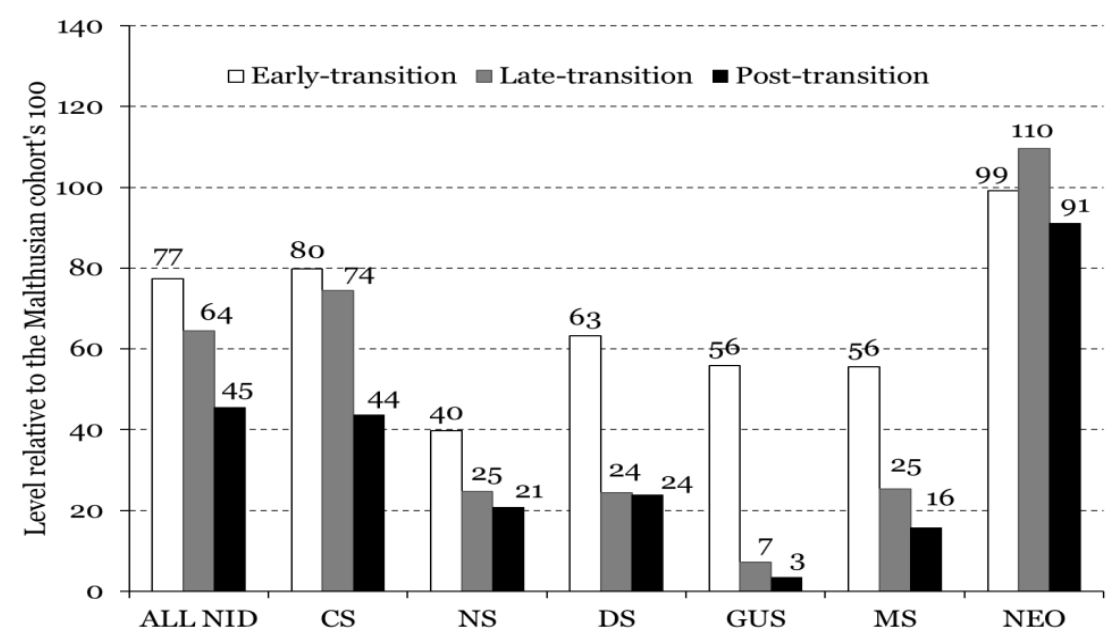

Figure 7d: Age 55-64

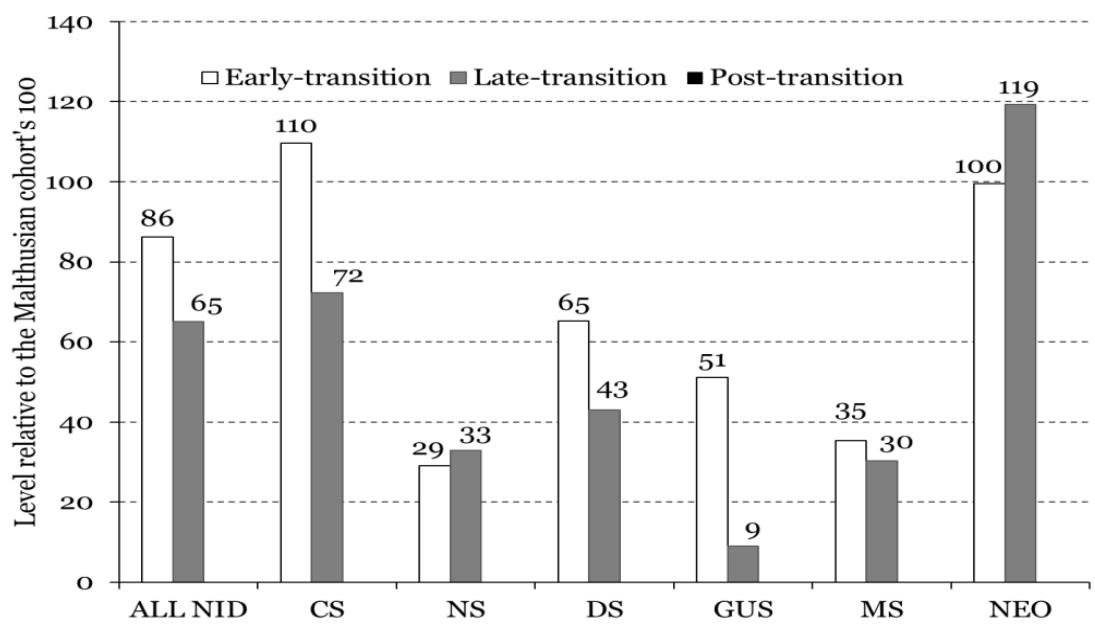

Figure 7e: Age 65-74

Figure 7: Levels of various noninfectious diseases at various ages relative to the Malthusian cohort's 100

Source: HMSO; author's calculations. 


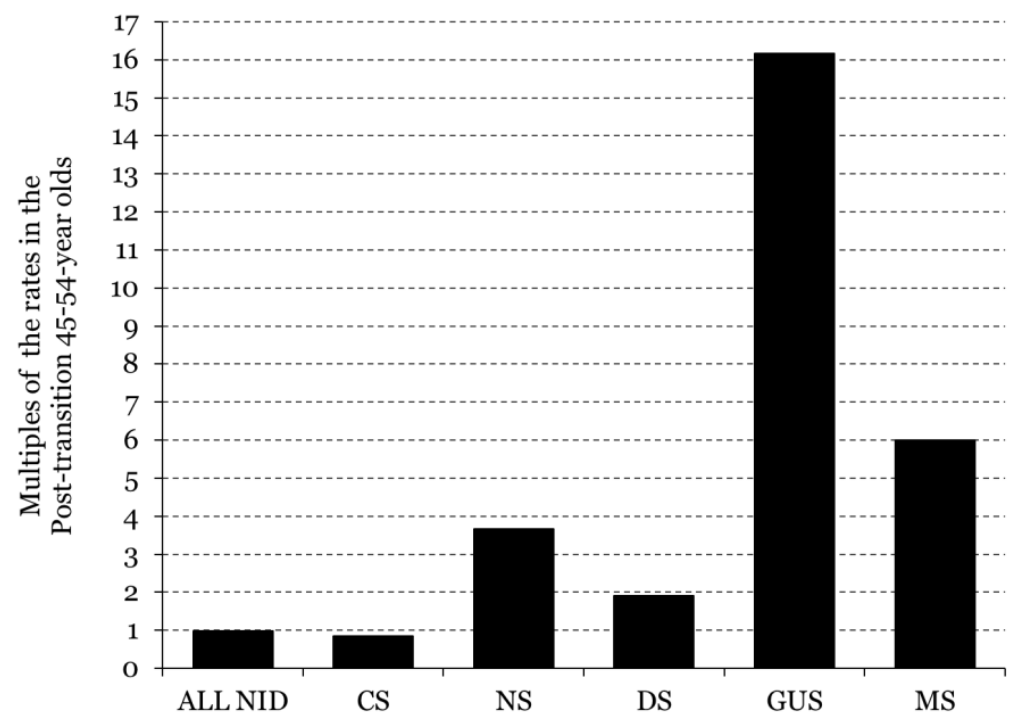

Figure 8: Rates in the Malthusian 25-34-year olds relative to rates in the post-transition 45-54-year olds Source: HMSO; author's calculations. 


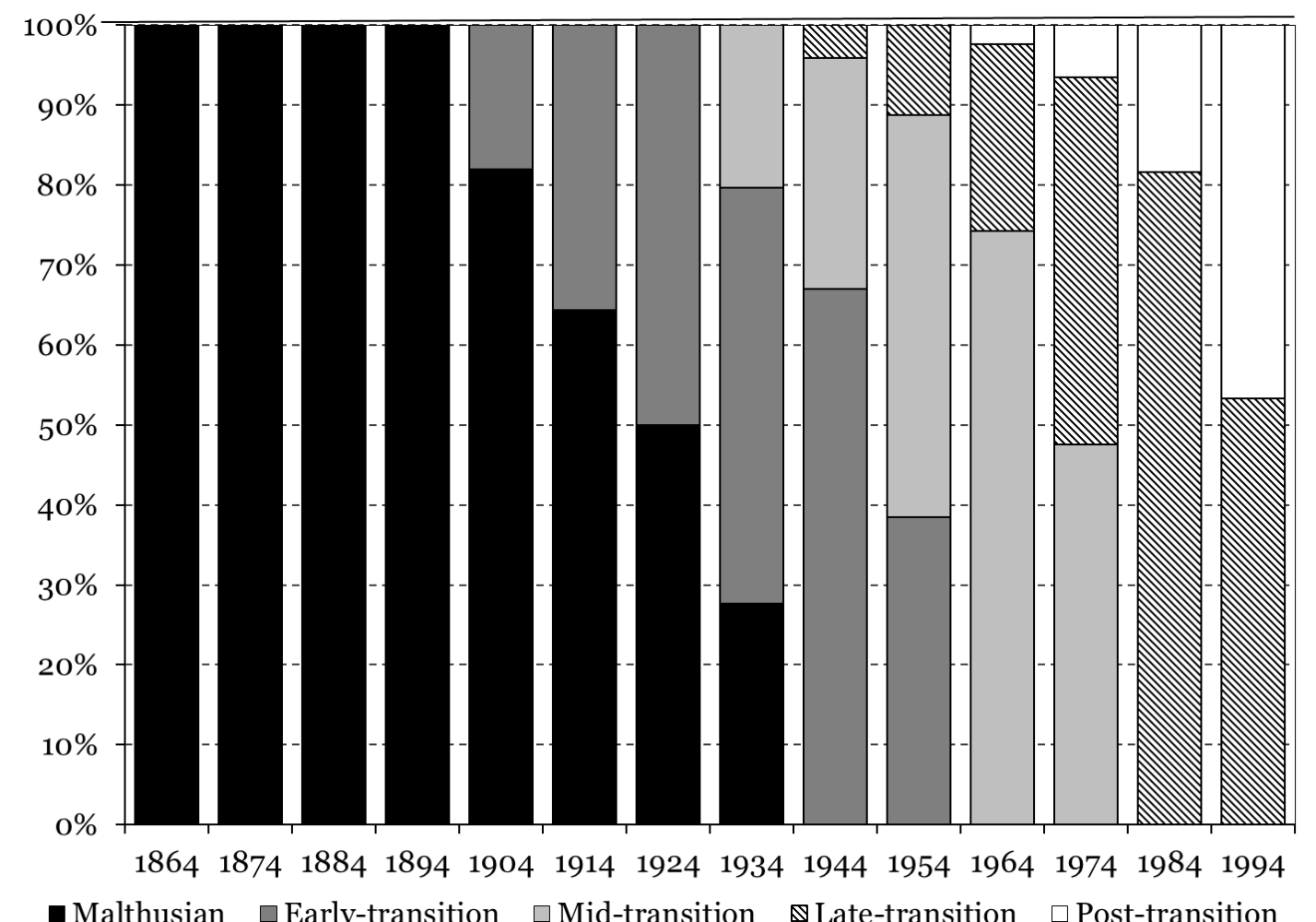

Figure 9: Contributions of various cohorts to the period rates of noninfectious diseases in ages 25-74 Source: HMSO; author's calculations. 


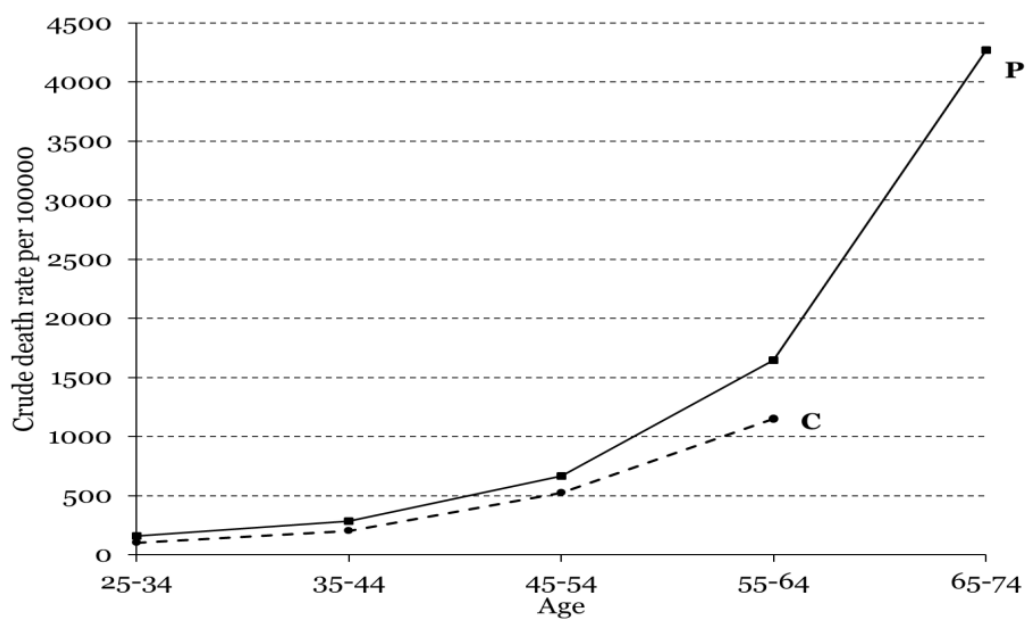

Figure 10a: 1930 s

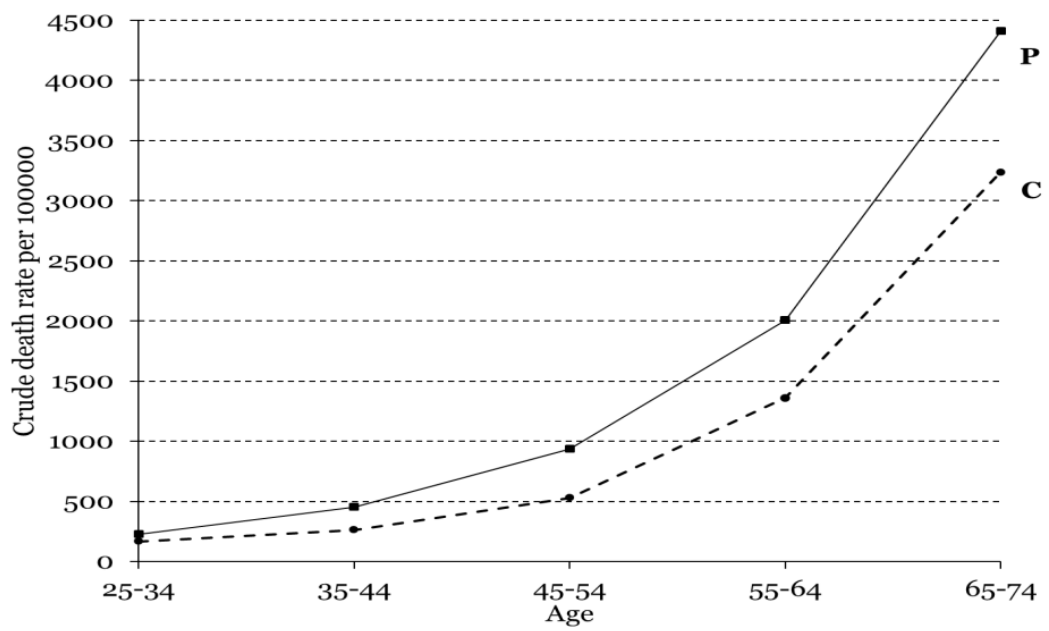

Figure 1ob: $1901 \mathrm{~s}$

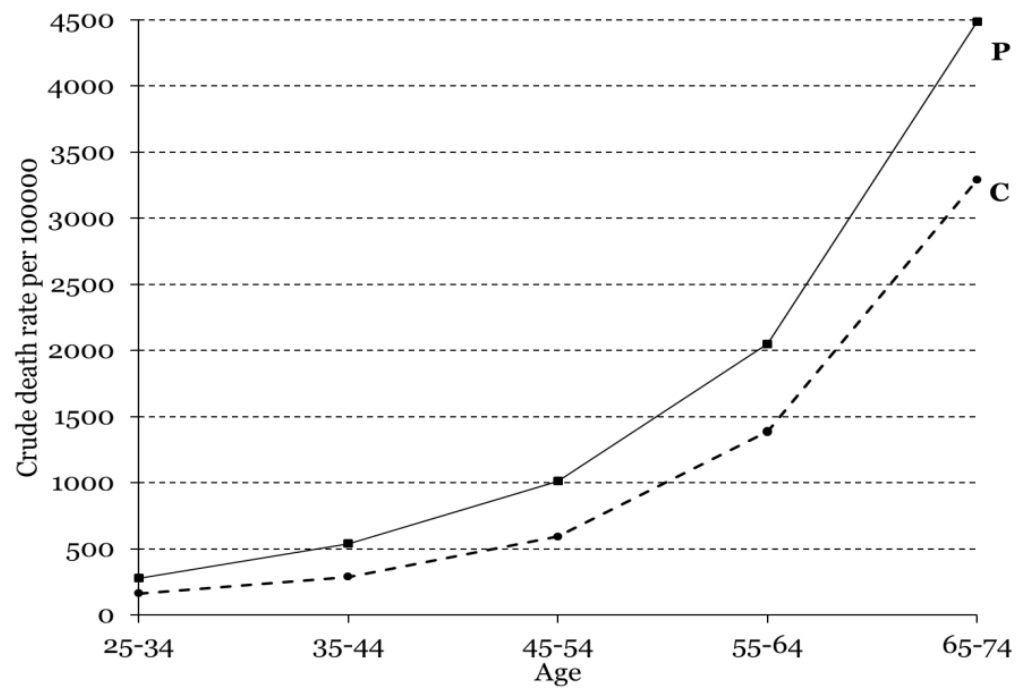

Figure 10c: 1890 s 


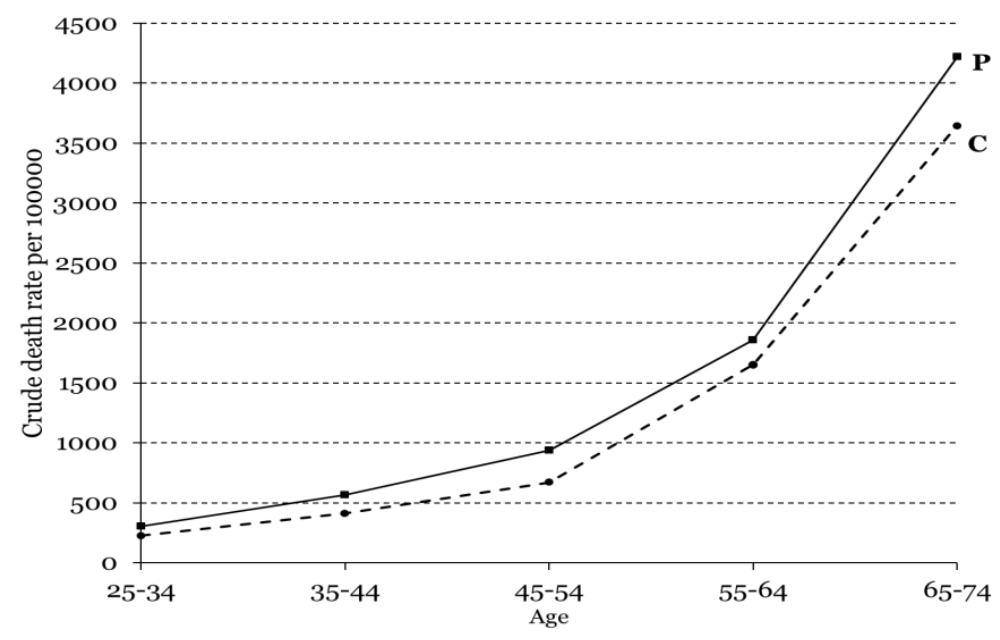

Figure 10d: 1870s

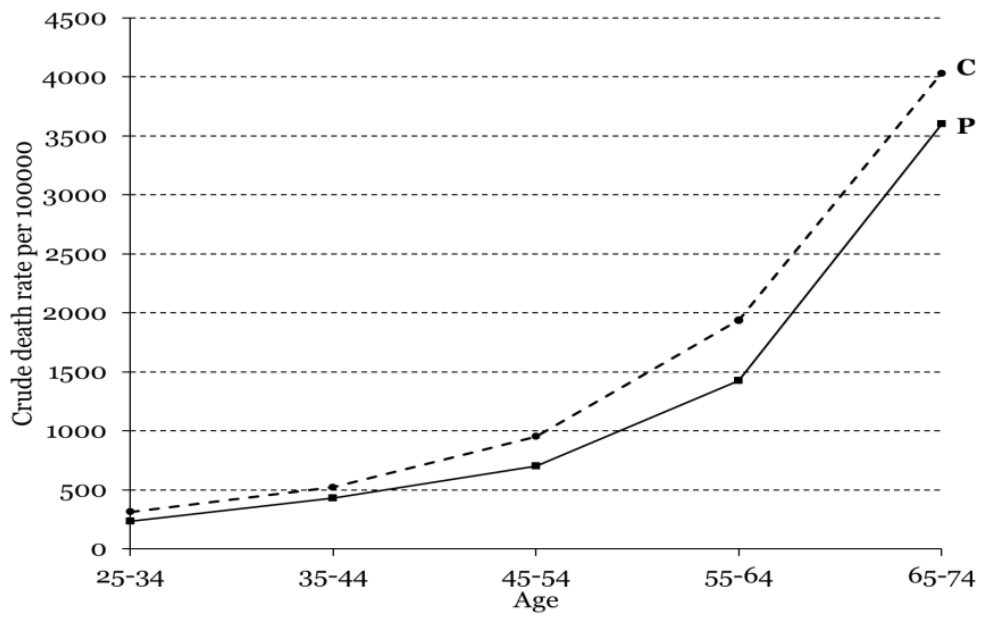

Figure 10e: 1850 s

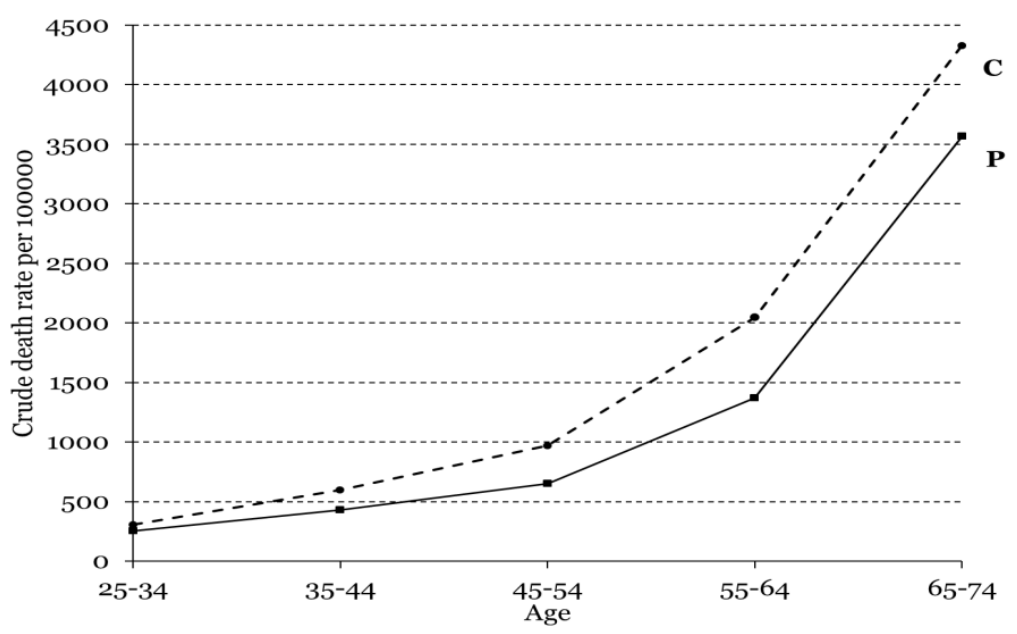

Figure 10f: $1840 \mathrm{~s}$

Figure 10: Comparisons of period age-profiles (P) and cohort age-profiles $(C)$ 


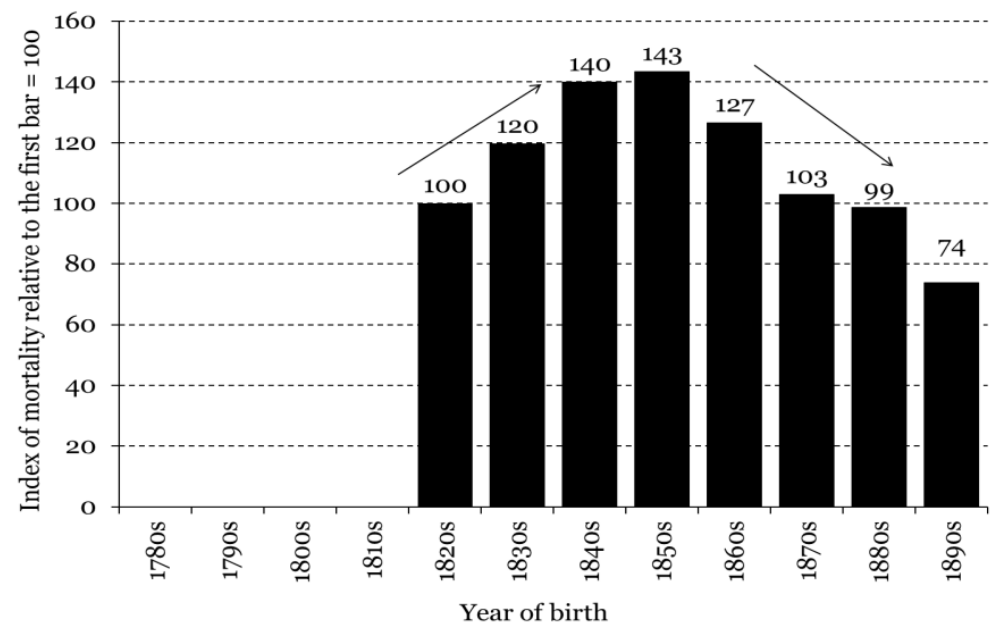

Figure 11a: Age 25-34

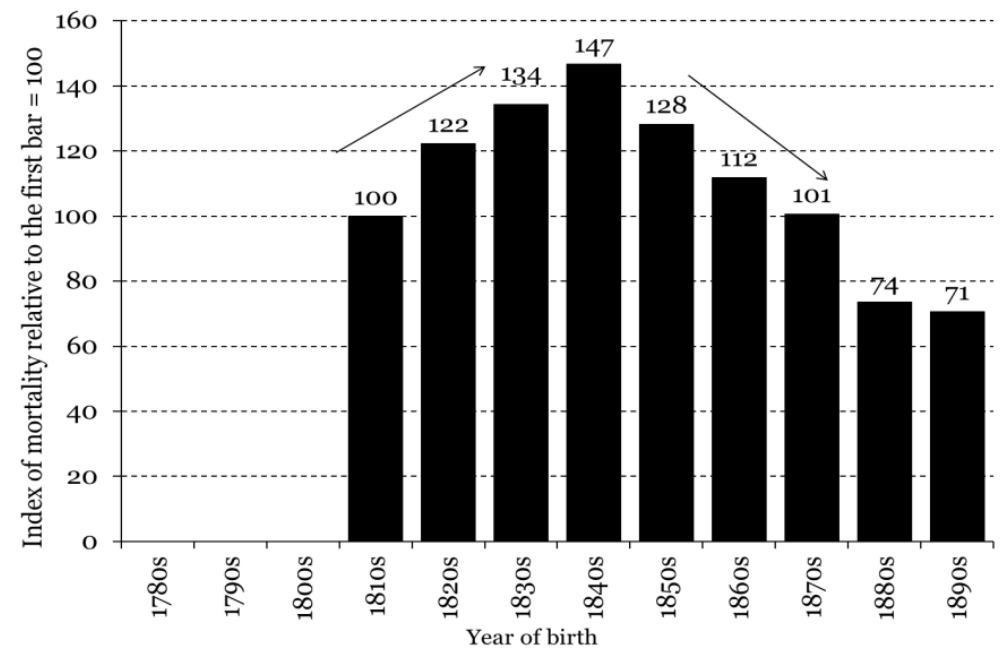

Figure 11b: Age 35-44

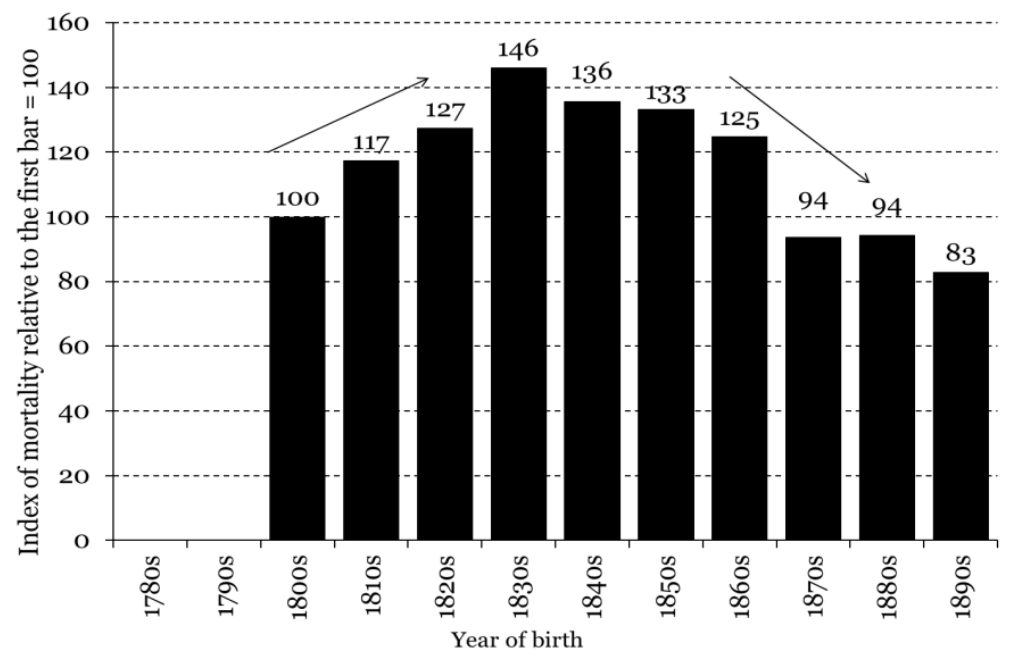

Figure 11c: Age 45-54 


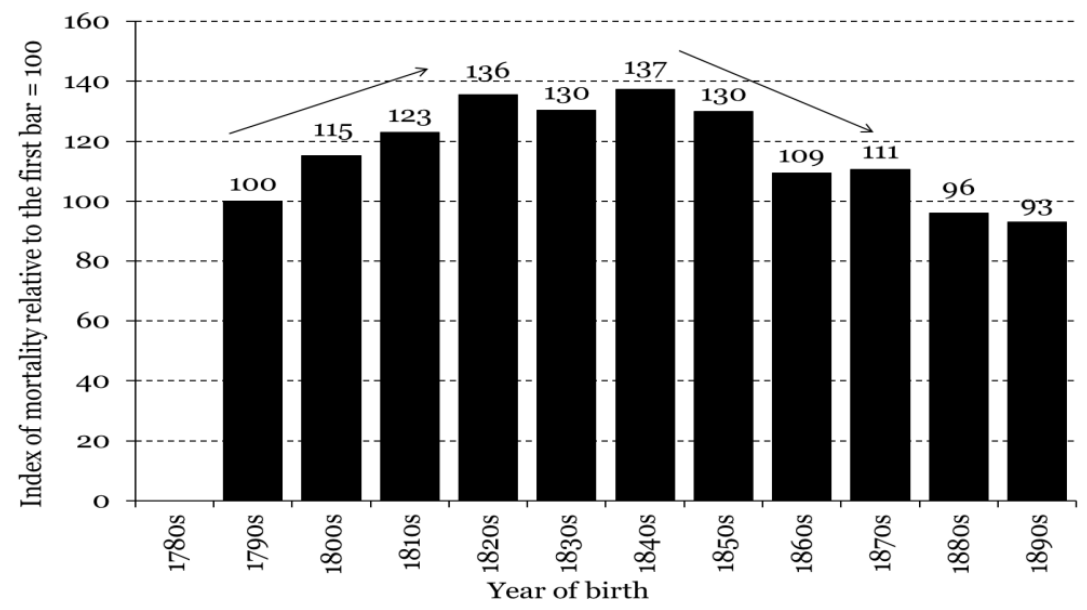

Figure 11d: Age 55-64

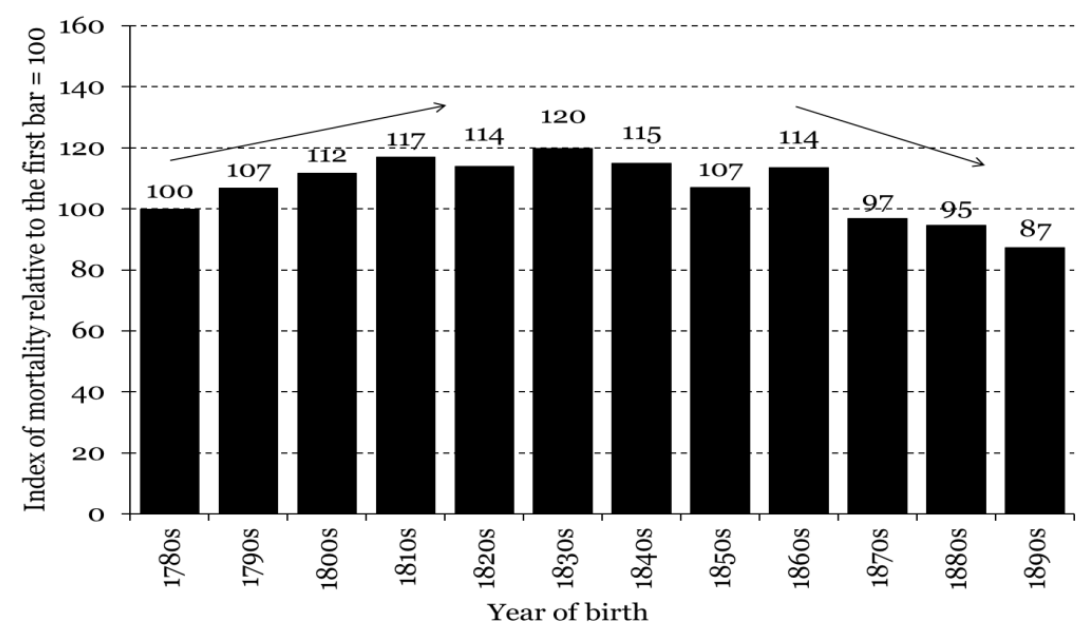

Figure 11e: Age 65-74

Figure 11: The Malthusian regime cycle in noninfectious maladies at various ages Source: HMSO; author's calculations. 


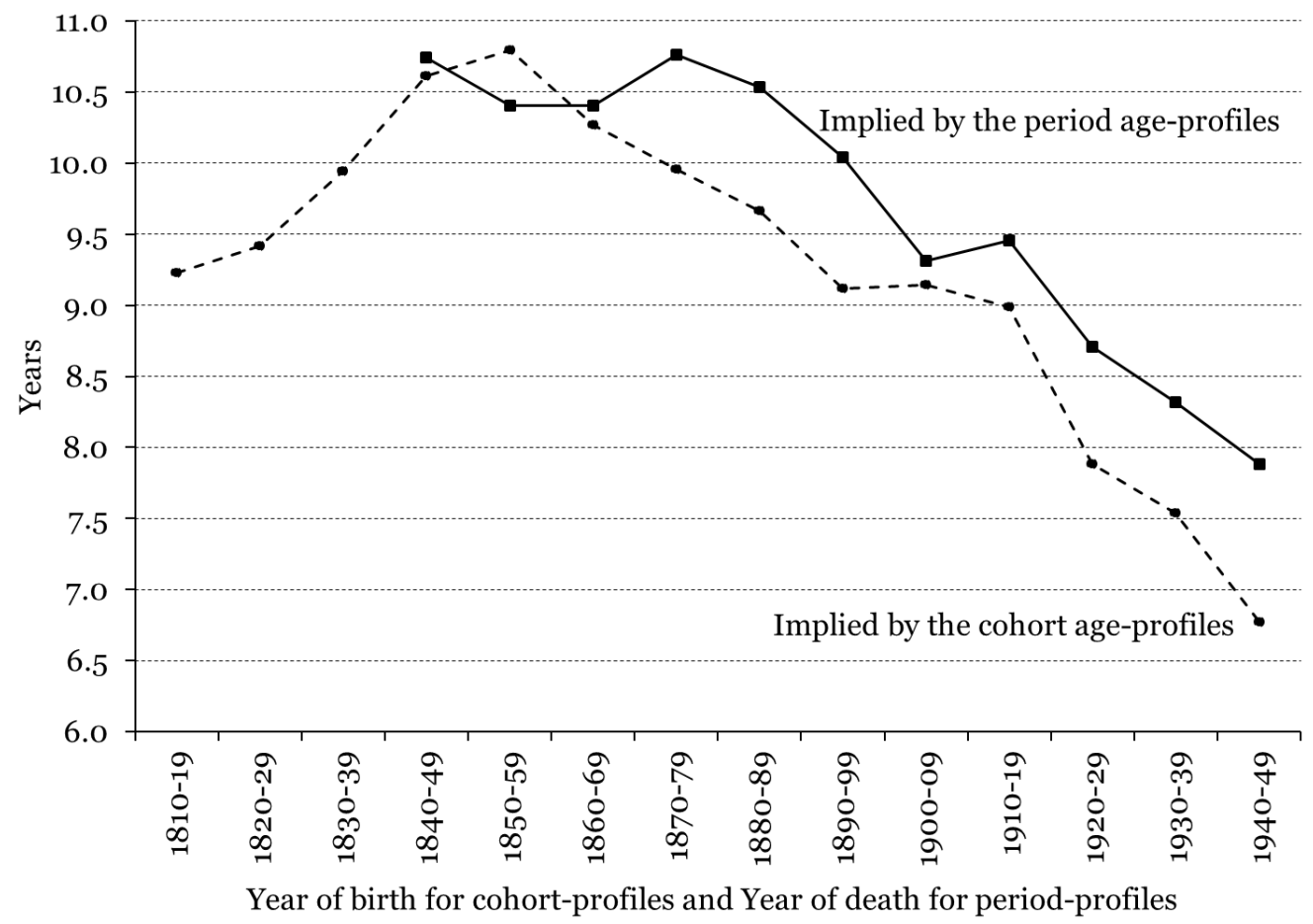

Figure 12: The doubling time implied by the cohort-age profiles versus the period age-profiles Source: HMSO; author's calculations. 


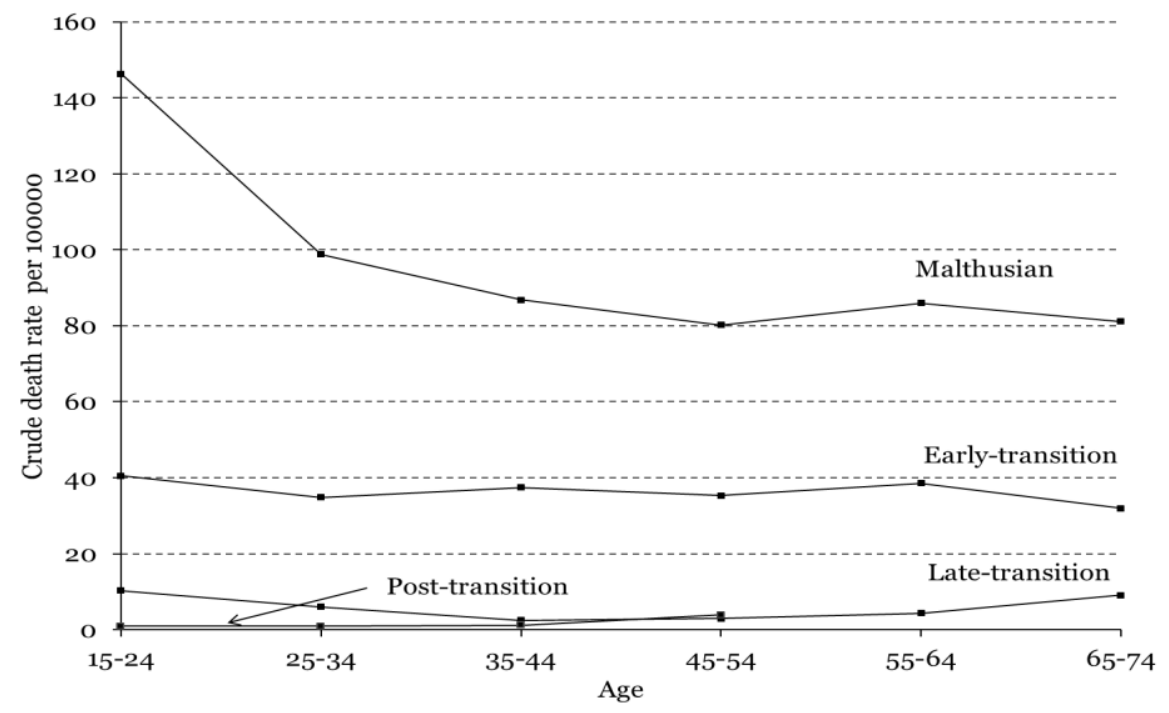

Figure 13a: Cohort age-profiles of all infectious diseases excluding tuberculosis

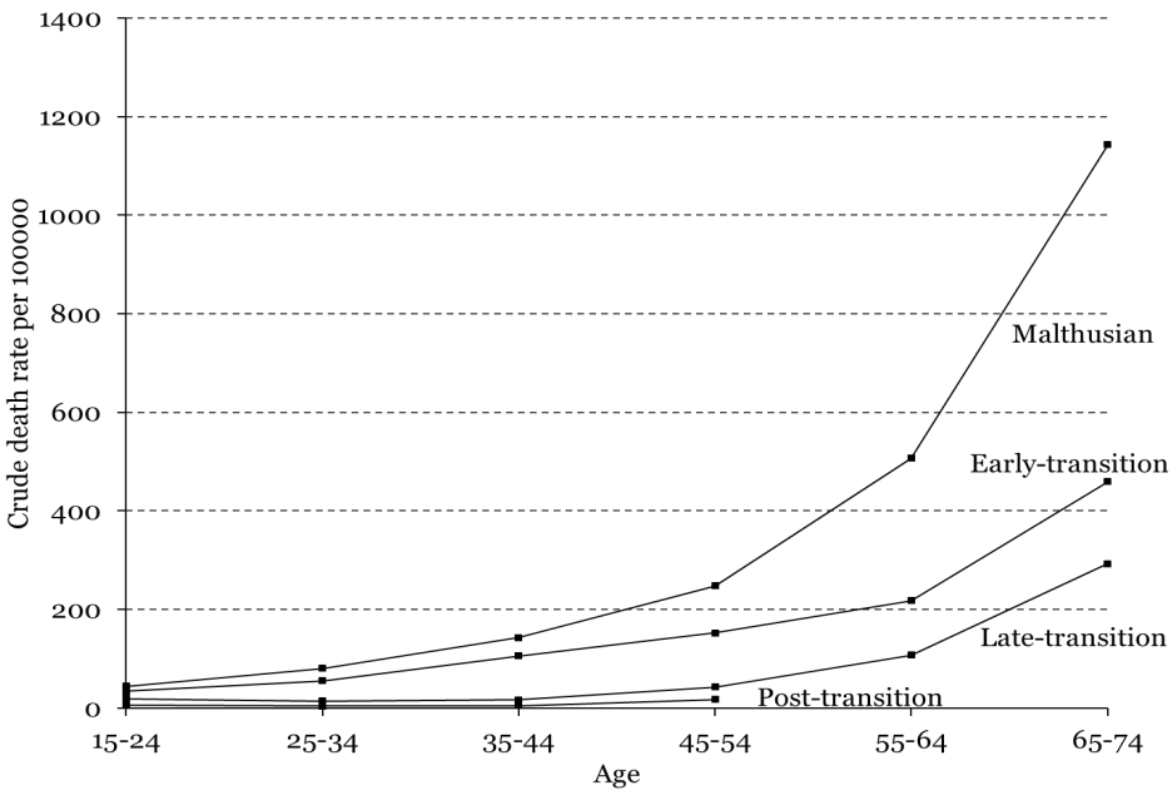

Figure 13b: Cohort age-profiles of diseases of the respiratory system 


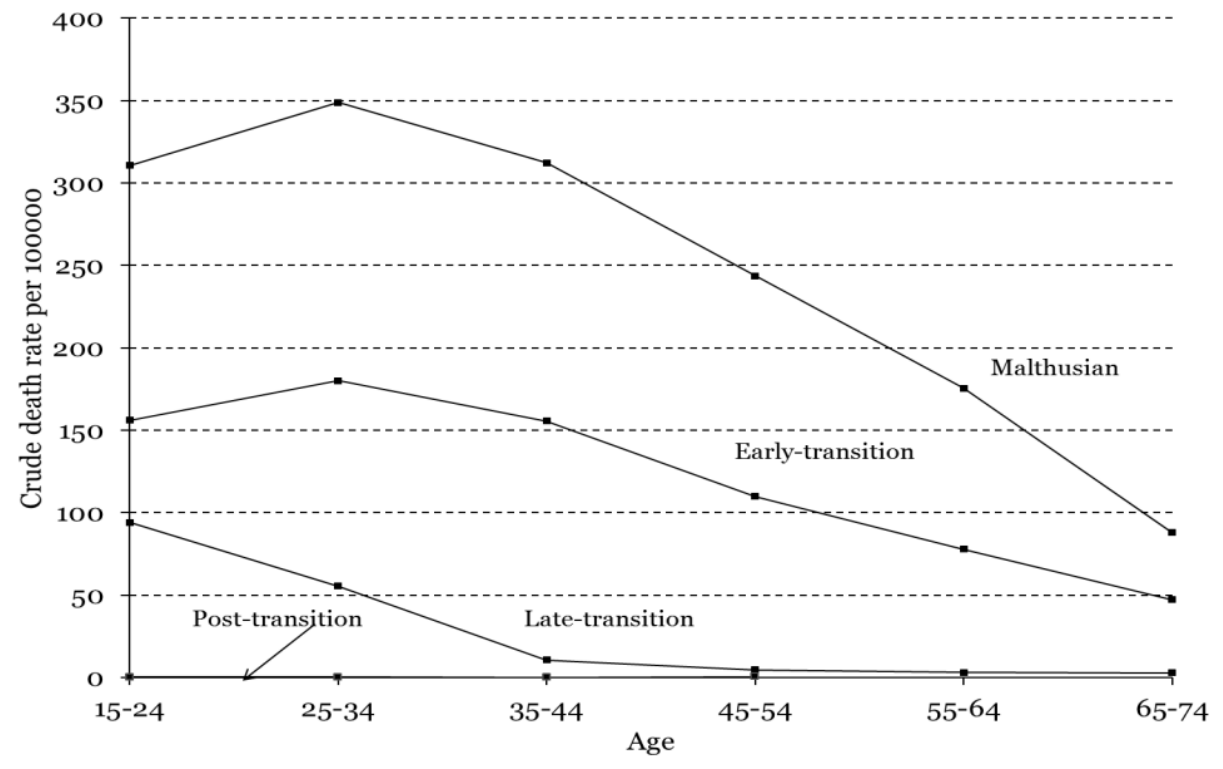

Figure 13b: Cohort age-profiles of tuberculosis (all types)

Figure 13: Age-profiles of various infectious diseases in cohorts from different regimes Source: HMSO; author's calculations. 


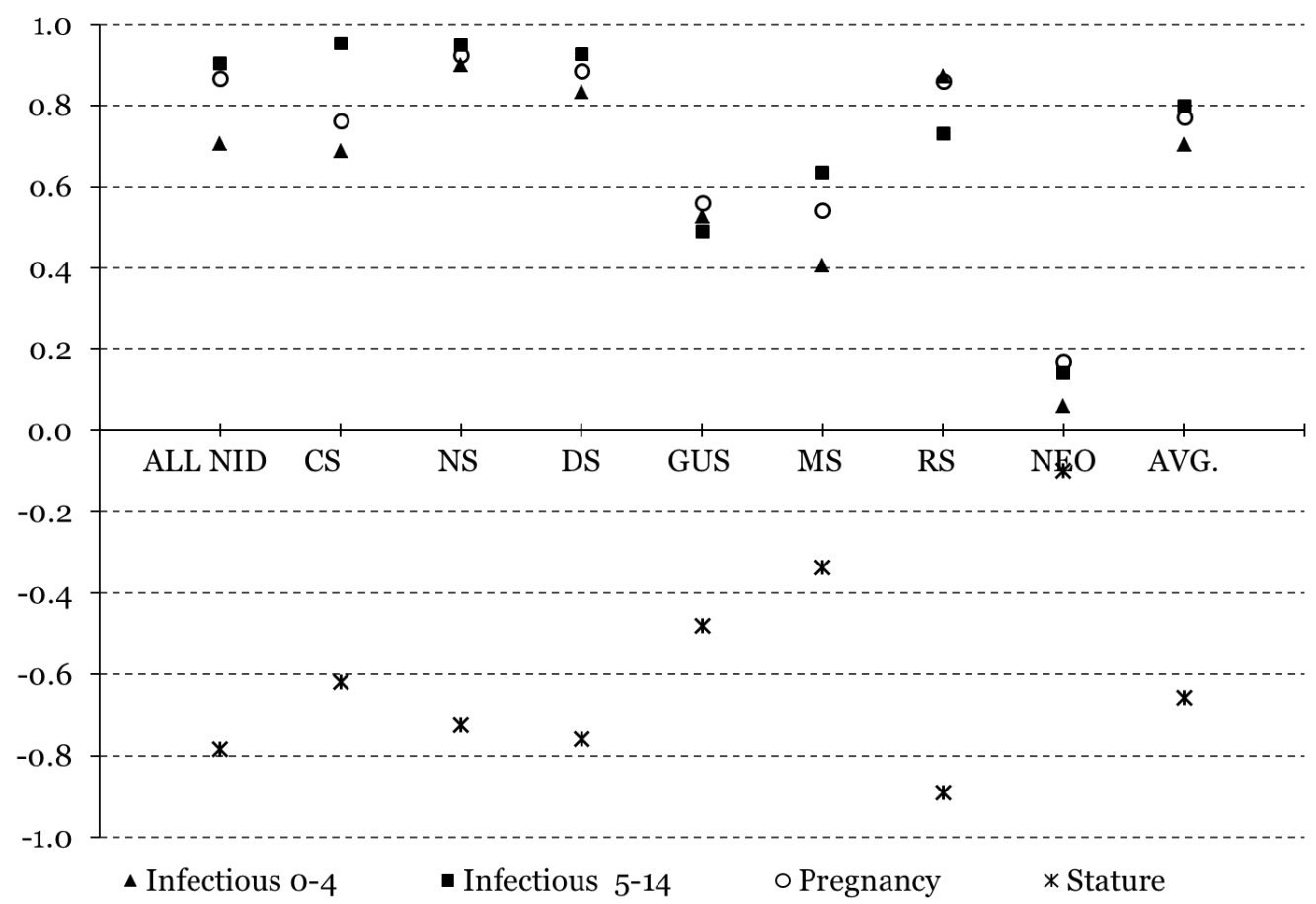

Figure 14a: Correlations between the childhood regime and the fitted intial levels of the cohort age-profiles

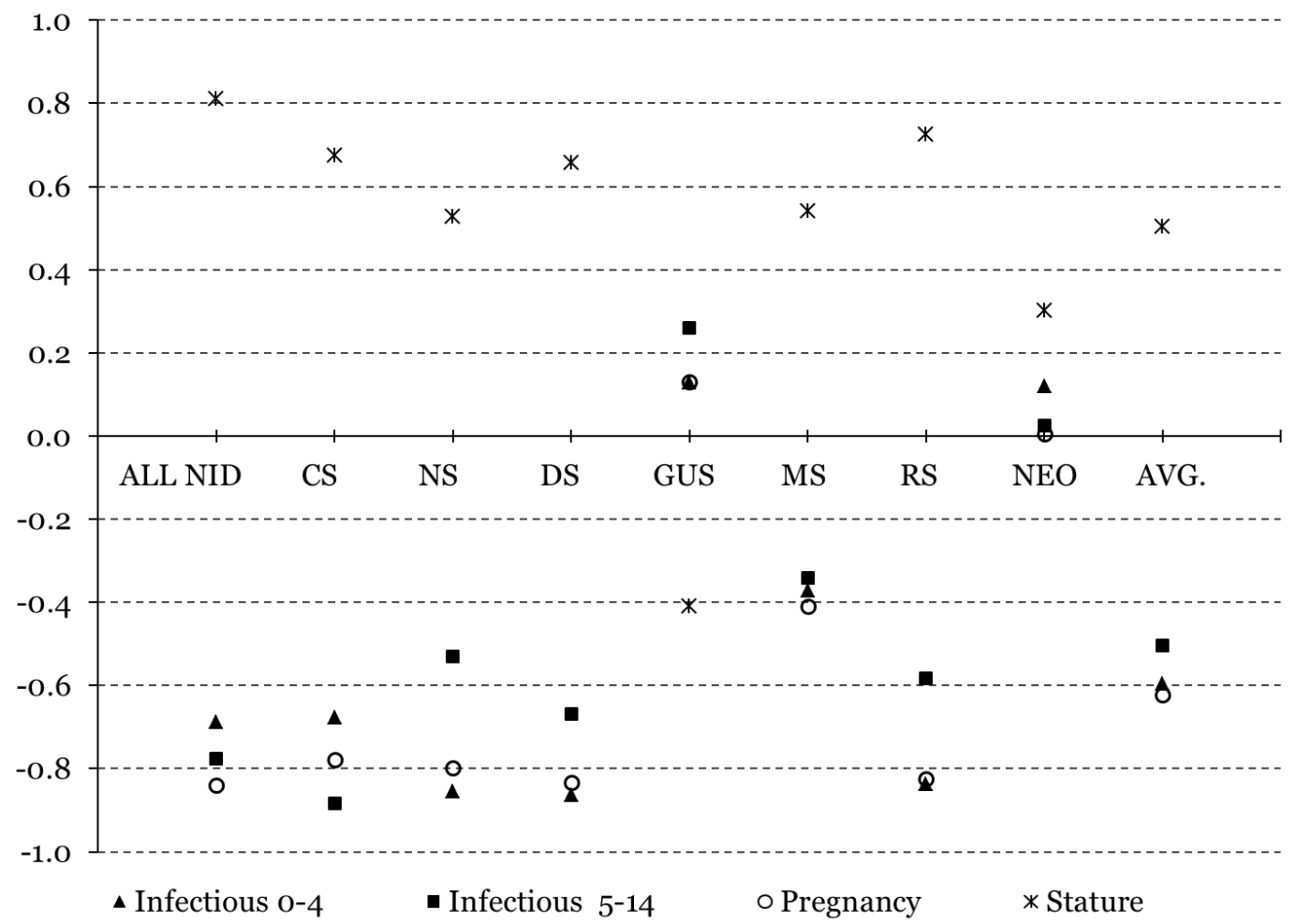

Figure 14b: Correlations between the childhood regime and the curvatures of cohort age-profiles 


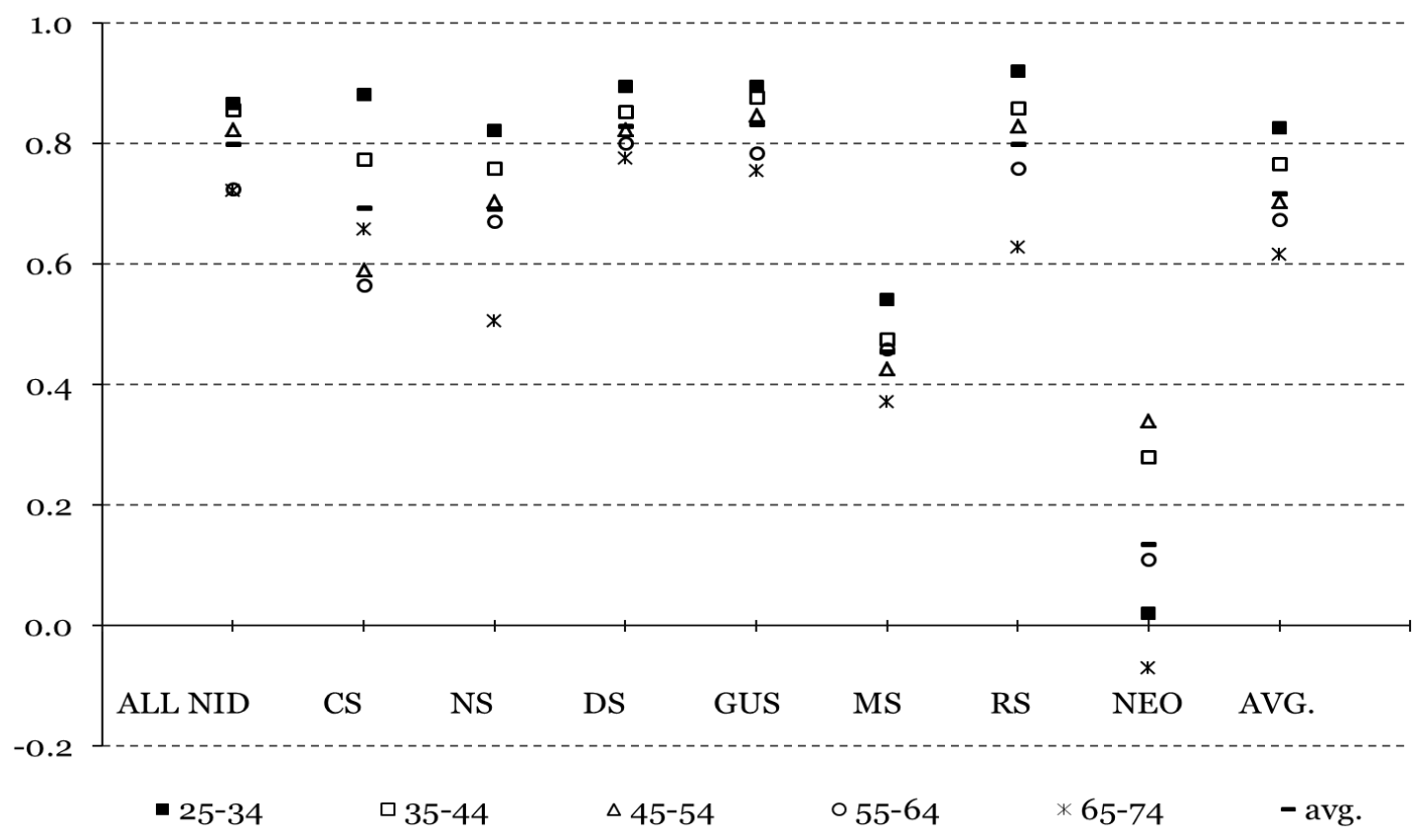

Figure 15a: Correlations between the indicator of infectious diseases at age o-4 and various noninfectious diseases at different adult ages

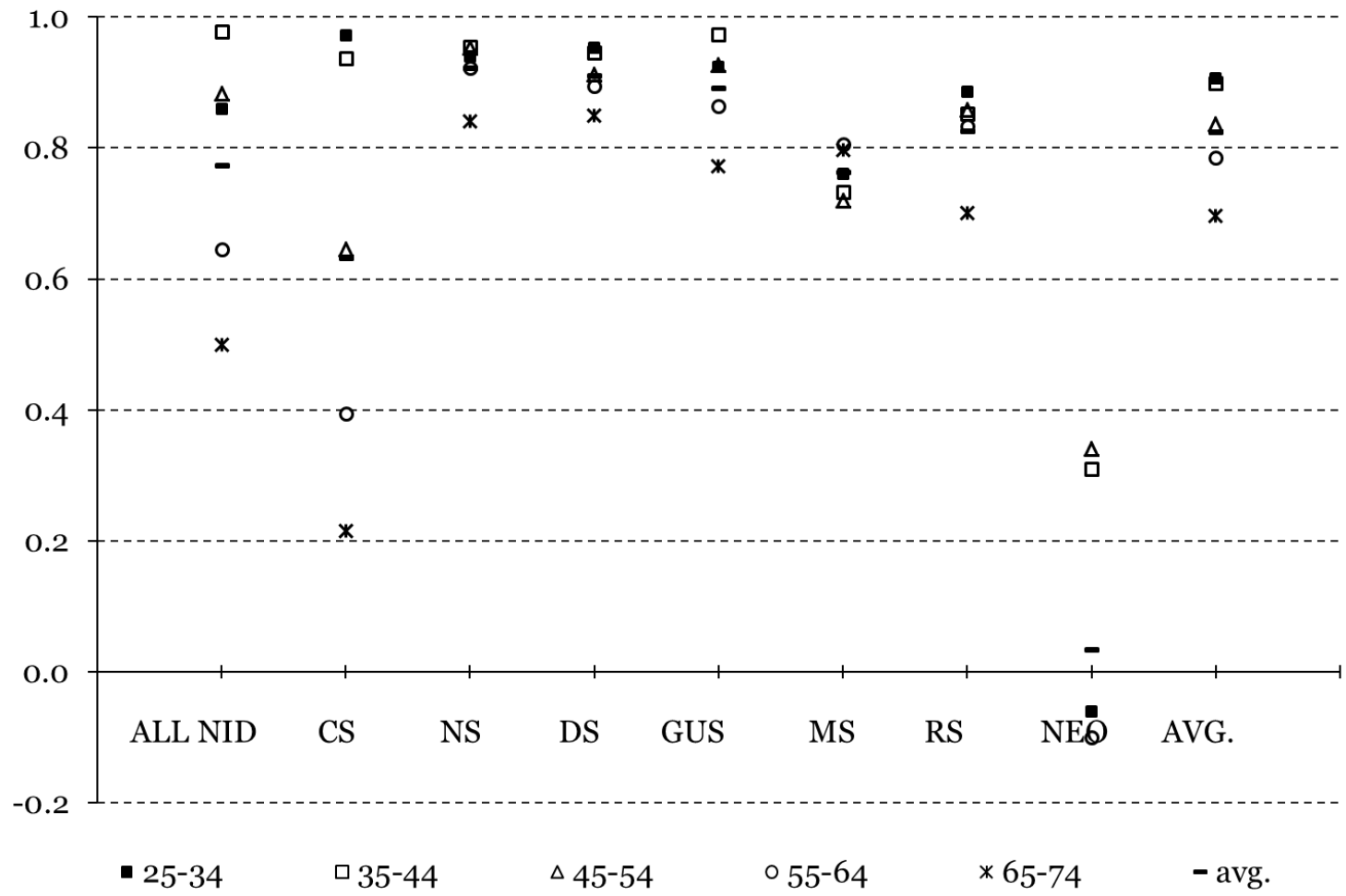

Figure15b: Correlations between indicators of infectious diseases at age 5-14 and various noninfectious diseases at different adult ages 


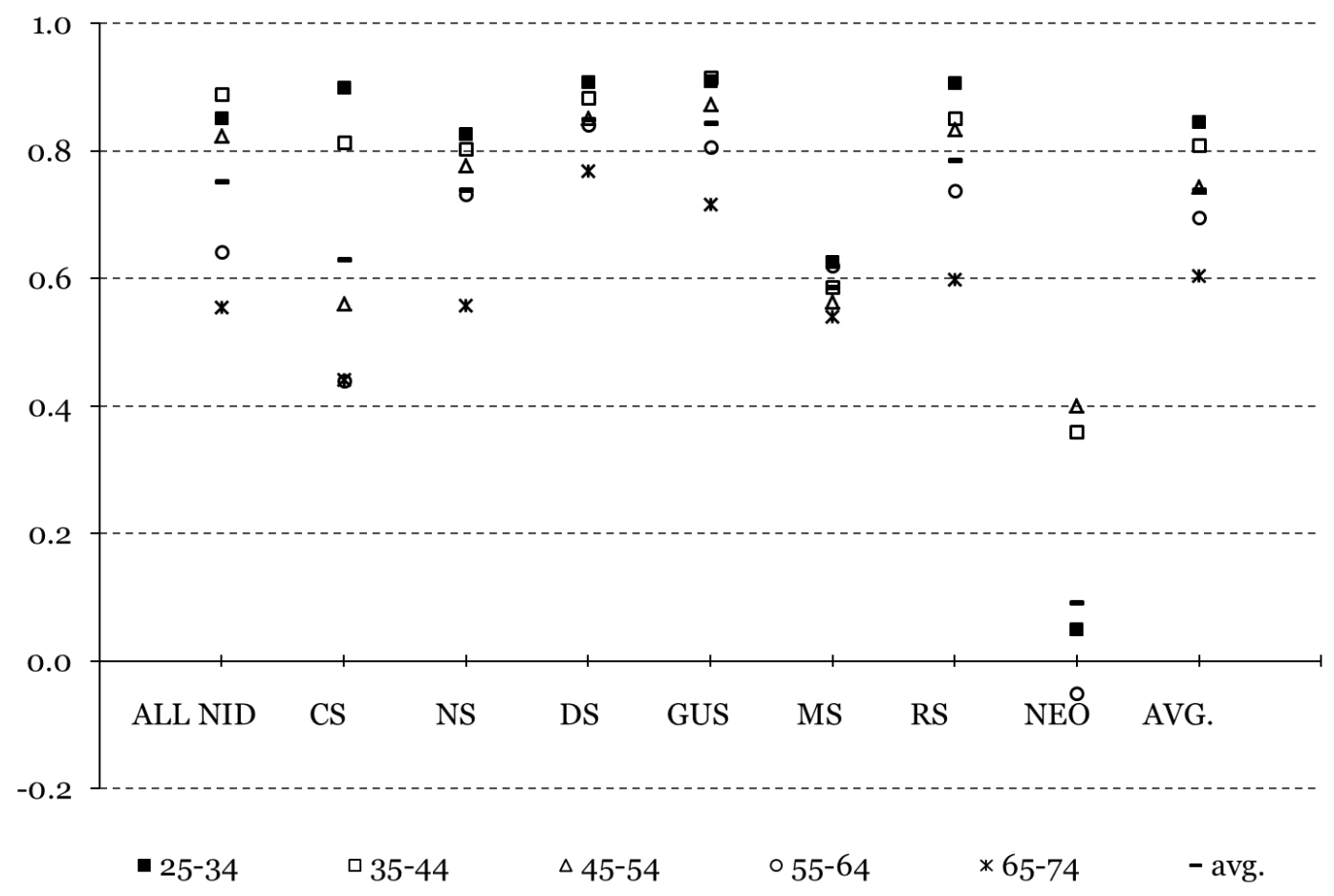

Figure 15c: Correlations between pregnancy complications during the decade of birth and various noninfectious diseases at different adult ages

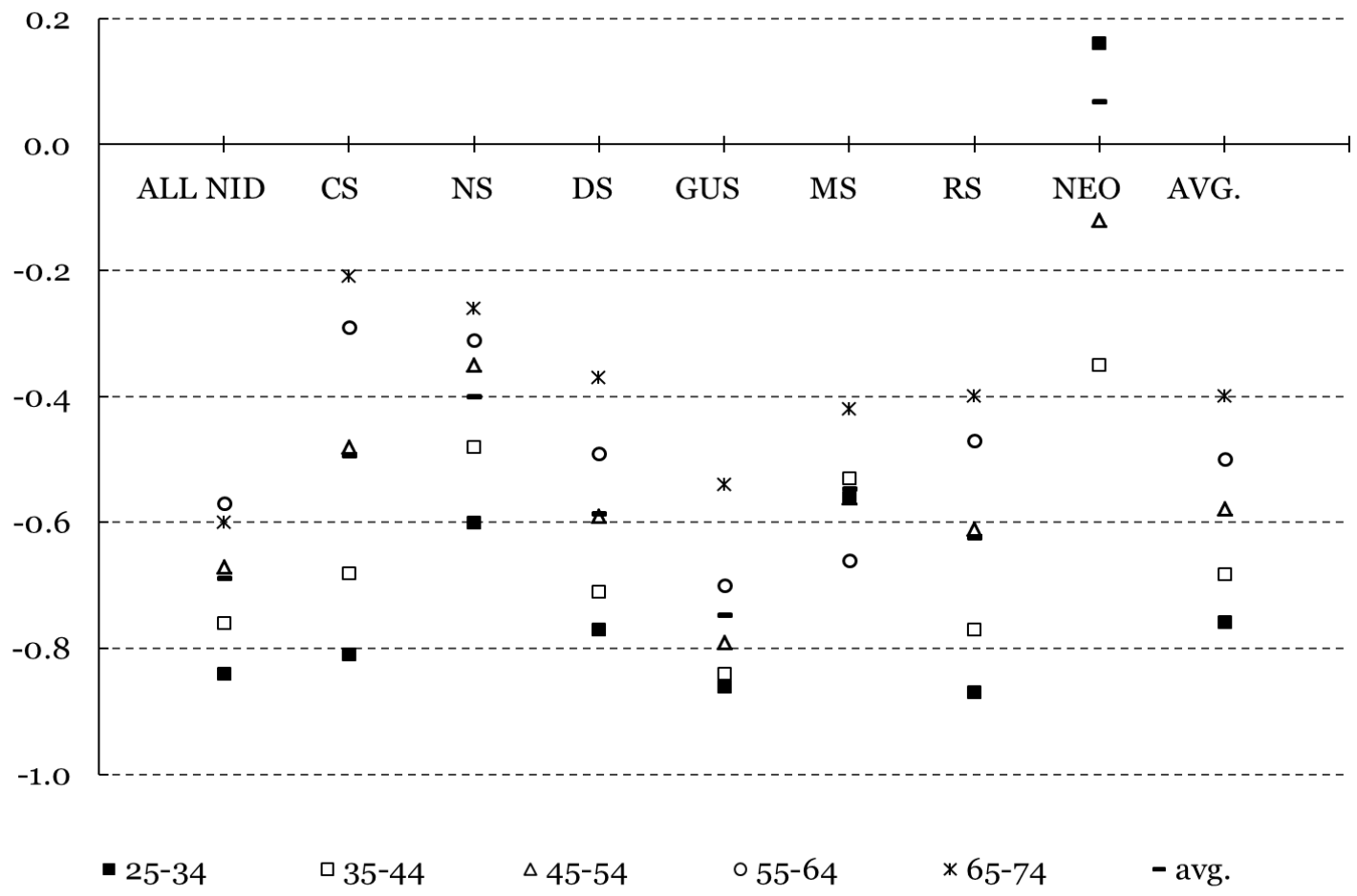

Figure 15d: Correlations between average adult stature and various noninfectious diseases at different adult ages 


\section{WORKING PAPERS DE L'AFC}

\section{Année 2012}

WP2012-1

WP2012-2

WP2012-3

WP2012-4

WP2012-5

WP2012-6

WP2012-7

WP2012-8

WP2012-9

LuCa PENSIEROSO

"The Great Depression in Belgium: an Open-Economy Analysis"

Amélie CHARLES, Olivier DARNÉ, Claude DIEBOLT, Laurent FERRARA

"A New Monthly Chronology of the US Industrial Cycles in the Prewar Economy"

\section{Charlotte LE CHAPELAIN}

"Allocation des talents et accumulation de capital humain en France de la fin du XIXe siècle"

Claude DIEBOLT, Mamoudou TOURÉ, Jamel TRABELSI

"Monetary Credibility Effects on Inflation Dynamics:

A Macrohistorical Case Study"

\section{Thi Hong Van HOANG}

"Has Gold been a Hedge against Inflation in France from 1949 to 2011? Empirical Evidence of the French Specificity"

\section{Georges PRAT}

"Equity Risk Premium and Time Horizon: What do the U.S. Secular Data Say?"

\section{Suchit ARORA}

"Understanding Aging during the Epidemiologic Transition"

Alexandru MINEA, Antoine PARENT

"Is High Public Debt Always Harmful to Economic Growth? Reinhart and Rogoff and some Complex Nonlinearities"

\section{Claude DIEBOLT, Antoine PARENT}

"Property Rights and Early Colonization in Algeria:

The Astonishing Travel Stories of Two Precursors, Tocqueville $(1837,1841)$ and Juglar (1853)"

\section{WP2012-10 \\ Mamata PARHI, Claude DIEBOLT, Tapas MISHRA, Prashant} GUPTA

"Convergence Dynamics of Output: Do stochastic Shocks and Social Polarization Matter?"

WP2012-11 Thierry AIMAR, Francis BISMANS, Claude DIEBOLT "Economic Cycles: A Synthesis"

WP2012-12 Claude DIEBOLT

"The Cliometric Voice"
La liste complète des Working Papers est disponible sur le site www.cliometrie.org 